
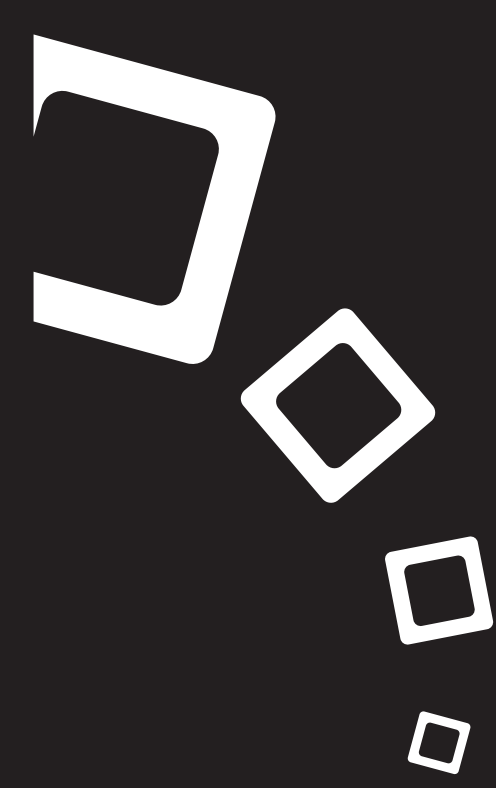

\section{Percepciones sobre alimentación, salud y autocuidado en personal de la Policía Nacional Civil de El Salvador*}

Walter Antonio Fagoaga López

Instituto Especializado de Educación Superior de Profesionales de la Salud de El Salvador, El Salvador fagoagagolf@hotmail.com

Recibido: octubre 9 de 2017 Aceptado: noviembre 15 de 2017 BIBLID [2225.5648 (2017), 7:2,227-300]

\section{Resumen}

El objetivo: de la investigación fue identificar la percepción sobre la alimentación, salud y autocuidado en miem. bros de la Policía Nacional Civil de El Salvador. La metodología: la investigación fue de carácter descriptivo y basada en percepciones y opiniones de los participantes, que fueron 300 miembros de la corporación policial seleccionados a conveniencia, a quienes se les administró un instrumento ah doc de preguntas categorizadas referentes a las variables en estudio. Resultados: el $40.7 \%$ está en el primer nivel de obesidad, $33.3 \%$ con sobre peso, $15 \%$ presentó obesidad mórbida, 5.3\% tiene el peso ideal, $5.0 \%$ obesidad tipo 2 y un $0.7 \%$ por debajo del peso normal. Conclusiones: La alimentación, salud y autocuidado en el personal de la Policía tiene importantes déficit de atención, considerando las valoraciones y prác. ticas que fueron identificadas durante esta investigación.

\section{Palabras clave}

Bienestar policial, salud, autocuidado, alimentación 

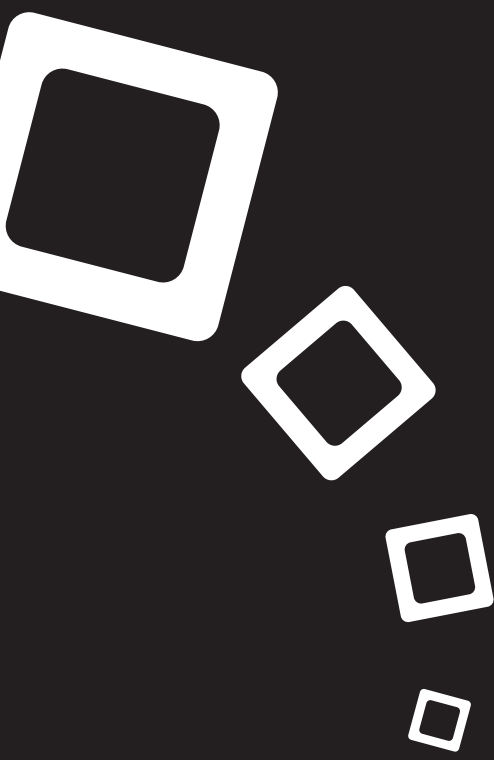

Perceptions about food, health and self-care in personnel of the National Civil Police of El Salvador*

Walter Antonio Fagoaga López

Instituto Especializado de Educación Superior de Profesionales de la Salud de El Salvador, El Salvador fagoagagolf@hotmail.com

Received: october 9, 2015 Accepted: november 15, 2016

BIBLID [2225.5648 (2017), 7:2, 227.300] rpsp.v7i2.5466

\section{Abstract}

The objective of the research was to identify the perception of food, health and self-care in members of the $\mathrm{Na}$ tional Civil Police of El Salvador. The methodology: the research was descriptive and based on perceptions and opinions of the participants, which were 300 members of the police corporation selected at their convenience, to whom an ah doc instrument of categorized questions related to the variables under study was administered. Results: $40.7 \%$ are in the first level of obesity, $33.3 \%$ with overweight, $15 \%$ presented morbid obesity, $5.3 \%$ have the ideal weight, $5.0 \%$ obesity type 2 and $0.7 \%$ below normal weight. Conclusions: The food, health and self-care of the police personnel has significant attention deficit, considering the valuations and practices that were identified during this investigation.

\section{Keywords}

Police welfare, health, self-care, food 


\section{Introducción}

La alimentación es un factor importante en la vida humana, representa más allá de todo, el momento donde se ingieren las sustancias que el cuerpo necesita para poder realizar las tareas propias de la actividad humana (Bellido y De Luis, 2006).

La alimentación también tiene una importante relación con la dieta, ya que e en buena parte está definida por un estilo de vida y también, porque es la forma de ingerir alimentos que favorezcan la integralidad de la persona (Durá, 2013).

También debe valorarse la salud, que es según la OMS (2017e), "un estado de completo bienestar físico, mental y social, y no solamente la ausencia de afecciones o enfermedades". Es decir, que el concepto deriva hacia una situación de bienestar individual, sin embargo, no es una definición acorde a realidades particulares en regiones, algo que actores como Hernán San Martín (1992) han valorado, y han visto la necesidad de tener un concepto ecológico de la salud, sosteniendo la urgente "desmedicalización" de su concepto, llevándolo hacia una visión bio-psico-social.

También se debe considerar como un elemento fundamental el autocuidado, referido a prácticas, acciones o desempeño para autocuidarse y que incluye lo realizado para evaluar, tomar decisiones y actuar en beneficio de la persona (Campos, et. al., 2008).

Con estas tres variables, se consideró abordar esta investigación en la población de la corporación de la Policía Nacional Civil de El Salvador, bajo la consideración de los siguientes objetivos, a saber:

- Identificar la percepción de los miembros de la corporación policial sobre la alimentación.

- Caracterizar la percepción de los miembros de la corporación policial sobre el autocuidado.

- Describir la percepción de la salud en miembros de la corporación policial

Se considera que es necesario hacer un análisis de estas variables, ya que dentro de la estructura orgánica de la Policía se encuentra la División de Bienestar Policial, la cual forma parte de la Subdirección de Administración. Esta división tiene una serie de funciones las cuales cumple en aras de proporcionar beneficios a sus miembros y una serie de servicios encaminados a una mejora de su calidad de vida. 
Dentro del Plan Estratégico 2015-2019 de la Policía Nacional Civil de El Salvador, se contempla la siguiente política:

"La Policía Nacional Civil deberá promover y regular acciones para la
asignación, desarrollo y bienestar del recurso humano, con apego a la
normativa y procedimientos, deberes, derechos y responsabilidades
del personal, orientado al logro de los objetivos institucionales en un
adecuado clima organizacional". (p.26)

Esto conlleva, precisamente, a valorar el importante papel que tiene el recurso humano de la corporación en el contexto de su trabajo, pero también, la necesidad de establecer mecanismos a través de los cuales es necesario proporcionar servicios de atención para mejorar no solo el clima laboral, sino también la incidencia del trabajo policial en toda la sociedad.

En ese marco, la investigación desarrollada obedece a generar al interior de la corporación, una discusión sobre la temática referente a la alimentación, la salud y el autocuidado; particularmente en cómo estas tres variables forman parte de un elemento fundamental de la vida humana, pero también de la vida laboral.

De esta forma, se pretende además, contribuir con elementos conceptuales a establecer un panorama general de como los miembros de la corporación valoran su alimentación, su salud y su autocuidado, ya que en buena parte, existen como en cualquier profesión, aspectos que pueden reñir con estos elementos y por lo tanto, es de suma urgencia su identificación.

Por ello, a continuación se presentan algunos antecedentes del problema, considerando algunos estudios realizados en lugares y tiempos diversos.

En el año 2008 se realizó en Argentina, un estudio sobre el estado nutri. cional de la Policía Marplatense (Compagnucci, 2008), donde caracterizó una muestra de 150 agentes policiales, encontrando que solo el $25.33 \%$ presentaba valores normales de peso, el resto tenía distintos grados de excesos nutricionales. En el riesgo cardiovascular, el $41.22 \%$ de los hombres y el $57.89 \%$ de las mujeres participantes, presentaron valores normales, los otros porcentajes no. Consideró, además, una baja ingesta de alimentos ricos en nutrientes tales como la verduras, frutas y lácteos.

Una investigación realizada con un grupo de policías retirados en el año 2009 (García, 2010), donde se definió que el problema de la obesidad está presente en buena parte de los policías en retiro, mostró que el $51.25 \%$ presentó sobrepeso, el $17.5 \%$ obesidad tipo I y el $1.25 \%$ obesidad tipo II. El estudio concluye que el $70 \%$ de los pensionados, presentan alteración de la nutrición por exceso, que conllevarían a problema crónico de salud. 
Un estudio realizado en Perú durante el año 2012 (Cárdenas, 2013) con miembros de la Policía, determinó que el $58 \%$ no tenían estilos de vida saludables y solo un $42 \%$ si los tenían. En cuanto al Índice de Masa Corporal $(\mathrm{IMC})^{1}$ el $48 \%$ presentaba obesidad grado I, el $38 \%$ sobrepeso y solamente un $14.0 \%$ tenían su peso en los valores normales. En cuanto a la definición de sus estilos de vida, el $61 \%$ no tenía una alimentación balaceada, el $76 \%$ no realizaba actividad física y el $51 \%$ no asistía a sus controles médicos.

También hay una investigación realizada en el año 2015 en Ecuador que aborda la situación de la alimentación y la condición física de policías (Sailema, 2015), la cual determinó que la alimentación nutritiva era de muy baja calidad, lo cual no permite que se tenga un adecuado rendimiento físico, además que esto repercute en una deficiente condición física para generar una orientación hacia su trabajo.

En el caso de El Salvador, al buscar estudios sobre temas relacionados con la dieta, nutrición y salud en agentes policiales, no se encontró ninguno es. pecífico para este grupo de población, pero se tienen estudios realizados en cuanto a la población salvadoreña en general y a grupos en estudiantes de niveles básicos.

La "Encuesta Nacional de Enfermedades Crónicas no Transmisibles en población adulta de El Salvador" presentada en el año 2017 por el Ministerio de Salud a través del Instituto Nacional de Salud, demostró que la población salvadoreña adulta, tiene graves problemas nutricionales y que esto genera obesidad y padecimientos crónicos degenerativos en gran medida y que impactan el estilo y la calidad de vida de estos.

La "Encuesta mundial de salud escolar, resultados El Salvador 2013", que realizó el Ministerio de Salud en colaboración con otros organismos públicos e internacionales, logra determinar que la nutrición en escolares en el país es deficiente y que esto está generando obesidad en los jóvenes, llevándolos a padecer enfermedades crónicas antes de cumplir los 30 años.

Este marco, permite valorar en gran medida el rumbo del estudio particularmente porque es un campo fértil de trabajo y, sobre todo, presenta una oportunidad para analizar con detenimiento cómo los agentes de la corporación policial se encuentran con respecto a su dieta, salud y autocuidado; bajo el precepto que su función y responsabilidad ante la sociedad es vasta, requiriéndose una persona sana y de buena condición física, para llevar a cabo las tareas que le demanda su profesión.

1 El Índice de Masa Corporal es, según la OMS, un indicador simple de la relación entre el peso y la talla que se utiliza frecuentemente para identificar el sobrepeso y la obesidad en los adultos. Se calcula dividiendo el peso de una persona en kilos por le cuadrado de su talla en metros (kg/2). 


\section{Metodología}

\subsection{Diseño metodológico.}

Este estudio se desarrolló bajo un método cuantitativo, de tipo descriptivo, observacional, y con un diseño de recolección transversal a través de las percepciones de los participantes.

Se consideró el método cuantitativo, tanto en la recolección, como en el procesamiento y en el análisis de la información. Además, se ha valorado el empleo del componente estadístico para visualizar las variables que se han definido estudiar.

Se considera de tipo descriptivo, porque la información recolectada se empleará para caracterizar las variables en estudio, sin llegar a la inferencia estadística, sino solo a analizarlas a fin de determinar aspectos que puedan llevarse a otro alcance en futuros estudios.

El diseño desarrollado fue observacional, porque las variables en estudio se analizaron de forma natural y sin intervención anticipada con los participantes, a efectos que sus respuestas fuera conforme a su percepción actual y sin algún sesgo que previamente pudo generarse, en caso de informárseles con antelación del estudio a realizar.

El diseño de recolección fue transversal, administrando el instrumento de recolección de información en un solo momento, considerando los tiem. pos de las sedes policiales que fueron contactadas para tal fin.

A partir de lo anterior, se definieron tres variables de estudio que fueron:

- Percepción de la alimentación.

- Percepción de la salud.

- Percepción del autocuidado.

A efecto de visualizar su análisis, se presenta la matriz de operacionalización de las variables en estudio a continuación: 
Percepciones sobre alimentación, salud y autocuidado en personal de la Policía Nacional Civil de El Salvador

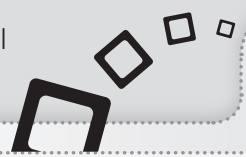

Matriz 1

Operacionalización de variables

\begin{tabular}{|c|c|c|c|}
\hline Variable & $\begin{array}{l}\text { Definición } \\
\text { operacional }\end{array}$ & Indicadores & Ítems \\
\hline \multirow{9}{*}{$\begin{array}{l}\text { Percepción } \\
\text { de la } \\
\text { alimentación. }\end{array}$} & \multirow{9}{*}{$\begin{array}{l}\text { Valoración que } \\
\text { tienen los partici- } \\
\text { pantes sobre los } \\
\text { hábitos e ingesta } \\
\text { de alimentos. }\end{array}$} & $\begin{array}{l}\text { Dieta o } \\
\text { sugerencia } \\
\text { alimentaria. }\end{array}$ & $\begin{array}{l}\text { ¿Actualmente, practica alguna dieta o sugerencia } \\
\text { de alimentación? } \\
\text { Sí /__ (1) No /__ (2) } \\
\text { Si su respuesta fue si, ¿cuál es la razón? } \\
\text { Indicación médica /__/ (1) Decisión propia /__ } \\
\text { (2) Es parte de su rutina /__ } \\
\text { Otra, indique_ }\end{array}$ \\
\hline & & \multirow{3}{*}{$\begin{array}{l}\text { Ingesta } \\
\text { de alimentos } \\
\text { durante el día. }\end{array}$} & $\begin{array}{l}\text { ¿Usted realiza el desayuno? } \\
\text { Siempre /__ / (1) Casi siempre / ___ (2) } \\
\text { A veces /__ (3) Nunca /__ / (4) }\end{array}$ \\
\hline & & & $\begin{array}{l}\text { ¿Usted realiza el almuerzo? } \\
\text { Siempre /__ / (1) Casi siempre /__ / (2) } \\
\text { A veces /__ (3) Nunca /__ (4) }\end{array}$ \\
\hline & & & $\begin{array}{l}\text { ¿Usted realiza la cena? } \\
\text { Siempre /__ / (1) Casi siempre (2) } \\
\text { A veces /__ (3) Nunca /__ / (4) }\end{array}$ \\
\hline & & $\begin{array}{l}\text { Inventario } \\
\text { de } \\
\text { alimentación } \\
\text { diaria. }\end{array}$ & $\begin{array}{l}\text { ¿Nos podría proporcionar su menú de comida } \\
\text { que comúnmente realiza en su rutina diaria? } \\
\text { (últimas } 24 \text { horas) } \\
\text { Desayuno } \\
\text { Almuerzo } \\
\text { Cena_ }\end{array}$ \\
\hline & & \multirow{4}{*}{$\begin{array}{l}\text { Consumo y } \\
\text { frecuencia de } \\
\text { ingesta de } \\
\text { alimentos. }\end{array}$} & $\begin{array}{l}\text { ¿Cuántas veces por semana consume snacks } \\
\text { (yuca frita o salcochada, papas, churros, etc.)? } \\
1 \text { vez o menos /__ (1) De } 2 \text { a } 3 \text { veces /__ ( (2) De } \\
4 \text { a más veces /__ (3) En ocasiones /__ (4) }\end{array}$ \\
\hline & & & $\begin{array}{l}\text { ¿Cuántas veces a la semana ingiere comida } \\
\text { rápida o "chatarra"? } \\
\text { Menos de } 1 / \text { / (1) } 1 \text { a } 3 \text { veces /___/(2) } \\
\text { Más de } 4 / \ldots /(3)\end{array}$ \\
\hline & & & $\begin{array}{l}\text { ¿Cuántas raciones de fruta come al día? } \\
\text { Cinco a más /__ (1) } 3 \text { a } 4 / \ldots / \text { (2) } 2 \text { o menos } \\
/ \text { _ (3) De vez en cuando /__ (4) }\end{array}$ \\
\hline & & & $\begin{array}{l}\text { ¿Cuántas raciones de verdura come al día? } \\
\text { Cinco o más /__ (1) } 3 \text { a } 4 / \ldots / \text { (2) } 2 \text { o menos } \\
\text { /__/(3) De vez en cuando /__ (4) }\end{array}$ \\
\hline
\end{tabular}




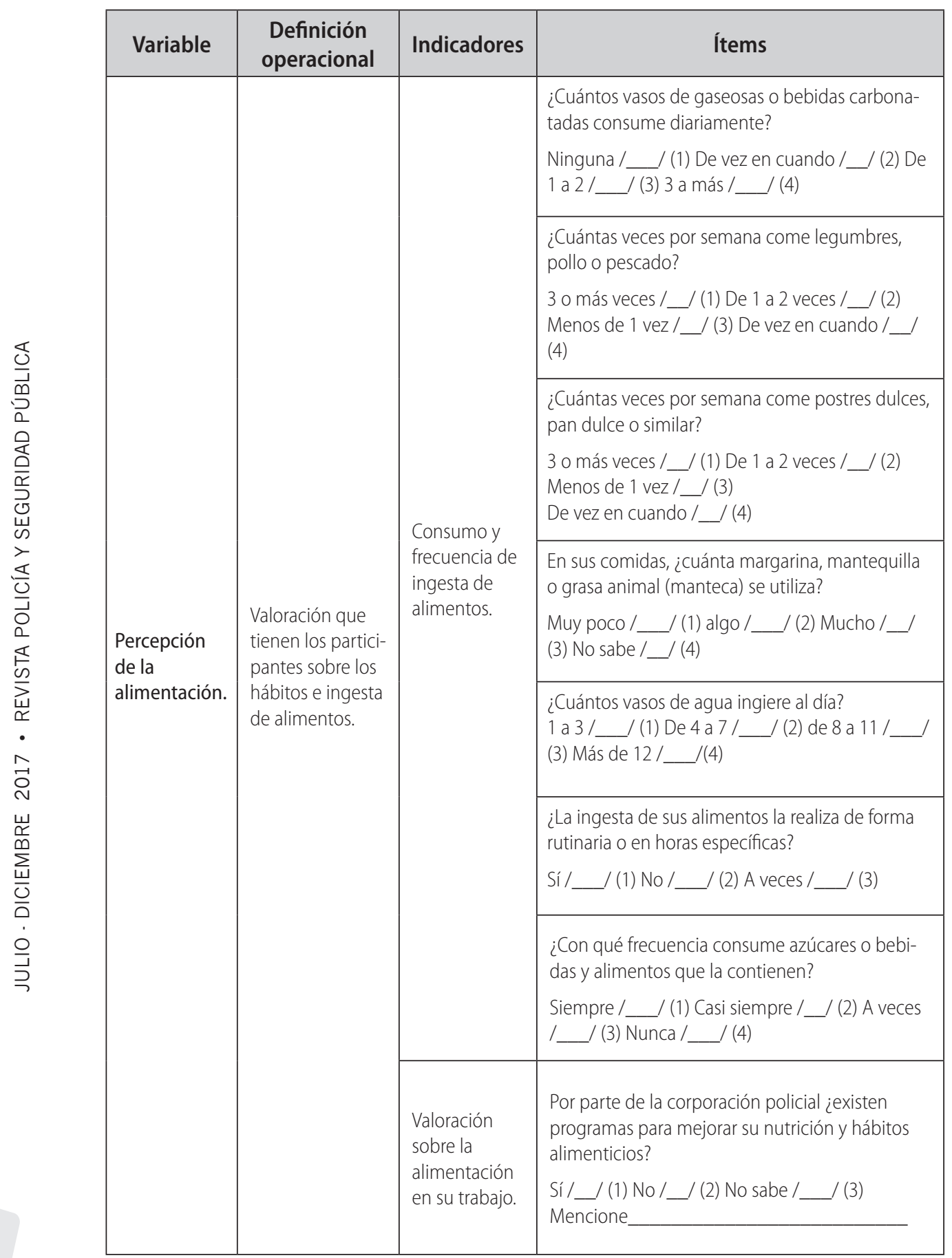


Percepciones sobre alimentación, salud y autocuidado en personal de la Policía Nacional Civil de El Salvador

\begin{tabular}{|c|c|c|c|}
\hline Variable & $\begin{array}{l}\text { Definición } \\
\text { operacional }\end{array}$ & Indicadores & Ítems \\
\hline \multirow{14}{*}{ Autocuidado } & \multirow{14}{*}{$\begin{array}{l}\text { Valoración que } \\
\text { tienen los partici- } \\
\text { pantes sobre } \\
\text { el cuidado que } \\
\text { deben tener de } \\
\text { forma individual } \\
\text { sobre su salud. }\end{array}$} & \multirow{2}{*}{$\begin{array}{l}\text { Práctica } \\
\text { de actividad } \\
\text { física. }\end{array}$} & $\begin{array}{l}\text { ¿Cuántas veces a la semana realiza actividad } \\
\text { física (caminar, correr, nadar, etc.) } \\
\text { Todos los días /__/ (1) De } 3 \text { a } 5 \text { veces /__/ (2) de } \\
1 \text { a } 2 \text { veces /__ (3) Nunca /__/(4) }\end{array}$ \\
\hline & & & $\begin{array}{l}\text { ¿Practica algún deporte? } \\
\text { Sí /___/(1) No /__ } /(2) \text { A veces /____/ (3) Si res- } \\
\text { puesta fue si, ¿cuál deporte es? }\end{array}$ \\
\hline & & \multirow{5}{*}{$\begin{array}{l}\text { Hábitos } \\
\text { alimentarios. }\end{array}$} & $\begin{array}{l}\text { ¿Su alimentación es baja en grasa? } \\
\text { Siempre /__ (1) A veces /__ (2) Nunca /__ (3) }\end{array}$ \\
\hline & & & $\begin{array}{l}\text { ¿Ingiere sus alimentos a la hora correspondiente? } \\
\text { Siempre /__ (1) A veces /__ ( (2) Nunca /__ (3 }\end{array}$ \\
\hline & & & $\begin{array}{l}\text { ¿Su ingesta de líquidos es constante? } \\
\text { Siempre /__ (1) A veces /__/ (2) Nunca /__ (3) }\end{array}$ \\
\hline & & & $\begin{array}{l}\text { ¿Consume al menos dos litros de agua (ocho } \\
\text { vasos) o líquidos (jugos naturales) al día? } \\
\text { Siempre /__ (1) A veces /__ (2) Nunca /__ (3) }\end{array}$ \\
\hline & & & $\begin{array}{l}\text { ¿Consume bebidas naturales? } \\
\text { Siempre /__ (1) A veces /__/ (2) Nunca /__ (3) }\end{array}$ \\
\hline & & \multirow{2}{*}{$\begin{array}{l}\text { Consumo } \\
\text { de alcohol } \\
\text { y tabaco. }\end{array}$} & $\begin{array}{l}\text { ¿Con que frecuencia consume bebidas alcohólicas? } \\
\text { Siempre /__ ( } 1 \text { ) A veces /__ (2) Nunca /__ (3) }\end{array}$ \\
\hline & & & $\begin{array}{l}\text { ¿Con que frecuencia consume cigarrillos? } \\
\text { Siempre /__ (1) A veces /__ (2) Nunca /__ (3) }\end{array}$ \\
\hline & & \multirow{2}{*}{$\begin{array}{l}\text { Cuidado de } \\
\text { evacuación } \\
\text { fisiológica. }\end{array}$} & $\begin{array}{l}\text { ¿Su evacuación intestinal es diaria y sin molestias? } \\
\text { Siempre /__ (1) A veces /__ (2) Nunca /__ (3) }\end{array}$ \\
\hline & & & $\begin{array}{l}\text { ¿Su eliminación urinaria es sin molestias? } \\
\text { Siempre /__ (1) A veces /__ (2) Nunca /__ (3) }\end{array}$ \\
\hline & & \multirow{3}{*}{ Salud mental. } & $\begin{array}{l}\text { ¿Se deja tiempo para reposar entre sus activida- } \\
\text { des diarias? } \\
\text { Siempre /__ (1) A veces /__ (2) Nunca /__ (3) }\end{array}$ \\
\hline & & & $\begin{array}{l}\text { ¿Comparte tiempo con sus familiares y amigos? } \\
\text { Siempre /__ (1) A veces /__ (2) Nunca /__ (3) }\end{array}$ \\
\hline & & & $\begin{array}{l}\text { ¿Realiza actividades para distraerse? } \\
\text { Siempre /__ (1) A veces /__ (2) Nunca /__ (3) }\end{array}$ \\
\hline
\end{tabular}




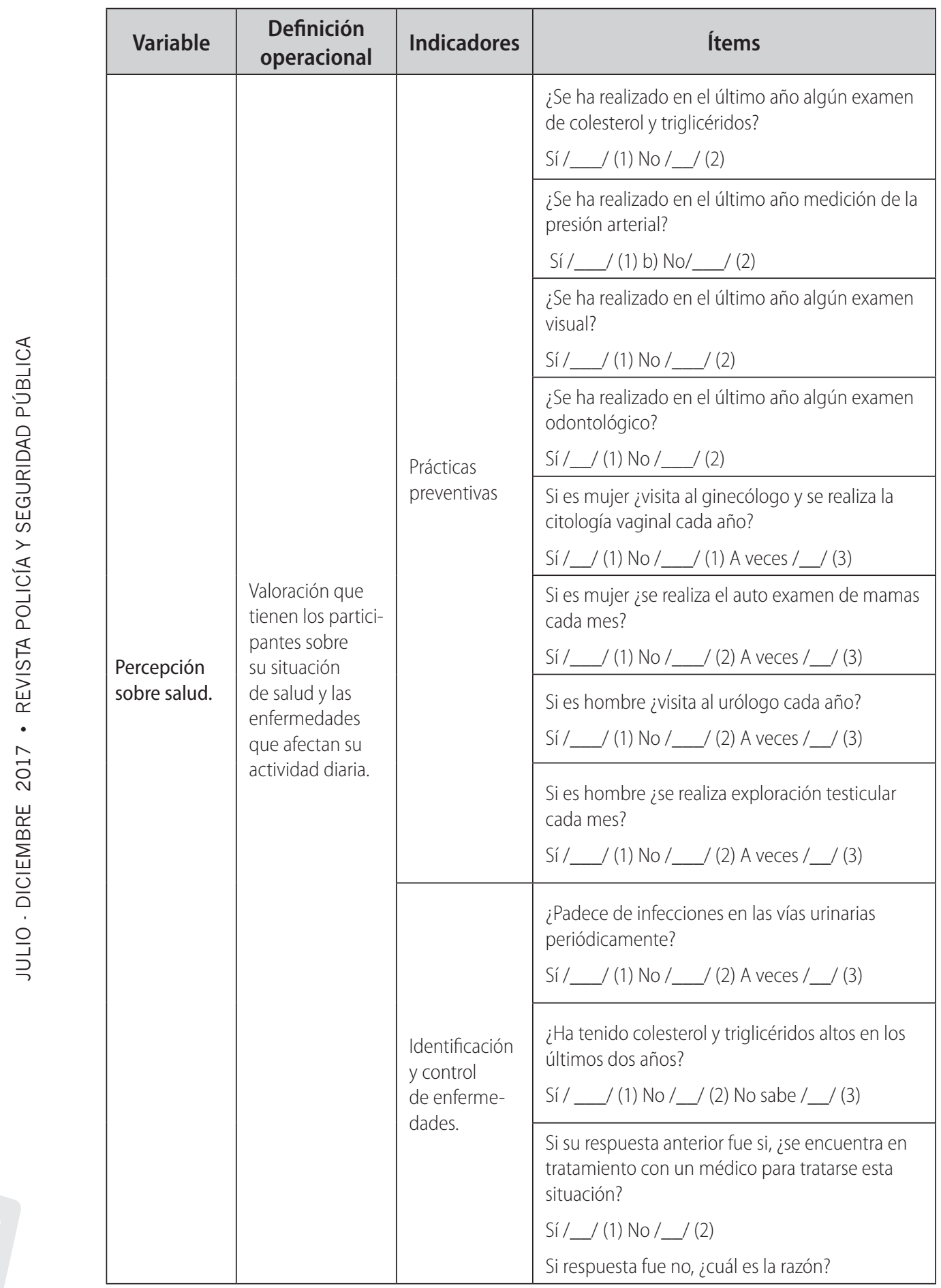




\begin{tabular}{|c|c|c|c|}
\hline Variable & $\begin{array}{l}\text { Definición } \\
\text { operacional }\end{array}$ & Indicadores & Ítems \\
\hline \multirow{6}{*}{$\begin{array}{l}\text { Percepción } \\
\text { sobre salud. }\end{array}$} & \multirow{6}{*}{$\begin{array}{l}\text { Valoración que } \\
\text { tienen los partici- } \\
\text { pantes sobre } \\
\text { su situación } \\
\text { de salud y las } \\
\text { enfermedades } \\
\text { que afectan su } \\
\text { actividad diaria. }\end{array}$} & \multirow{3}{*}{$\begin{array}{l}\text { Identificación } \\
\text { y control } \\
\text { de enferme- } \\
\text { dades. }\end{array}$} & $\begin{array}{l}\text { ¿Usted tiene diagnóstico con Diabetes Mellitus? } \\
\text { Sí /__ (1) No /__ (2) No sabe /__ (3) }\end{array}$ \\
\hline & & & $\begin{array}{l}\text { ¿Ha sido diagnosticado con hipertensión } \\
\text { arterial? } \\
\text { Sí /__ (1) No /__ (2) No sabe /__ (3) }\end{array}$ \\
\hline & & & $\begin{array}{l}\text { Si su respuesta anterior fue sí, ¿se encuentra en } \\
\text { tratamiento con un médico para tratarse esta } \\
\text { situación? } \\
\text { Sí /__ (1) No /__ (2) } \\
\text { Si respuesta fue no, ¿cuál es la razón? }\end{array}$ \\
\hline & & \multirow{3}{*}{$\begin{array}{l}\text { Valoración de } \\
\text { los servicios } \\
\text { de salud. }\end{array}$} & $\begin{array}{l}\text { ¿Cada cuánto tiempo visita al médico? } \\
\text { De } 1 \text { a } 2 \text { veces al año /__ / (1) De } 3 \text { a } 4 \text { veces } \\
\text { al año /__ (2) Más de } 5 \text { veces /__ / (3) Solo } \\
\text { cuando me enfermo /__ / (4) Cuando me dejan } \\
\text { el control /__ (5) }\end{array}$ \\
\hline & & & $\begin{array}{l}\text { ¿Qué servicios de salud utiliza Ud. con mayor } \\
\text { frecuencia? } \\
\text { Seguro Social /__ (1) Red pública de salud del } \\
\text { MINSAL /__ (2) Servicios privados de salud /__ / } \\
\text { (3) Bienestar policial /__ } \\
\text { (4) Otras, mencione: }\end{array}$ \\
\hline & & & $\begin{array}{l}\text { ¿Por qué hace uso con mayor frecuencia de } \\
\text { estos servicios? } \\
\text { Por su costo /__ / (1) Por la calidad del servicio } \\
\text { /__ (2) Mayor accesibilidad /__ (3) Otra, } \\
\text { mencione: }\end{array}$ \\
\hline
\end{tabular}

Fuente: Elaboración propia. 


\subsection{Población y muestra.}

La población objeto de estudio de esta investigación, son miembros de la Policía Nacional Civil de El Salvador; considerando los siguientes criterios de inclusión y exclusión para su definición:

Criterios de inclusión:

- Mayor de 18 años.

- Ambos sexos.

- Tener al menos un 1 año de laborar en la institución.

\section{Criterios de exclusión:}

- No mostrarse dispuesto(a) a completar la información.

- Haber participado en el estudio en otra sede.

Considerando lo anterior, la muestra se determinó por conveniencia (Bonilla, 1999), considerando cuatro delegaciones representativas del país que se definieron por ser de las de mayor presencia territorial, asignándoles una cuota por cada una para su participación, de la siguiente manera:

TABLA 1. Delegación

\begin{tabular}{|l|l|l|}
\hline Delegación & \multicolumn{1}{|c|}{ Frecuencia } & Porcentaje \\
\hline San Miguel & 65 & 21.7 \\
\hline Santa Ana & 88 & 29.3 \\
\hline San Salvador & 77 & 25.7 \\
\hline La Libertad & 70 & 23.3 \\
\hline Total & $\mathbf{3 0 0}$ & $\mathbf{1 0 0}$ \\
\hline
\end{tabular}

Fuente: Elaboración propia. 
En cuanto a la relación de género, también se buscó que pertenecieran a ambos, según la representatividad que se tiene a nivel de la corporación policial, así:

Tabla 2. Género según participantes

\begin{tabular}{|l|c|c|}
\hline Género & Frecuencia & Porcentaje \\
\hline Masculino & 215 & 72.5 \\
\hline Femenino & 85 & 27.5 \\
\hline Total & $\mathbf{3 0 0}$ & $\mathbf{1 0 0 . 0}$ \\
\hline
\end{tabular}

Fuente: Elaboración propia.

Fue importante también distinguir sobre su función dentro de la Policía Nacional Civil, distribuyéndose así:

Tabla 3. Función asignada en la corporación policial

\begin{tabular}{|l|c|c|}
\hline Función & Frecuencia & Porcentaje \\
\hline Personal operativo & 237 & 79.0 \\
\hline Personal administrativo & 63 & 21.0 \\
\hline Total & $\mathbf{3 0 0}$ & $\mathbf{1 0 0 . 0}$ \\
\hline
\end{tabular}

Fuente: Elaboración propia.

En relación a las edades de los participantes en el estudio, se determinó a través del perfil demográfico nacional, tratándose de reflejar la concentración del dato en los grupos de edad de mayor representación en la corporación policial.

Tabla 4. Rangos de edad

\begin{tabular}{|l|c|c|}
\hline Edad & Frecuencia & Porcentaje \\
\hline 18 a 25 años & 34 & 11.7 \\
\hline 26 a 35 años & 93 & 30.7 \\
\hline 36 a 45 años & 113 & 36.6 \\
\hline 46 a 55 años & 51 & 17.2 \\
\hline Más de 56 años & 9 & 3.6 \\
\hline Total & $\mathbf{3 0 0}$ & $\mathbf{1 0 0 . 0}$ \\
\hline
\end{tabular}

Fuente: Elaboración propia. 


\subsection{Técnicas e instrumentos de recolección de la información.}

Para la recolección de la información, se utilizó la técnica de la encuesta, y como instrumento, se pasó un cuestionario "ad hoc" de preguntas categorizadas, elaborado a partir de las variables en estudio (que se presentaron en la matriz de operacionalización) y considerando los elementos teórico-conceptuales de diversos autores y organismos multilaterales relacionados al tema en cuestión. Solo en el caso de los relacionados con la salud mental y el estrés, se empleó el test del Instituto Mexicano del Seguro Social (2017), que es de acceso libre y elaborado para analizar tales dimensiones de análisis.

El instrumento fue validado previamente con especialistas y se hizo una prueba piloto con personas que cumplieran las características de la población objetivo de estudio.

Para el caso de las medidas antropométricas, se consideraron los valores e indicadores que proporcionan organismos como el Fondo de las Naciones Unidas para la Alimentación y la Agricultura (FAO) y la Organización Mundial de la Salud (OMS).

Para la recolección de la información, se trabajó con profesionales en el área de medicina y enfermería, quienes también tomaron las medidas antropométricas y evaluaron el Índice de Masa Corporal (IMC) de cada participante.

\subsection{Procesamiento y análisis de la información.}

En el caso del procesamiento de la información, se utilizó el software PSPP de código abierto para procesar la información y así poder definir cruces y medidas estadísticas que se pudieran generar en el proceso de la investigación.

Para el análisis de la información, se consideró la estadística descriptiva, principalmente para establecer el análisis e interpretación de los resultados.

\subsection{Consideraciones éticas.}

Durante el proceso de la investigación, se respetaron todos los procedimientos éticos de resguardo de la autonomía, beneficencia e identidad de cada participante. Por lo cual, el llenado de los instrumento fue de forma anónima, no identificándose a fin de resguardar su información. 


\section{Resultados}

\subsection{Percepción de la alimentación.}

La alimentación es un proceso fundamental en la vida humana, determina su existencia misma. A continuación, se analizará la variable relacionada con la percepción que tienen los participantes de la investigación sobre esta, considerando los aspectos relacionados a diversos indicadores, a fin de determinar cómo valoran esta situación, como parte de una práctica vital de su vida.

Para estos efectos, el análisis de los indicadores trata de mostrar la caracterización de estas valoraciones de los miembros de la corporación policial, en cuanto al tema alimentario y, sobre todo, algunas prácticas que realizan en su cotidianeidad.

\section{Práctica de dieta actualmente}

\section{GRÁFICO 1}

\section{¿Actualmente practica alguna dieta o sugerencia de alimentación?}

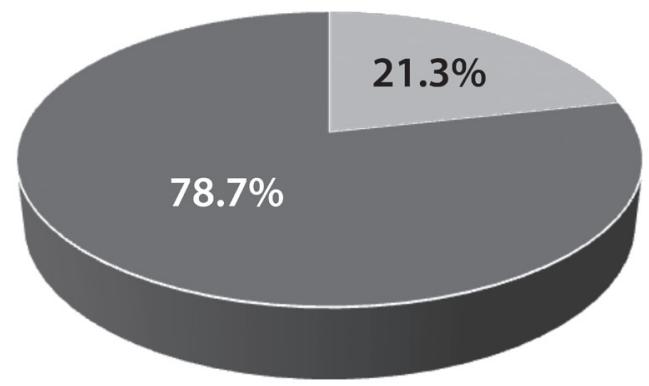

- Si practica dieta $\quad$ No practica dieta

Fuente: Elaboración propia en base a encuesta²

El desarrollo de una dieta alimenticia, es un factor importante para la mejora significativa en la salud y en el bienestar de la persona (Hernández et al, 2015).

Al consultarle al personal de la corporación, el 21.3\% mencionó que sí se encuentran desarrollando algún tipo de dieta o sugerencia alimenticia actualmente, mientras el $78.7 \%$ contrariamente no se encuentra bajo ningún régimen alimentario concreto, haciéndose valorar que existe una situación que se describirá con mayor precisión más adelante.

2 Todos los gráficos han sido elaborados por el autor en base a datos recolectados de primera mano en la encuesta. 


\section{Indicación de la dieta}

\section{GRÁFICO 2}

\section{Indicación de la dieta}

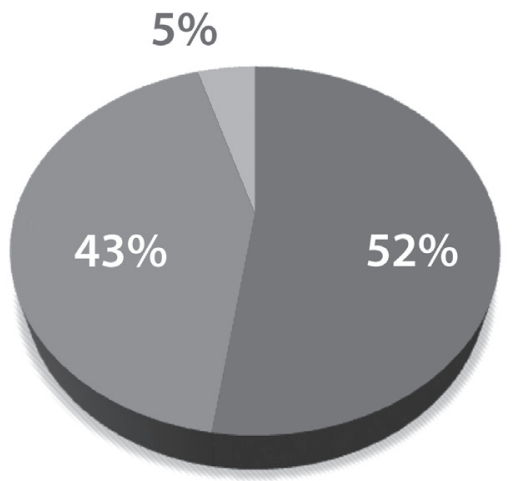

En consideración a la pregunta anterior, se les consultó únicamente a quienes expresaron que sostenían alguna dieta o régimen alimentario en particular, sobre cuál era la razón principal del porqué lo hacían.

El 43\% manifestó que era una decisión propia, mientras el 52\% dijo que era por una indicación médica y un $5 \%$ era parte de la rutina.

Como se evidencia, mayoritariamente las personas llegan a definir su régimen alimentario en el momento en el cual existe alguna alteración en su salud, previamente pasan por alto esto, aunque hay un buen porcentaje de quienes lo deciden con antelación.

\section{Orientación de la dieta}

\section{GráfICO 3}

Orientación profesional de la dieta

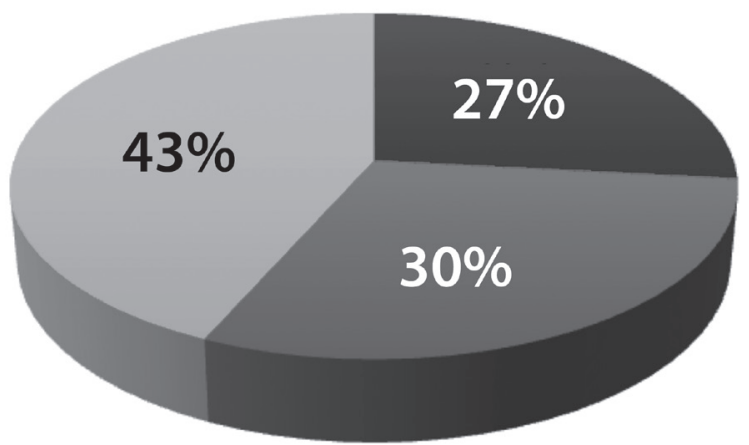


Como se mencionó antes, realizar alguna dieta puede dar beneficios importantes a la persona, sin embargo, esta debe realizarse bajo la orientación de un profesional pertinente.

Al consultar a los participantes en el estudio, quien les orientaba sobre su situación nutricional, el 43\% manifestó que a discreción personal habían tomado la decisión de la dieta y no tienen una orientación profesional, mientras el $30 \%$ la recibe a través de un médico y el $27 \%$ por un profesional nutricionista. Esto puede propiciar que, aunque exista un importante esfuerzo, se tienda a una alimentación no balaceada y generar otros problemas de salud.

\section{Ingesta de tiempos de comida recomendados}

Un aspecto importante en la nutrición es mantener la regularidad en los tiempos de la ingesta de los alimentos (Marín, 1998), por tal razón, se consultó a los participantes al respecto.

En el caso del almuerzo, resulta ser el tiempo que se respeta con mayor precisión, siguiéndole la cena y el desayuno, el cual reduce su frecuencia significativamente, aunque estudios sugieren que es el más relevante para efectos de la nutrición, siempre y cuando se haga adecuadamente (Durá, 2013).

\section{Consumo de snacks a la semana}

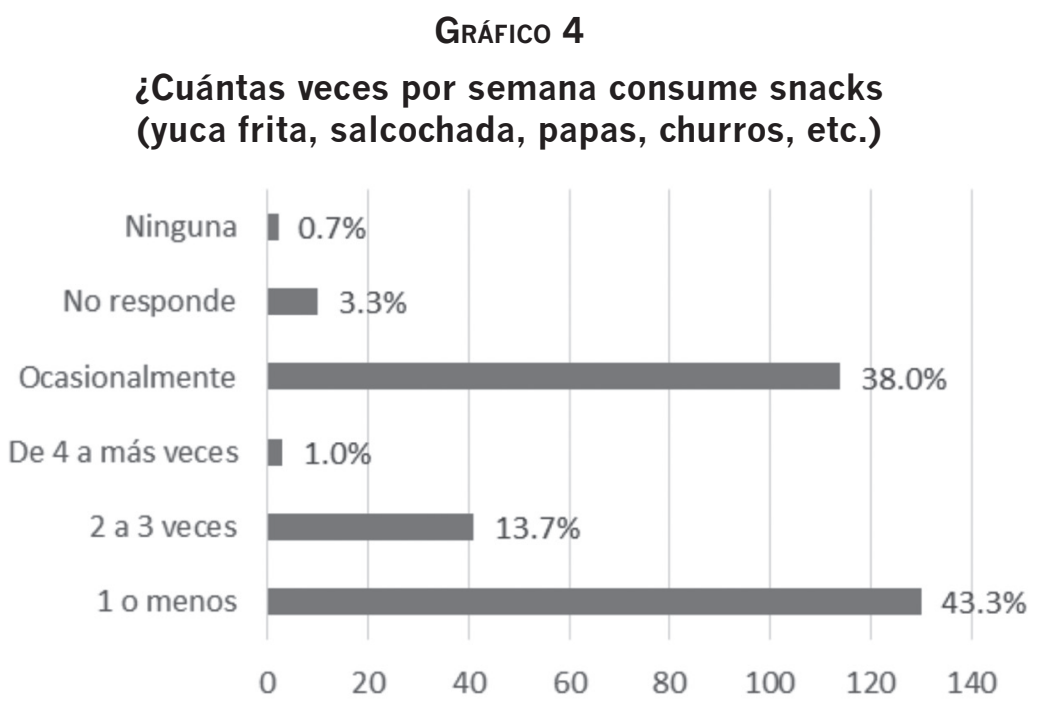

Los snacks son un tipo de alimento que se utiliza para satisfacer temporalmente la sensación de hambre, pero su aporte nutricional, dependiendo de su elaboración, puede variar (Requejo y Ortega, 2002). 
Al consultarles a los participantes en el estudio sobre el consumo de estos, la mayoría (43.3\%) lo hace al menos 1 vez a la semana, mientras un porcentaje representativo (38.0\%) solo de forma ocasional. Esto es algo positivo en la medida que puede plantearse que existe un consumo bastante reducido de estos alimentos de forma azarosa, es decir, sin existir un hábito en su consumo. Esto puede tener implicaciones en la situación de nutrición y salud, considerándose más adelante.

\section{Consumo de comida "rápida" o "chatarra" a la semana}

Las denominadas comidas "rápidas" o "chatarra", son un tipo de alimentación basado en una preparación rápida y con un costo económico menor, sin embargo, su aporte nutricional es alto en grasas y azúcares, lo que genera obesidad y algunos trastornos alimenticios serios (Meléndez, 2008).

Al consultar a los encuestados, se evidenció que el $27 \%$ consume este tipo de alimentos de 1 a 3 veces a la semana, mientras un $5 \%$ lo realiza más de 4 veces, es decir, que cerca de un 30\% de la población en estudio tiene una situación que merece mayor atención, aunque el $62.3 \%$ expresó que no es parte de su consumo semanal porque lo realiza menos de 1 vez.

\section{GráfICo 5}

\section{¿Cuántas veces a la semana ingiere comida rápida o chatarra?}
En ocasiones
$0.3 \%$
Nada
$0.3 \%$
Ninguna
I $0.7 \%$
No responde
$3.7 \%$
Más de 4 veces
$5.0 \%$
De 1 a 3 veces
$27.7 \%$
Menos de 1
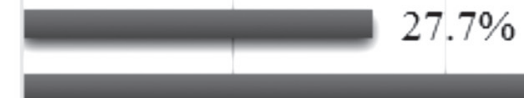
0
50
100
150
$62.3 \%$

50

100




\section{Consumo de frutas por día}

\section{GRÁfICO 6}

¿Cuántas raciones de frutas consume al día?

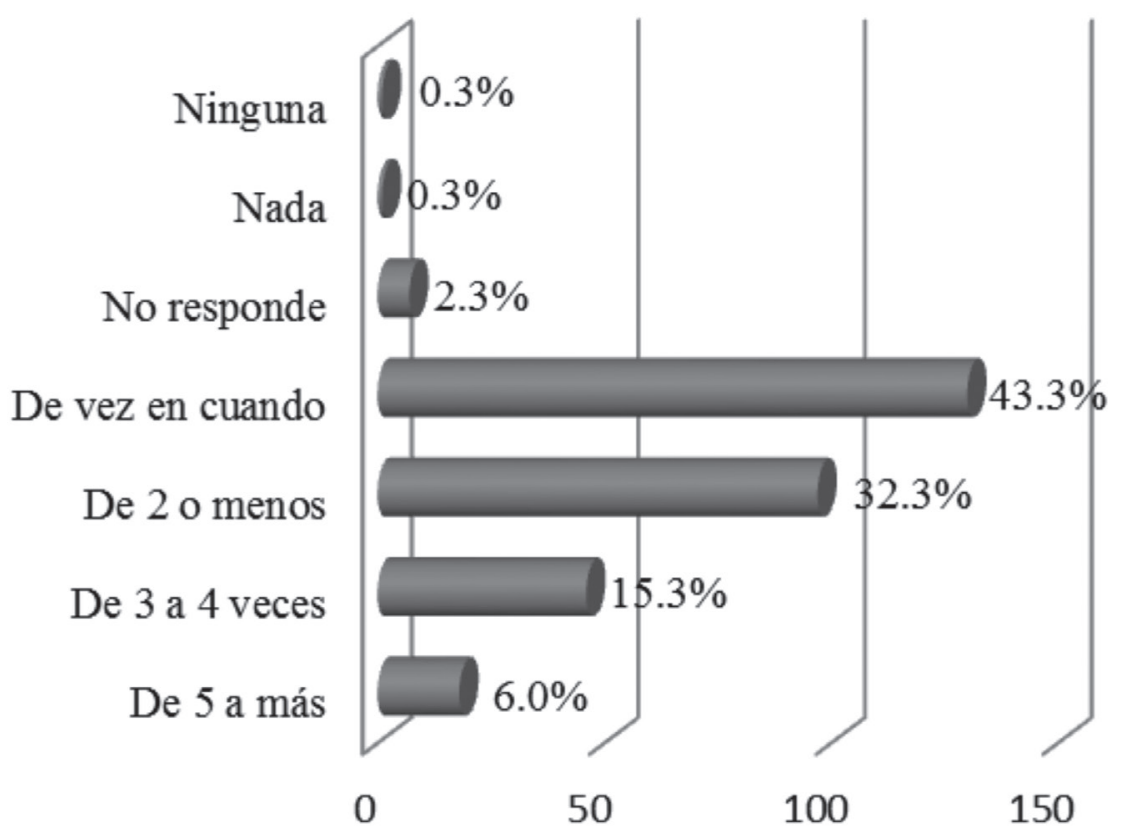

El consumo de frutas es clave para una nutrición balanceada, ya que permite que se generen nutrientes importantes para diversos procesos fisiológicos (Marín, 1998) y su consumo es recomendado a diario en tres porciones (Gil, 2010).

Al consultar a los participantes, se evidencia que el consumo de frutas durante el día es mínimo, ya que solamente un $15.3 \%$ hizo mención que de 3 a 4 veces y un $6.0 \% 5$ a más, mientras el $43.3 \%$ mencionó que solamente de vez en cuando y un $32.3 \%$ de 2 o menos. Esto indica que existe un bajo consumo de este importante nutriente, el cual es fundamental para el balance alimenticio de una persona, siendo una recomendación que debe dársele un seguimiento importante. 


\section{Consumo de verduras por día}

\section{GráfICO 7}

\section{¿Cuántas raciones de verduras come al día?}

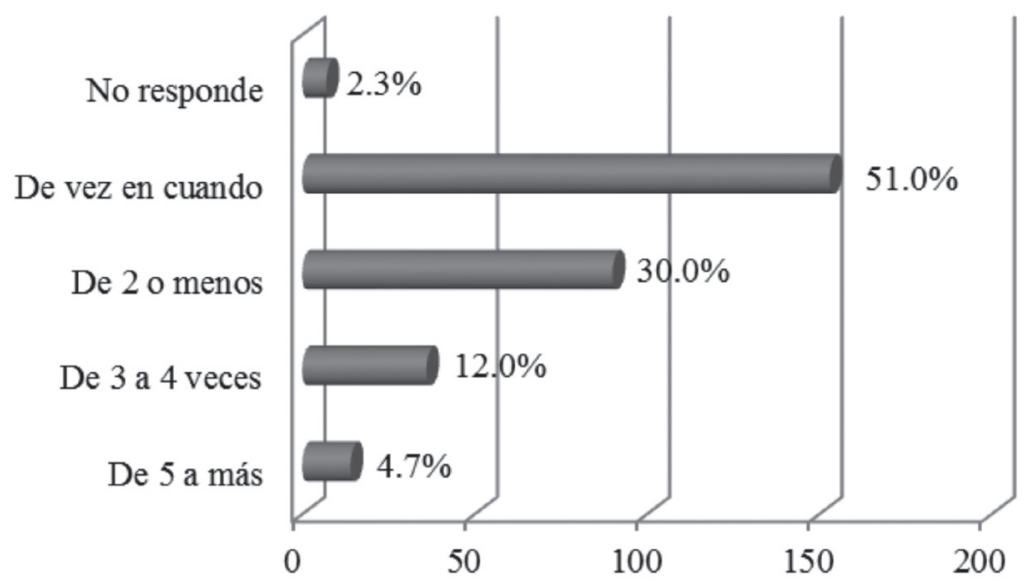

Al igual que las frutas, las verduras son fundamentales para una adecuada nutrición, ya que sus propiedades posibilitan una serie de beneficios en pro de la salud (Gil, 2010).

Por ello se les consultó a los participantes sobre su práctica de consumo, no obstante, de igual forma que la anterior, más de la mitad no tiene la correcta ingesta de estos, ya que solamente un $12 \%$ lo hace de 3 a 4 veces a la semana y un mínimo del $4.7 \%$ más de 5 .

\section{Consumo de bebidas carbonatadas por día}

El consumo de bebidas carbonatadas se ha convertido en parte de la die. ta diaria de muchas personas, a pesar de sus consecuencias en la salud, como afirman algunos estudios (Durán, et al, 2015).

En la información recolectada se puede observar que un $4.7 \%$ las ingiere de 3 a más veces, el $20.3 \%$ de 1 a 2 veces, el $55 \%$ de vez en cuando y el $18.7 \%$ no las consume en ningún momento. Estas bebidas no contribuyen a un dieta saludable, porque sus contenidos de azúcares y carbohidratos exacerbados pueden inclusive afectar la salud. 


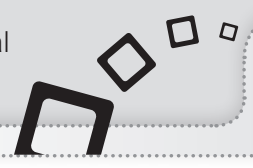

\section{GRÁFICO 8}

¿Cuantos vasos de gaseosa o bebidas carbonatadas consume diariamente?

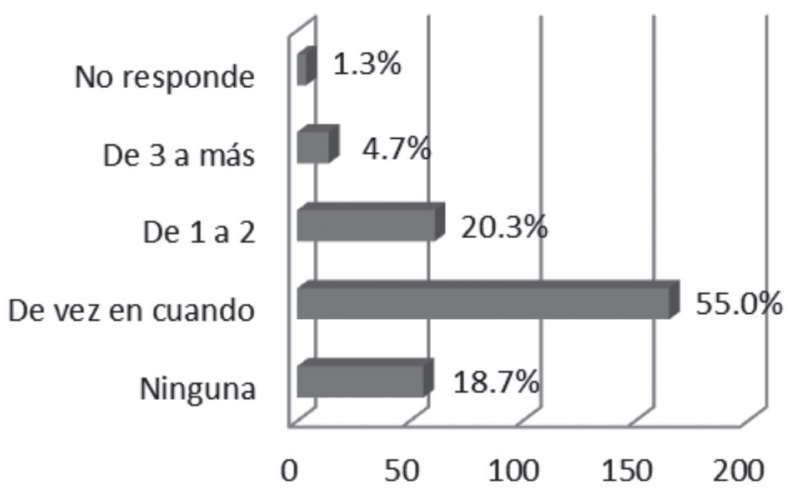

\section{Consumo de legumbres y carnes blancas}

GráfICo 9

¿Cuántas veces por semana come legumbres y carnes blancas?

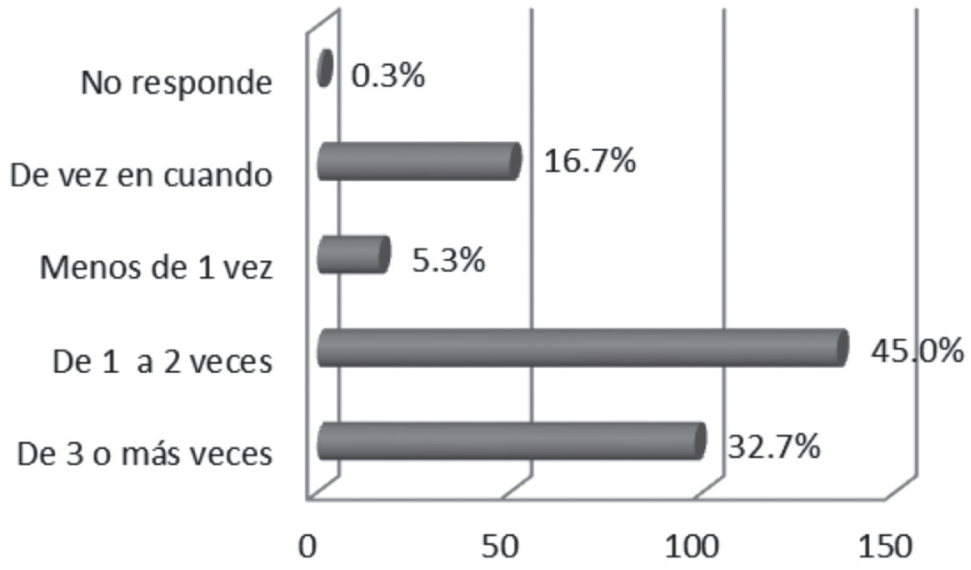

El consumo de legumbres y carnes blancas es vital para el establecimiento de una dieta balanceada, ya que ambos tipos de ingestas, contienen nutrientes que posibilitan importantes aportes al estado nutricional (Gil, 2010).

Al consultar sobre el consumo de estos alimentos, se puede observar que resulta ser variado, ya que un $45 \%$ menciona que solo lo hace de 1 a 2 veces por semana, mientras un $32.7 \%$ de 3 o más veces. 


\section{Consumo de azúcares}

\section{GrÁfICo 10}

¿Cuántas veces por semana come postres dulces, pan dulce o similar?

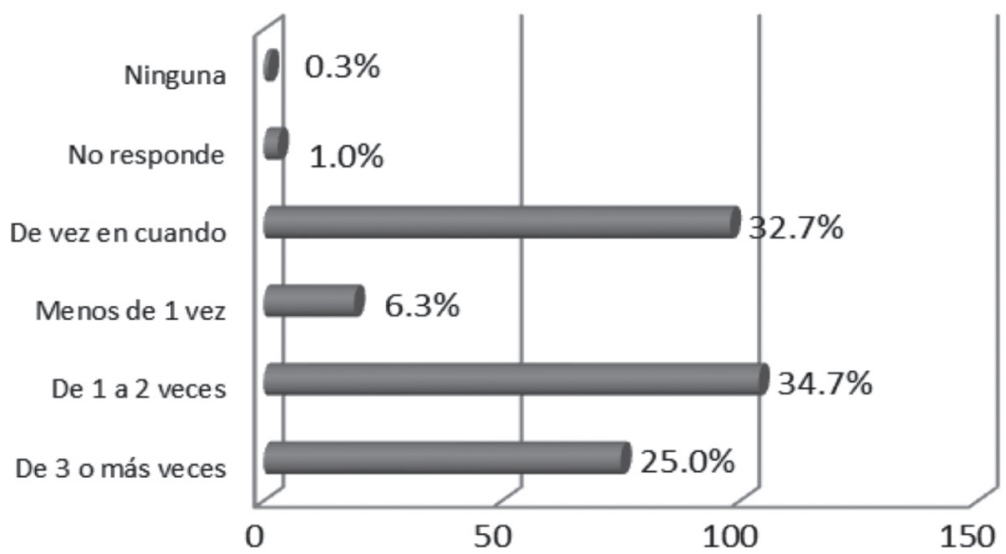

El consumo de azúcares en exceso puede generar una serie de trastornos metabólicos y conllevar también al padecimiento de obesidad y diabetes (Meléndez, 2008).

A partir de lo anterior, se consultó a los participantes, sobre su consumo ya sea en postres, dulces, pan dulce y otros; teniéndose que el $25 \%$ los consume más de 3 veces a la semana, mientras el $34.7 \%$ de 1 a 2 veces. Como se muestra, el consumo de azúcar en por lo menos 3 de cada 10 personas es elevado, tomando en consideración que este tipo de alimentos puede propiciar trastornos metabólicos y enfermedades crónicas degenerativas.

\section{Consumo de mantequillas y grasas de origen animal}

\section{GRÁFICO 11}

En su comida, ¿Cuánta margarina, mantequilla o grasa animal (manteca) utiliza?

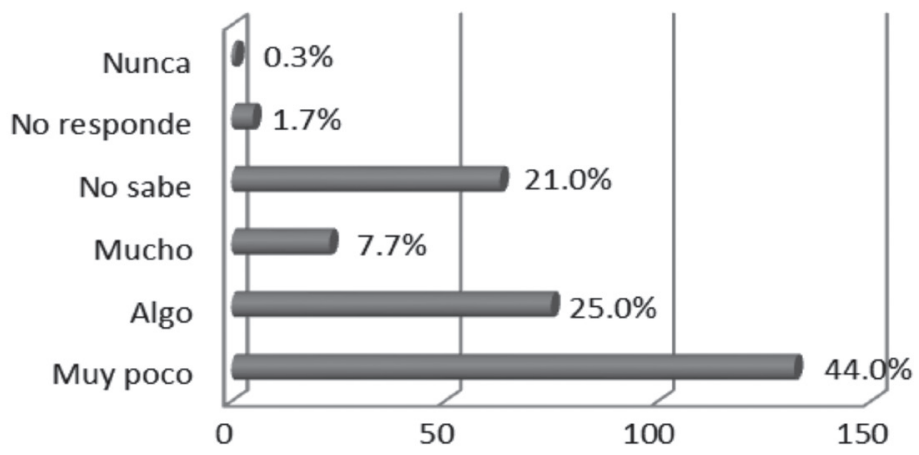


El consumo de grasas de origen animal, es un factor que podría derivar en diversos padecimientos de salud. Por otra parte, en la actualidad, ha aparecido una serie de productos que buscan tener una mayor incidencia en la nutrición de las personas, pero aun así, su aporte no es el óptimo (Valenzuela, Yánez, y Golusa, 2010).

Respecto a este aspecto, el $44 \%$ hizo la mención que es muy poco el consumo en sus alimentos de estas grasas y un $25 \%$ es cantidades mínimas. Solamente un $7 \%$ hizo la mención que es representativa en sus alimentos.

\section{Consumo de agua}

Gráfico 12

¿Cuántos vasos de agua consume al día?

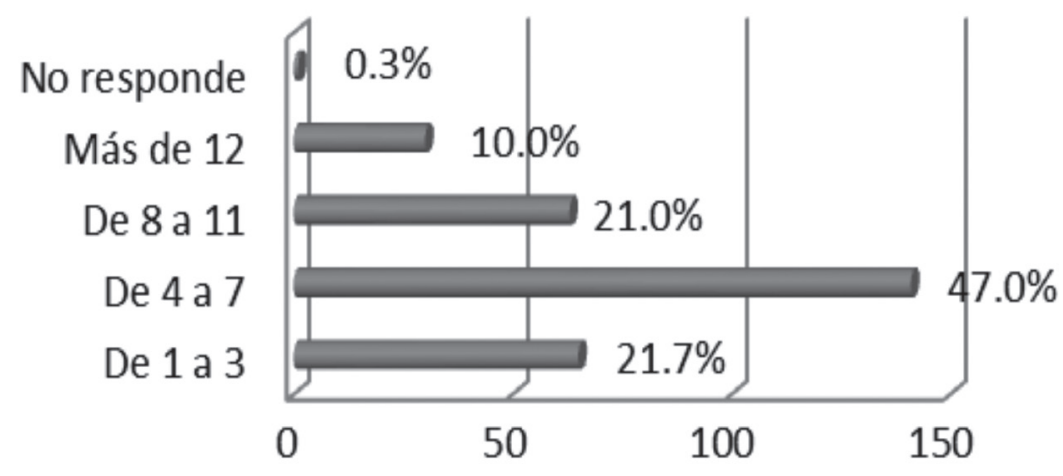

El consumo de agua es un aspecto fundamental en la nutrición humana, por el papel que juega el vital líquido en el funcionamiento del cuerpo, recomendándose ingerir al menos ocho vasos al día. (Ayus, Tejedor y Caramelo, 2007).

Al consultarles a los participantes, se obtuvo que solamente un $21 \%$ está consumiendo la cantidad de agua requerida por el organismo, ya que cerca de un $70 \%$, consume menos de ocho vasos diarios, lo que podría generar en el futuro problemas renales, entre otros. Además, se debe considerarse que la tarea del policía es principalmente en el área operativa, lo cual lleva un esfuerzo de trabajo donde podrían generarse episodios de deshidratación, por no ingerir dosis adecuadas de agua. 


\section{Consumo de calorías diarias}

\section{GrÁfICo 13}

\section{Consumo calórico calculado por inventario alimenticio de 24 horas}

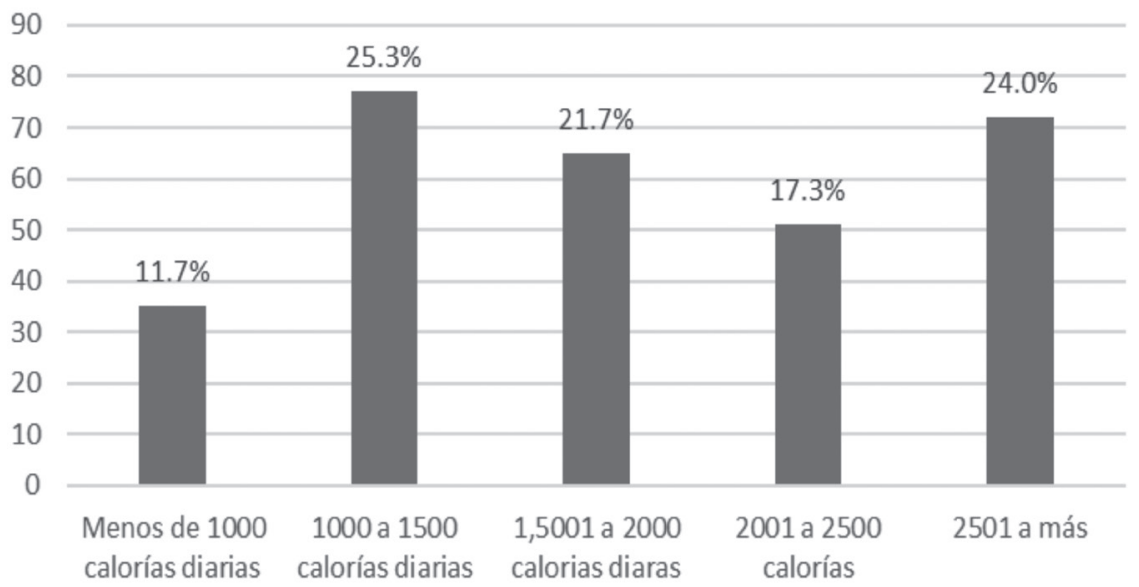

El organismo humano necesita energía para poder subsistir, esta se obtiene de la alimentación, la cual es una fuente para hacer funcionar la ma. quinaria humana a partir del consumo de calorías, las cuales varían según algunos indicadores; sin embargo, existe una medición de las necesidades energéticas mínimas, dictaminadas por la FAO (2008), la cual es de 1690 para la zona urbana y 1650 para la zona rural, además, se relaciona a factores como el peso, la edad, el sexo, entre otros.

Con base a eso, se elaboró un inventario de alimentación diaria, considerando la técnica de consulta de la ingesta de 24 horas, para así definir el consumo de calorías. Al respecto, el $11.7 \%$ consume menos de 1000 calorías diarias, el 25.3\% de 1000 a 1500 calorías, el 21.7\% de 1501 a 2000 calorías, el $17.3 \%$ de 2001 a 2500 calorías y el 24\% más de 2501 calorías. Esto indica que con base a los factores antes mencionados, no existe un balance alimentario adecuado, de hecho, al consultarles sobre los alimentos que se consumen en los diversos tiempos, generalmente estos fueron: pupusas revueltas, pan dulce, tamales, yuca frita, entre otros.

En el caso de las bebidas, usualmente son café, chocolate y bebidas carbonatadas. Las bebidas naturales son de mínima mención y generalmente se dispone de alguna de tipo enlatado o en envase de plástico.

Con respecto al consumo de frutas y verduras, es bastante mínimo. Es un número muy bajo el que consume frutas después de determinados tiem. pos y las verduras de igual forma son de menos aceptación. 
En el marco de la recolección de la información, muchos miembros de la corporación hicieron ver que por su trabajo, el régimen alimentario es difícil, particularmente porque no cuentan con el tiempo y la disposición de alimentos con mejores valores nutricionales. Aparte de esto, en las ventas o comedores que se encuentran ya sea dentro de las sedes o en sus alrededores, no se cuenta con un menú saludable, de ahí que las pupusas y los alimentos de ese orden se convierten en parte de la dieta diaria.

\section{Control del consumo de calorías}

\section{GRÁFICO 14}

¿Controla usted el consumo de calorías en sus alimentos a diario?

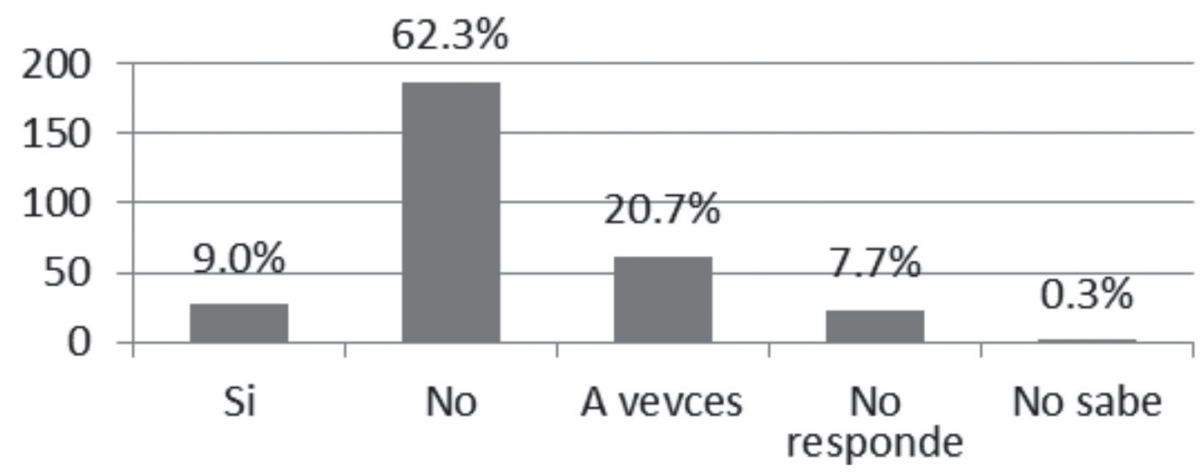

El consumo de calorías, como ya se mencionó, es fundamental para el funcionamiento del cuerpo humano, sin embargo, si no se logra un consumo balanceado, se puede o bien caer en desnutrición o en obesidad (Bellido y De Luis, 2006).

Al consultar a los participantes en el estudio, el $62 \%$ mencionó que no tiene un control sobre el consumo calórico diario, mientras que un $21 \%$ dijo que a veces y un $9 \%$ que sí. Como se puede mostrar con la evidencia recolectada, no existe mayoritariamente un hábito hacia la forma en que se alimentan, por lo cual no se tiene un control de lo consumido, situación que puede generar problemas asociados a la obesidad o la desnutrición, aparte de la falta de energías para la realización de las actividades del día. 


\section{Aspectos que afectan la nutrición}

\section{GRÁFICo 15}

\section{A su criterio, ¿Cuáles de los siguientes factores afectan su nutrición y alimentación}

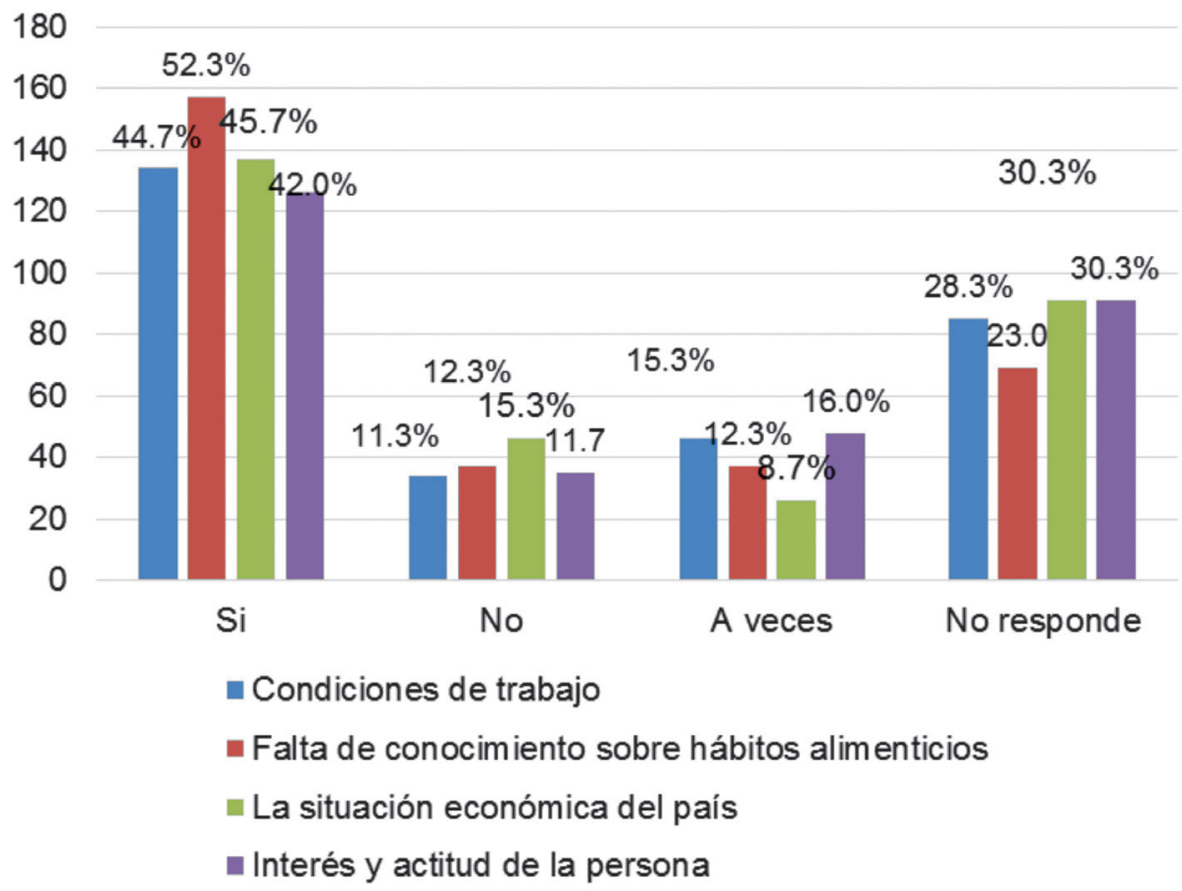

La alimentación saludable puede verse afectada por diversos factores, entre los cuales están aquellos que son propios de la actividad diaria y otros, derivados de la educación nutricional que se haya recibido (Marín, 1998).

En ese sentido, se consultó a los participantes, sobre qué factores afec. taban su nutrición, y el mayor porcentaje se ubicó en la "falta de conocimientos sobre hábitos alimenticios", posteriormente aparece la situación económica del país, le sigue la condición del trabajo y por último la actitud e interés de la persona. 


\subsection{Percepción del autocuidado.}

\section{Actividad física}

\section{GRÁFICO 16}

\section{¿Cuántas vecesa la semana realiza actividad física?}

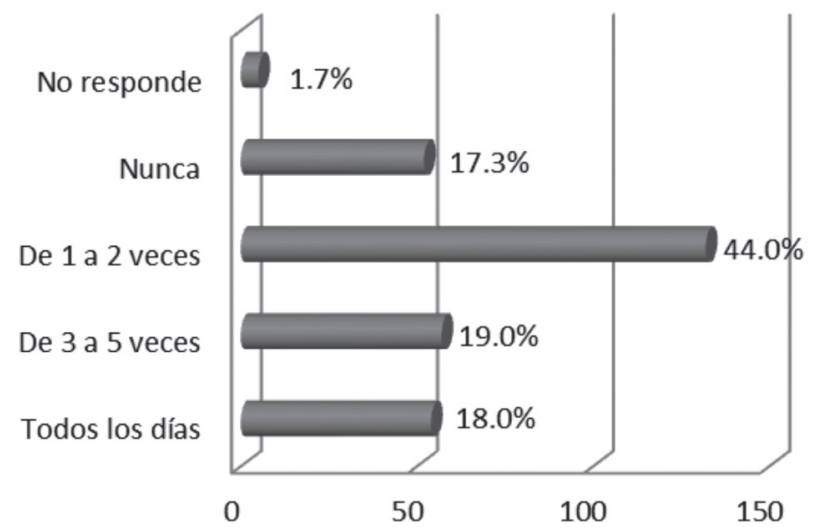

La actividad física constante es un factor importante para el autocuidado de una persona, porque posibilita un mejor funcionamiento del organismo y, además, se previenen múltiples enfermedades crónicas degenerativas (Ochoa, Rivas, Miguel-Soca, Batista, y Leyva, 2015).

Al consultar sobre la realización de actividad física, un $18 \%$ mencionó que todos los días y el $19 \%$ de 3 a 5 días, es decir, que casi el $60 \%$, equivalente a 6 de cada 10 personas, no realiza actividad física de forma continua, exponiéndose se esa manera a una complicación en su salud en el futuro.

\section{Práctica de deporte}

\section{GrÁFICO 17}

¿Practica algún deporte?

No responde
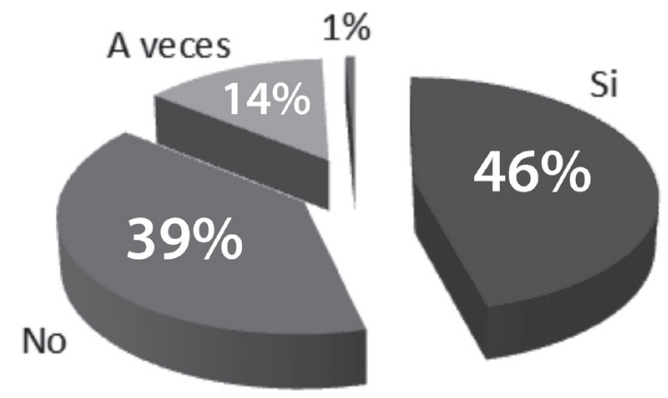
Siempre, con relación al tema de la actividad física, se consultó sobre la práctica de algún deporte ya que esta constituye también una importante forma de quemar calorías y mantener un cuerpo sano y fuerte (Ramírez, Vinaccia, y Suárez, 2004).

Sobre la consulta de la práctica de deportes, se obtuvo que el $46 \%$ sí realiza, pero el $39 \%$ no y solamente un $14 \%$ a veces. Con esto se muestra que la realización de actividad física, incluyendo el deporte, no es algo constante en todo el personal de la corporación, situación que puede tener consecuencias en el futuro.

\section{Caminar diariamente}

Como se ha visto, la actividad física es importante para el autocuidado. Evitar la vida sedentaria puede propiciar una mejoría importante en la salud de las personas, por ello, se recomienda caminar al menos 30 minutos al día, para darle al sistema cardiovascular, una adecuada oxigenación y evitar enfermedades vinculadas a este (Romero, 2009).

Al preguntar si se caminaba al menos 30 minutos diarios, un 39\% expresó que sí, pero un $43.3 \%$ que no y un $16.3 \%$ que nunca. Esto muestra en buena parte, que el sedentarismo es evidente, y recalca el hecho que la práctica de actividad física a diario en períodos repetitivos durante la semana, puede favorecer significativamente la salud de la persona, además de prevenir el padecimiento de enfermedades coronarias e inclusive, contribuir a la salud mental, reduciendo la ansiedad y el estrés (Ramírez, Vinaccia y Suárez, 2004).

\section{GRÁfICo 18}

\section{¿Camina al menos 30 minutos diarios?}

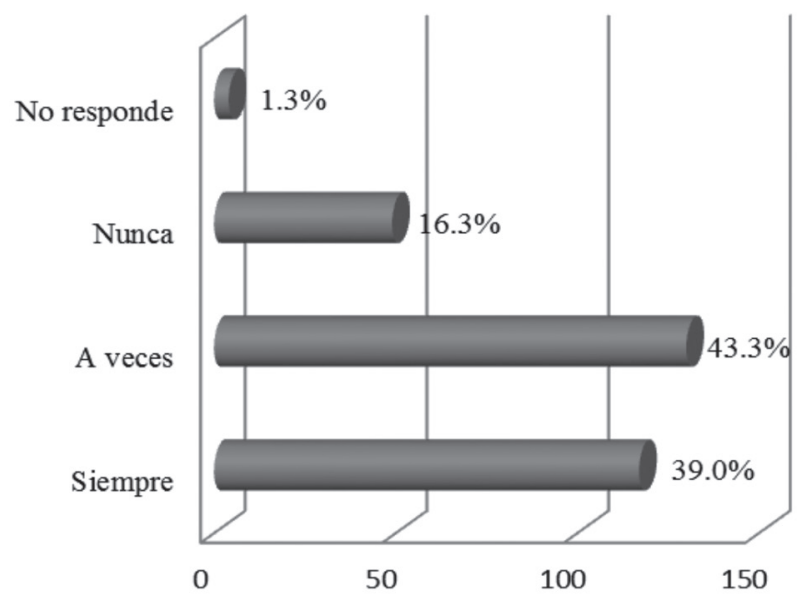




\section{Alimentación baja en grasas}

\section{Gráfico 19}

\section{¿Su alimentación es baja en grasa?}

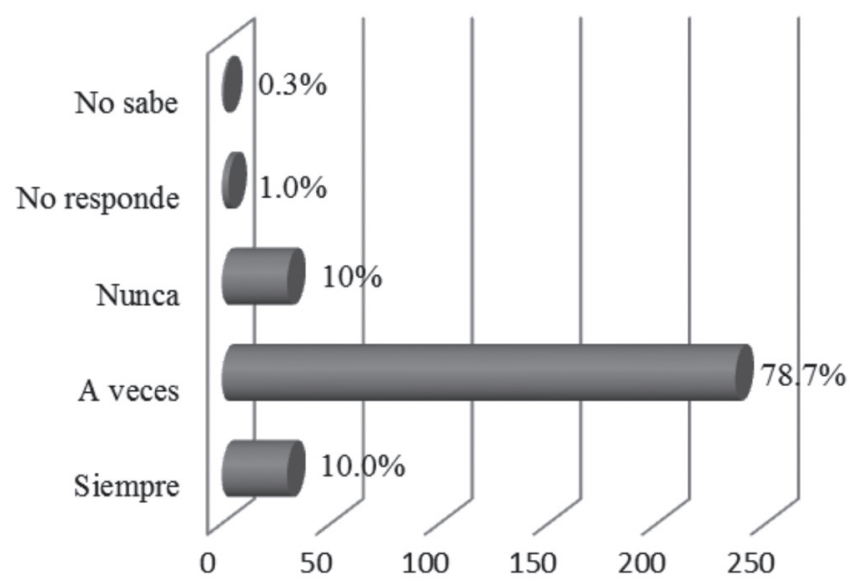

Aunque el componente nutricional se abordó anteriormente, es necesario considerar a nivel de autocuidado, cuánto las personas gestionan su alimentación en referencia al consumo de grasas, ya que el consumo de estas -más aún si son trans-, puede generar padecimientos de salud en el futuro (Meléndez, 2008).

Al consultar al respecto, se obtuvo que el $78.7 \%$ de participantes, mencionaron que a veces su alimentación es baja en contenido grasoso y un $10 \%$ que siempre, solamente un $10 \%$ mencionó que nunca.

\section{Frecuencia de ingesta de líquidos}

\section{GráfICo 20}

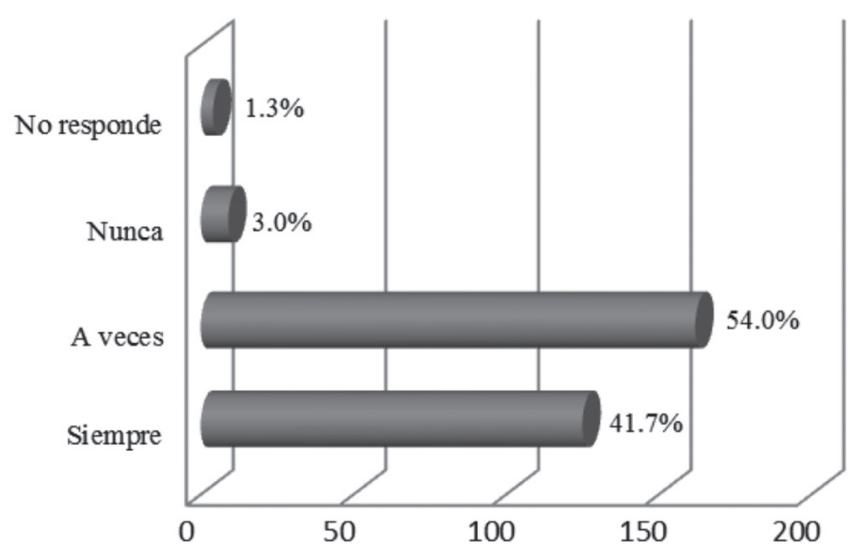


La ingesta de líquidos es importante, particularmente por la hidratación y los efectos que corresponden en la salud humana (Ayus, Tejedor, y Caramelo, 2007).

Hay que recordar que el personal operativo de la Policía Nacional Civil, se encuentra muchas veces en situaciones de constante actividad, por ello, este dato es relevante.

Según lo planteado por el 54\% de los encuestados, la ingesta constante de líquidos la realizan solo a veces, sin embargo, el $41.7 \%$ menciona que siempre. Esto muestra que, mayoritariamente, existe el hábito del consumo de líquidos, que como se mencionó antes, surte un efecto importante para el bienestar y la salud de los agentes de la corporación.

\section{Consumo de jugos naturales}

\section{GRÁFICO 21}

\section{¿Consume jugos naturales sin preservantes?}

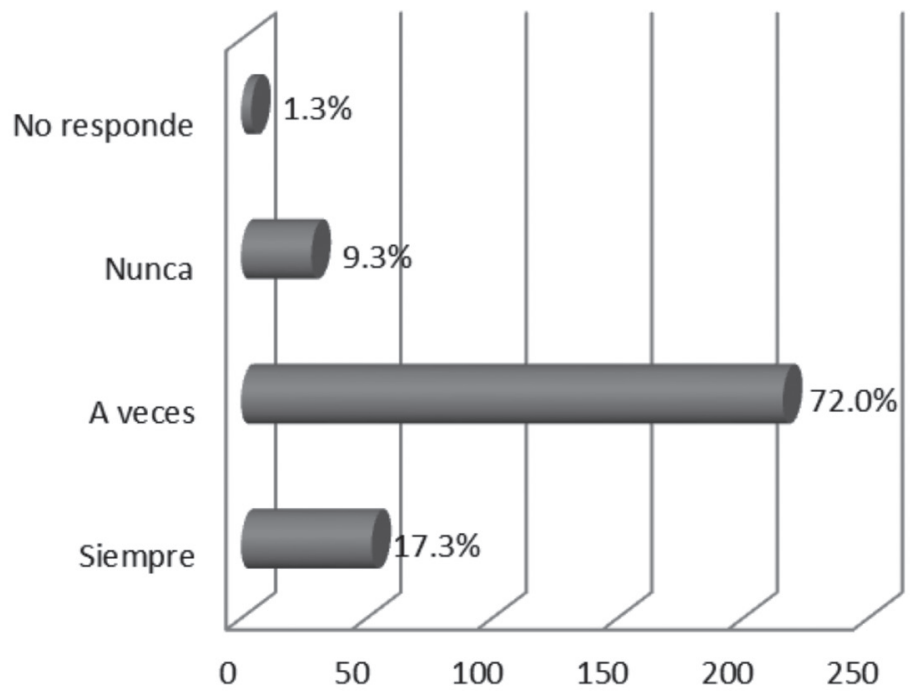

El consumo de bebidas naturales es un importante hábito, ya que estas brindan mayores beneficios nutricionales, aparte de vitaminas y minerales esenciales (Requejo y Ortega, 2002).

Al consultarle a los participantes del estudio, el $72 \%$ manifestó que a veces consume jugos de origen natural, mientras que el $17.3 \%$ siempre lo realiza y un $9.3 \%$ nunca. 


\section{Consumo de bebidas alcohólicas}

El consumo excesivo de bebidas alcohólicas es parte de un hábito no recomendable para la salud de las personas, además, las consecuencias no solo generan afecciones físicas, sino también emocionales y sociales (Laespada, 2014).

Por otra parte, el consumo de alcohol puede conllevar a problemas psiquiátricos y períodos de depresión, que trágicamente llevan algunas veces al suicidio (Goldman y Schafer, 2013).

En tal sentido, se consultó sobre el consumo de bebidas alcohólicas entre el personal en estudio de la corporación policial. Al respecto, el $66.3 \%$ mencionó que nunca ingiere, mientras que un $32 \%$ lo realiza a veces y un $0.7 \%$ siempre. Lo visto en la evidencia, denota que al menos 3 de cada 10 agentes consumen bebidas alcohólicas y 1 de cada 10 tiene problemas de adicción a la misma, situación que puede ser preocupante.

\section{GráfICO 22}

¿Con qué frecuencia consume bebidas alcohólicas?

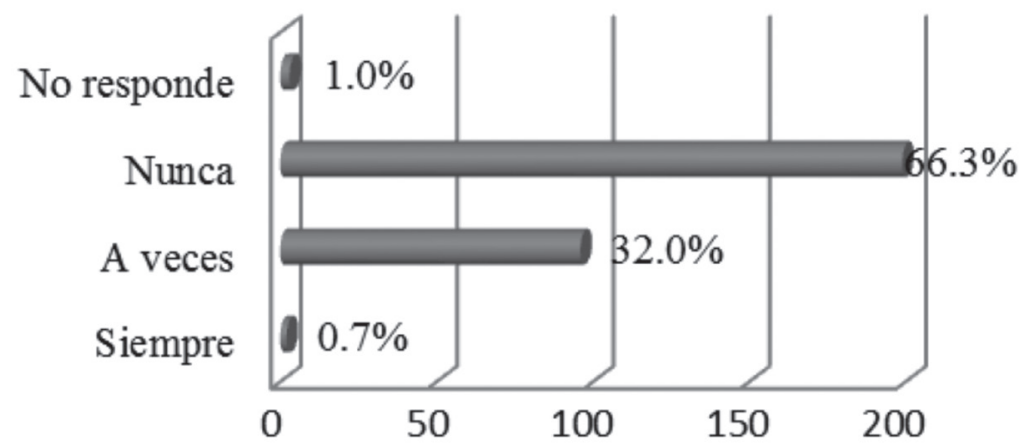

\section{Consumo de tabaco}

\section{GrÁfICO 23}

\section{¿Con qué frecuencia consume cigarrillos?}

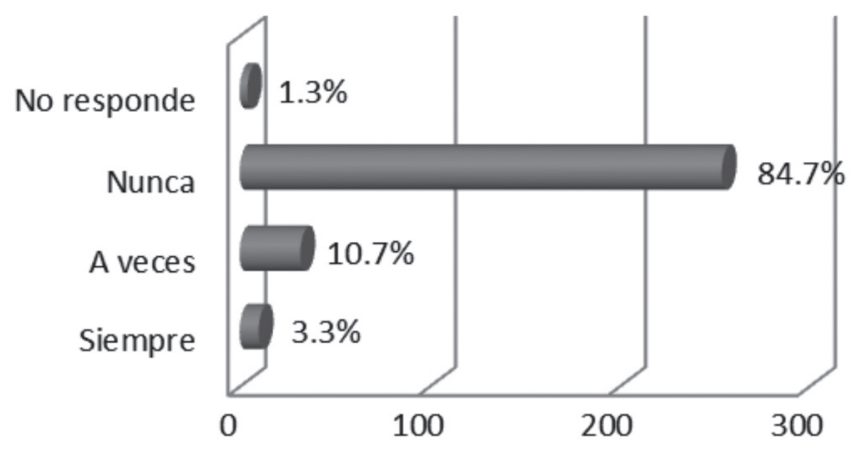


El consumo de tabaco es considerado un factor detonante de diversos padecimientos crónicos degenerativos y enfermedades mortales como el cáncer (Samet, 2002).

Según la OMS (2017d), cada año mueren 7 millones de personas por el tabaco, de las cuales, casi un millón son fumadores pasivos y el resto activo.

En vista de lo anterior, se consultó a los participantes sobre su consumo de tabaco, encontrándose que cerca del $85 \%$ no son consumidores de tabaco, pero un $10 \%$ lo realiza a veces y un $3.3 \%$ siempre. Esto muestra que a pesar que el consumo del tabaco es reducido, es un factor de riesgo también para quien no lo consume, es más, resulta más riesgoso para quien no lo hace que para quien si lo hace.

\section{Evacuación intestinal}

\section{GRÁFICO 24}

\section{¿Su evacuación intestinal es diaria o sin molestia?}

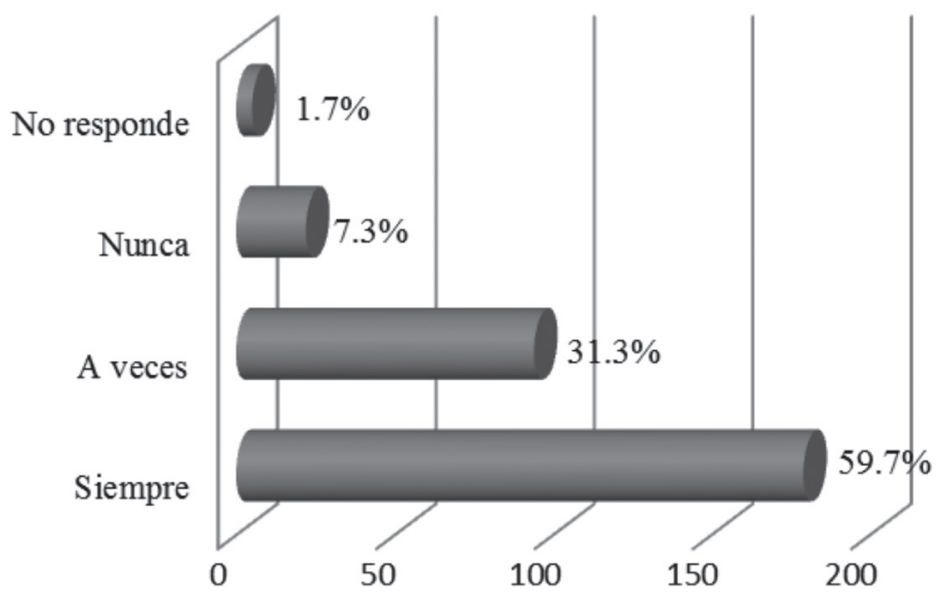

La salud del aparato digestivo es importante para un buen funcionamiento de este, por otra parte, existen padecimientos que pueden ser prevenibles si son detectados a tiempo, siendo un parámetro la evacuación diaria, a la cual al prestársele atención puede brindar un indicador para la prevención (Díaz y Rey, 2007).

Al consultar a los entrevistados sobre su evacuación intestinal diaria, el $59.7 \%$ expresó que es siempre sin molestias y de forma diaria, sin embargo, un $31.3 \%$ dijo que a veces es así y un $7.3 \%$ que nunca es así. Por ello, se puede valorar que cerca de un $40 \%$, es decir 4 de cada 10 personas, tienen algún problema con respecto a esto, que puede estar vinculado a padecimientos gastrointestinales crónicos o inclusive a alguna enfermedad más grave, por tanto se debería prestar atención a esto de forma oportuna. 


\section{Frecuencia de eliminación urinaria}

\section{GRÁfICo 25}

\section{¿Su eliminación urinaria es sin molestia?}

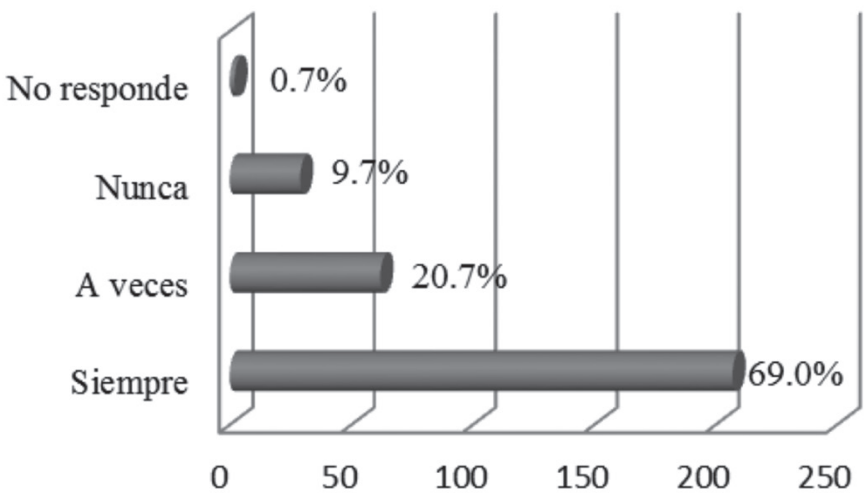

La salud del aparato urinario es importante por todas las implicaciones que este tiene para el funcionamiento de todo el cuerpo humano. Tanto en el hombre como en la mujer, su cuidado también se asocia a la prevención de diversas enfermedades (Cataño, De los Ríos, Díaz, Samacá, y Wilde, 2006).

Al consultar al respecto, el $69 \%$ mencionó que no tiene ninguna molestia al momento de evacuar la orina, sin embargo, un $20.7 \%$ mencionó que a veces y un $9.7 \%$ que siempre. Estos últimos, en el caso de ser hombres, inclusive podrían estar en una situación de riesgo de padecimientos vinculados a problemas de próstata (Cataño et al., 2006).

\section{Tiempo para reposar entre sus actividades diarias}

El descanso es parte importante para una persona, particularmente cuando las jornadas de trabajo son extenuantes y llenas de conflictos, y donde se vuelve necesario generar espacios de paliativos en función de propiciar un manejo de situaciones afectivas (Elizondo, 2001).

A ese respecto, se consultó si se dejaba tiempo para reposar entre las actividades laborales diarias, encontrándose que solamente un $15.7 \%$ lo hace siempre, mientras un $61.7 \%$ a veces y un $21.0 \%$ nunca.

Esto muestra que el descanso no siempre en posible, las diversas actividades que se realizan y los hábitos ya establecidos se configuran a fin de no propiciarlo adecuadamente. 


\section{Gráfico 26}

¿Se deja tiempo para reposar entre sus actividades diarias?

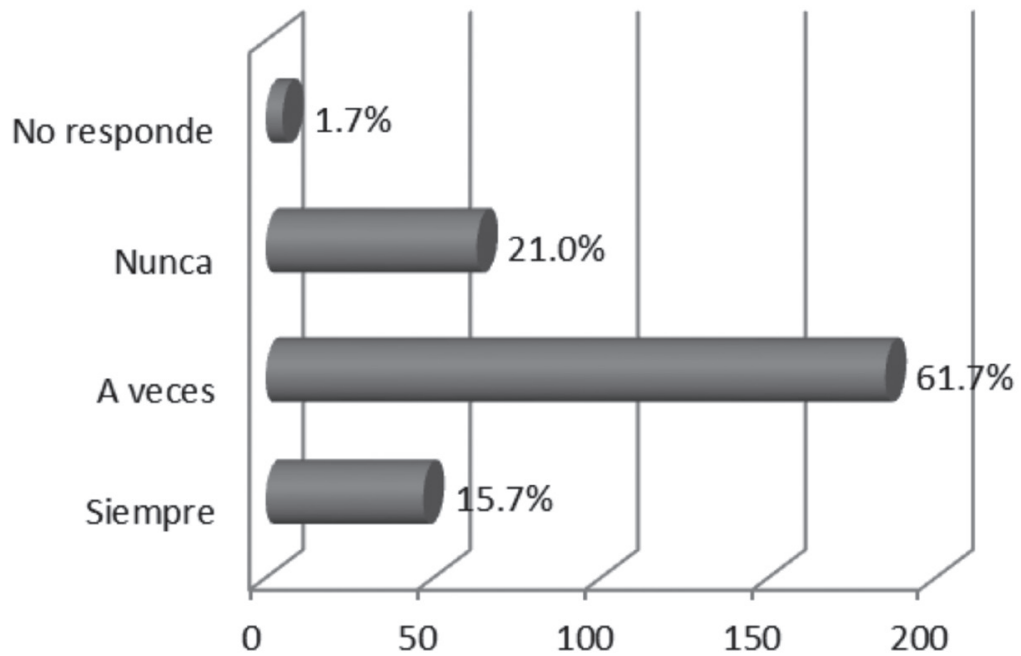

Frecuencia de relaciones sociales sanas

\section{Gráfico 27}

¿Comparte tiempo con sus familiares y amigos?

Solo con familia
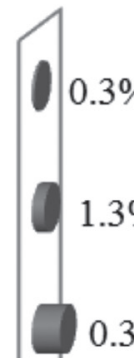

No responde

Nunca

A veces

Siempre

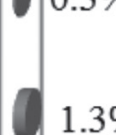




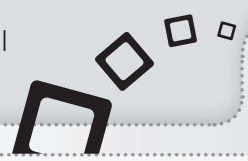

El manejo adecuado de relaciones personales puede generar un importante elemento para la salud mental de la persona, particularmente si las mantiene con sus familiares y amigos más cercanos (Elizondo, 2001).

El resultado muestra que el $54 \%$ expresa que comparte tiempo con sus familiares y amigos, mientras que un $41.4 \%$ lo hace a veces.

Como se muestra, la mayoría mantiene una relación de compartimiento adecuada con la familia, algo que es bastante propicio para la generación de vínculos afectivos y también contribuye a la salud mental de los miem. bros de la corporación.

\subsection{Percepción de la salud.}

\section{Colesterol y triglicéridos}

\section{GRÁfICo 28}

\section{¿Se ha realizado en el último año examen de colesterol y triglicéridos?}

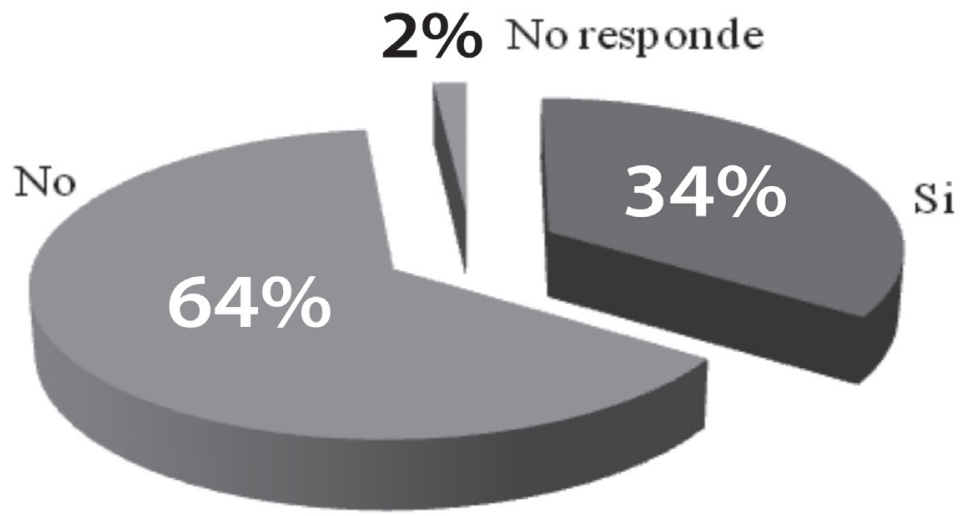

El colesterol y los triglicéridos son sustancias que se encuentran en la sangre y que son vitales para el funcionamiento del organismo humano, sin embargo, cuando sobrepasan la cantidad necesaria, pueden repercutir gravemente en la salud de las personas (Richardson, 2004).

Al consultarles a los entrevistados, el $64 \%$ mencionó que no se ha realizado estas pruebas y solamente un 34\% mencionó que sí se las ha realizado en el último año. Esto muestra que, al menos 6 de cada 10 personas, no tienen un diagnóstico sobre la presencia de colesterol o triglicéridos elevados. 


\section{Valoración sobre el diagnóstico de colesterol y triglicéridos elevados}

\section{GRÁFICO 29}

\section{¿Ha tenido colesterol o triglicéridos altos en los últimos dos años?}

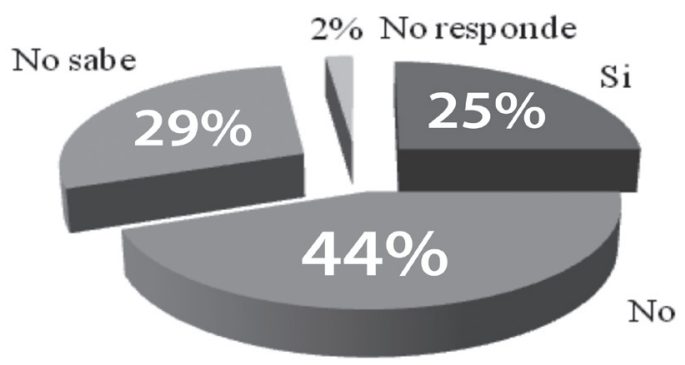

El diagnóstico oportuno de un nivel de colesterol y triglicéridos altos, puede propiciar la atención oportuna y evitar las complicaciones que derivan de estos (Richardson, 2004).

A los participantes del estudio se les consultó si habrían tenido en los úl. timos 2 años un diagnóstico de colesterol o triglicéridos elevados del nivel normal.

Según los resultados, el 44\% expresó que su diagnóstico era negativo, sin embargo, un 25\% mencionó que sí tenía un diagnóstico de colesterol o de triglicéridos elevados, pero un 29\% desconoce su situación, algo que puede ser perjudicial para su salud posterior.

\section{Medición de la presión arterial}

La hipertensión arterial es una condición de salud, que de no ser tratada de forma adecuada y oportuna, puede conllevar a problemas cardiacos, renales y visuales, entre otros (Elizondo, 2001).

La toma de la presión arterial permite establecer un diagnóstico sobre el desarrollo de una hipertensión, a fin de detectarla a tiempo y evitar sus complicaciones.

Al consultar a los participantes en el estudio, si se habría realizado un chequeo en su presión arterial, el 55\% asegura que sí, pero un $43 \%$ dijo que no. 


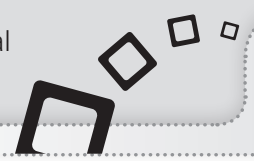

\section{Gráfico 30}

\section{¿Se ha realizado en el último año medición de la presión arterial?}

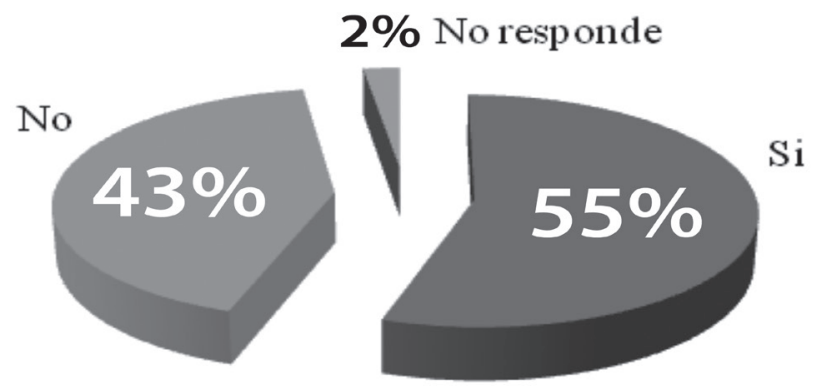

Valoración de diagnóstico de hipertensión

\section{Gráfico 31}

\section{¿Ha sido diagnosticado con hipertensión arterial?}

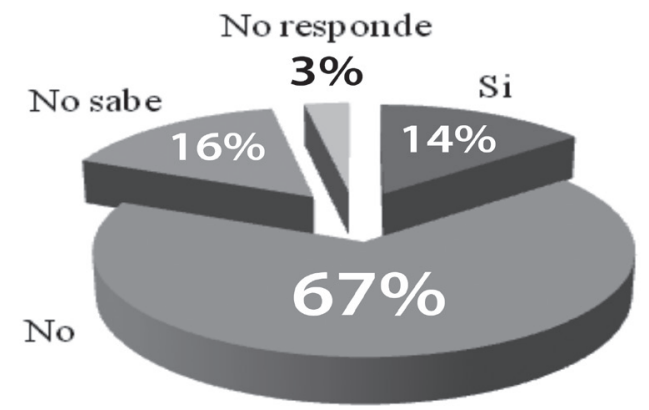

La hipertensión debe ser detectada a tiempo, ya que sus secuelas suelen ser graves para el organismo, y además pueden ser confundidas con otros padecimientos o simplemente pasar desapercibidas; de ahí que ha sido denominada como "el asesino silencioso" (García de Guadiana, 2002).

Un chequeo periódico de la presión arterial, puede permitir establecer un diagnóstico oportuno para así comenzar las indicaciones dadas por un médico.

Al consultarle a los participantes si tenían un diagnóstico de hipertensión, el $14 \%$ mencionó que sí, mientras que el $67 \%$ dijo que no. No obstante, un $16 \%$ prefirió manifestar que no sabe aún. Esto muestra que existen por lo menos de 1 a 2 de cada 10 personas de la corporación policial, con este padecimiento crónico degenerativo, que debe ser tratado oportunamente para no derivar en sus consecuencias para la salud. 


\section{Tratamiento de la hipertensión}

\section{Gráfico 32}

\section{Si su respuesta anterior fue sí, ¿Se encuentra en tratamiento con un médico para tratarse esta situación?}

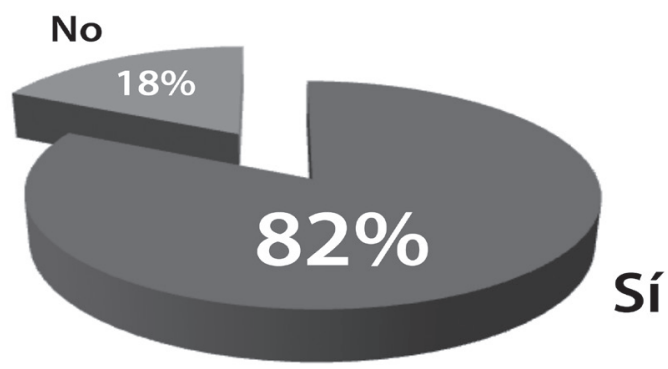

El diagnóstico de hipertensión debe ser tomando con seriedad y, sobre todo, llevar el tratamiento al pie de la letra como lo indica el médico, sobre todo cuando se realizan diversas pruebas para determinar el factor de riesgo (García de Guadiana, 2002).

Al consultarle a las personas que tienen el diagnóstico de hipertensión y excluyendo a quienes no hicieron mención de tenerlo, se obtuvo que el $82 \%$ se encuentra recibiendo un tratamiento médico y lo completan según lo indicado, sin embargo, un $18 \%$ mencionó que no lo lleva a cabo, lo cual está asociado a que las personas no le prestan la suficiente atención a la enfermedad o aducen que no tienen el tiempo para ir a sus controles médicos.

\section{Valoración del padecimiento de diabetes}

\section{GrÁfico 33}

¿Usted tiene diagnóstico de diabetes mellitus?
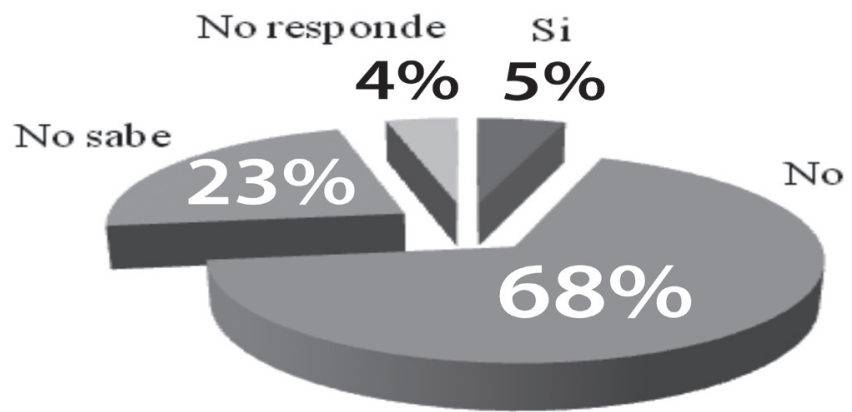


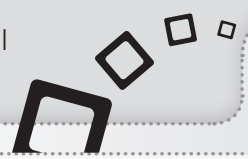

La diabetes es una enfermedad crónica degenerativa que se genera cuando el páncreas no produce insulina suficiente o el organismo no es capaz de utilizarla eficazmente (Tebas y Escobar, 2009).

Según la OMS (2017c), el número de personas con diabetes ha aumentado de 108 millones en 1980 a 422 millones en 2014, provocando para 2015 la muerte de 1.6 millones de personas a nivel mundial.

Al consultar a los participantes si tenían un diagnóstico de diabetes, se encontró que un 5\% manifestaron que sí, mientras un $68 \%$ dijo que no y un $23 \%$ que no sabía. Como puede verse en la muestra, hay un porcentaje que evidencia la existencia de esta enfermedad crónica degenerativa, la cual es de vital importancia prestarle la atención oportuna.

\section{Tratamiento de diabetes}

La diabetes puede tratarse, evitarse o retrasar sus consecuencias; para ello, se requiere que el paciente tenga un peso normal y evite el consumo de tabaco, además de la dieta, la medicación y exámenes periódicos (OMS, 2017c).

Al consultar a los participantes que expresaron que tenían el diagnóstico de esta enfermedad, el 68\% mencionó que sí se encuentra recibiendo un tratamiento médico, mientras un $32 \%$ dijo lo contrario, atribuyendo a la falta de tiempo tal situación.

La diabetes debe ser atendida oportunamente, para evitar sus complicaciones, además, en un régimen de trabajo, deben adecuarse algunas condiciones para que la persona con este diagnóstico tenga ciertas concesiones en cuanto a funciones que podrían derivar en una complicación de su salud.

\section{Gráfico 34}

Si su respuesta anterior fue sí, ¿Se encuentra en tratamiento con un médico?

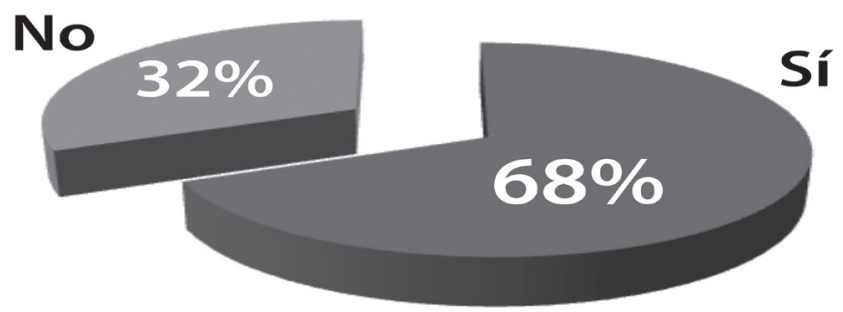




\section{Salud visual}

\section{Gráfico 35}

¿Se ha realizado en el último año examen visual?

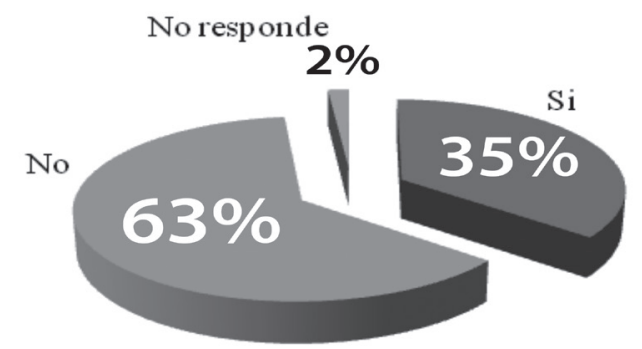

La salud visual es una situación muy particular, pero importante en la medida en que muchos padecimientos asociados a esta pueden ser prevenibles, si son detectados a tiempo (OMS, 2013b).

En el año 2010, según la OMS (2013b), habían en el mundo cerca de 285 millones de personas que padecían discapacidad visual, de las cuales 39 millones son ciegas; se considera entonces que el $80 \%$ de las causas de discapacidad visual pueden ser prevenibles.

En tal sentido, se consultó a los participantes si se habían realizado un examen visual en el último año, para lo cual el $63 \%$ expresó que no, mien. tras un $35 \%$ que sí. Por ello, se corrobora que la parte de salud visual aún no logra tener mayor demanda, a pesar de ser tan fundamental para las tareas y actividades diarias, en tal sentido, se debe valorar este indicador, ya que un diagnóstico temprano puede evitar consecuencias futuras.

\section{Salud bucal}

\section{Gráfico 36}

¿Se ha realizado en el último año examen odontológico?

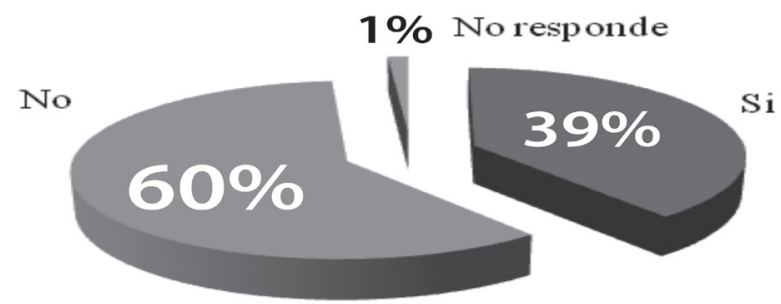


Según la OMS (2012), la salud bucal es fundamental para el goce de una buena salud y está definida por la ausencia de dolor orofacial, cáncer de boca o garganta, infecciones y llagas bucales, entre otras.

Según este organismo (OMS, 2012), alrededor del 30\% de la población entre los 65 y los 74 años no tiene dientes naturales. Por esta razón, se les consultó a los participantes si se había realizado un examen odontológico durante el último año, teniéndose que el $60 \%$ no y el $39 \%$ sí. Esto indica que 6 de cada 10 personas, no cuentan con una adecuada práctica preventiva de su salud bucal, por ende, están expuestos a los padecimientos derivados, que incluyen la extracción de una pieza dental o el padecimiento de alguna enfermedad asociada a esta falta de atención.

\section{Enfermedades gastrointestinales}

\section{GRÁfICO 37}

\section{¿Padece de enfermedades gastointestinales (gastritis, colitis, reflujo, etc.)}

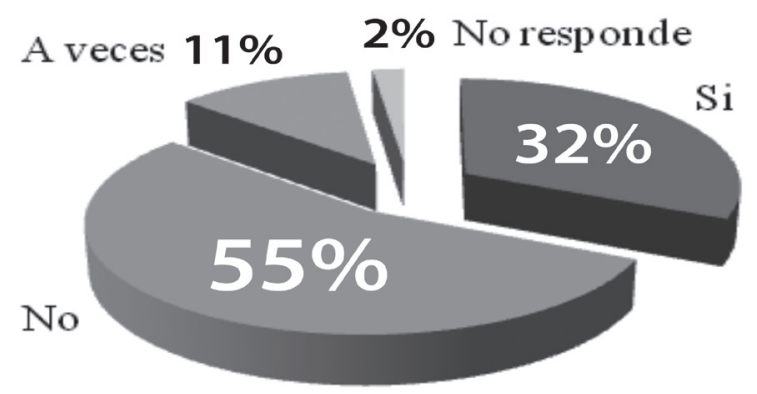

Las enfermedades gastro-intestinales comprenden un conjunto de padecimientos, los cuales están vinculados directamente al funcionamiento del aparato digestivo y a las funciones que de este derivan y que pueden generar una serie de síntomas diversos que afectan la calidad de vida de las personas (Feldman y Friedma, 2004).

Por otra parte, las enfermedades gastrointestinales tienen diversas causas, entre las que se pueden mencionar están la ingesta de alimentos y el estrés.

Al consultar con los participantes, se encontró que el 32\% padece alguna enfermedad de este tipo, mientras que un $11 \%$ únicamente a veces, mostrándose una tendencia que de cada 10 miembros de la corporación, 4 tienen algún problema gastrointestinal. 


\section{Padecimiento de infecciones urinarias}

Las infecciones en las vías urinarias tienen diversas causas y pueden ocurrir en diversas partes del aparato urinario, además, su presencia recurrente puede estar asociada a otros padecimientos que las provocan a los cuales se les debería prestar atención oportuna (Dalet y Del Río, 1997).

Aspectos como la edad, embarazo y algunas enfermedades como la diabetes, problemas de vejiga, incontinencias intestinales, próstata agrandada, cálculos renales, entre otros; están vinculados a la recurrencia de infeccio. nes urinarias (Dalet y Del Río, 1997).

En ese sentido, al consultar a los participantes en el estudio, el $71 \%$ mencionó que no tiene infecciones urinarias de forma recurrente, sin embargo, un $8 \%$ expresó que sí y un $19 \%$ dijo que a veces. Esto muestra que sí existe una parte del personal de la corporación que debe considerar la realización de algún examen que le permita establecer la causa por la que se presentan las infecciones.

\section{Gráfico 38}

\section{¿Padece de infecciones urinarias periódicamente?}

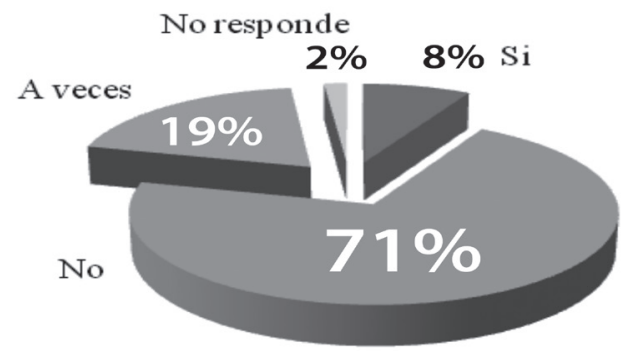

Salud de la mujer: toma de citología anual

Gráfico 39

Si es mujer, ¿realiza la citología cada año?

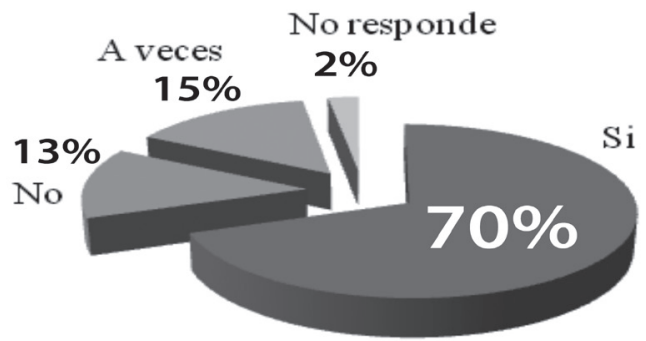


En la salud de la mujer, un punto importante es la toma de la citología, la cual permite diagnosticar entre otras cosas, un posible cáncer cérvico uterino, que es causado por infecciones de transmisión sexual por determinados tipos del virus del papiloma humano (Alonso de Ruiz, Lazcano y Hernández, 2005).

Según la OMS (2015), para el año 2012 aproximadamente 270000 mujeres murieron en el mundo a causa del cáncer cérvico uterino, que a la vez se convierte en la segunda causa de muerte más frecuente en las mujeres, principalmente en las regiones menos desarrolladas. Al consultar a las mujeres participantes, el $70 \%$ manifestó que sí se realiza el examen una vez año, sin embargo, un $13 \%$ dijo que no y un 15 que a veces.

\section{Salud de la mujer: autoexamen de mama}

\section{GRÁFICo 40}

\section{Si es mujer, ¿Se realiza el auto examen de mama cada mes?}

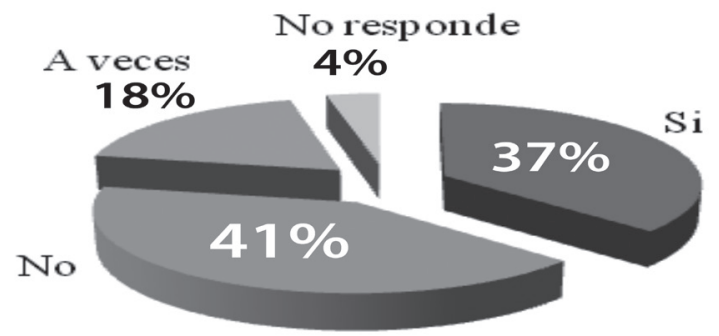

Según la OMS (2017a), el cáncer de mama es el más frecuente en las mujeres, tanto en los países desarrollados como en los subdesarrollados y para el año 2004, provocó la muerte de 519000 mujeres y para el año 2012, se estimó la detección de al menos 1,7 millones de casos nuevos, según un informe del mismo organismo.

El cáncer de mama puede ser prevenible y detectable fácilmente en sus primeras etapas, para lo cual es necesario realizarse la autoexploración, a partir de una prueba que es fácil, pero cuyos resultados pueden obrar para salvar una vida (Lostao, 2001).

Al consultarles a las mujeres participantes en el estudio, solamente un $37 \%$ se realiza la autoexploración de mama, mientras un $41 \%$ no lo hace y un $18 \%$ mencionó que a veces. Este dato es preocupante, ya que solamente 4 de cada 10 mujeres, realiza esta práctica, colocando a las otras 6 en un riesgo eminente. 
Salud del hombre: visita al urólogo

\section{Gráfico 41}

Si es hombre, ¿visita al urólogo cada año?

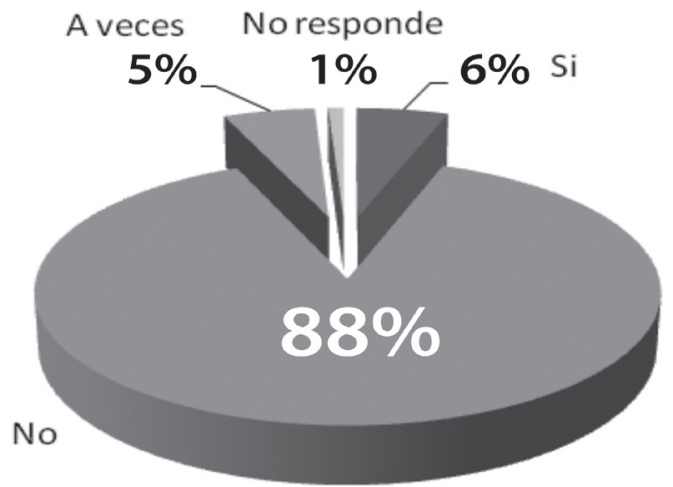

En el hombre, el cuidado de la salud de su aparato reproductor pasa necesariamente por el control y visita periódica al urólogo, sin embargo, según los estudios, la frecuencia es baja a pesar de que se recomienda realizarse periódicamente (Vinaccia, Fernández, Monsalve, y Quiceno, 2008).

Por ello y considerando que las edades de los participantes sobrepasan los 30 años mayoritariamente, se les consultó si visitaban al urólogo una vez al año, sobre lo cual el $88 \%$ mencionó que no, un $6 \%$ dijo que si lo visita y un $5 \%$ que a veces. Esto muestra que existe para el caso de los hombres, una situación de déficit de autocuidado al no tener la práctica de una visita periódica al especialista.

\section{Salud del hombre: autoexploración testicular}

\section{GRÁfico 42}

Si es hombre, ¿Se realiza la exploración testicular cada mes?

\section{No responde}

\section{A veces $8 \% \quad 3 \% \quad 5 \%$ Si}

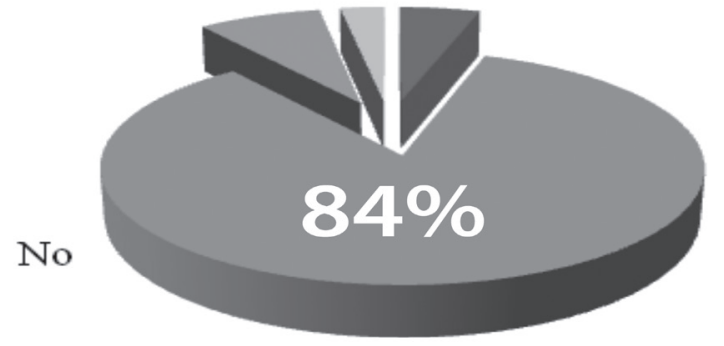


En el hombre, un aspecto importante de su autocuidado es la exploración testicular, en la cual se deben buscar nódulos o bultos duros así como tam. bién cambios perceptibles como engrosamiento y tumoraciones (Gutiérrez y Zapata Boluda, 2016).

En este sentido y considerando la necesidad de la salud en el hombre, se consultó sobre la exploración testicular, encontrándose que el $84 \%$ no se la realiza, mientras que un $8 \%$ dijo que lo hacía a veces y un $5 \%$ que sí.

Con esta información, se corrobora en buena parte la noción de que el hombre tiende a ser menos cuidadoso con su salud que la mujer (Vinaccia, Fernández, Monsalve, y Quiceno, 2008).

\section{Visita anual al médico}

La visita periódica al médico es parte de un importante autocuidado, porque es una forma a través de la cual se puede facilitar la prevención de enfermedades y el tratamiento de otras, siendo un hábito para la salud en general, recomendable por lo menos una vez al año cuando no se tiene ningún problema de salud (Elizondo, 2001).

Al consultar en el estudio sobre esta práctica, el $41 \%$ mencionó que vista al médico de 1 a 2 veces al año, mientras el $27.3 \%$ solo lo realiza al tener una enfermedad.

Como se muestra en el resultado, la visita al médico entre los miembros de la corporación policial, varía en cuanto al tiempo, pero se muestra una tendencia positiva, a pesar de que no es la deseada.

\section{GRÁfICo 43}

\section{¿Cada cuanto tiempo visita al médico?}

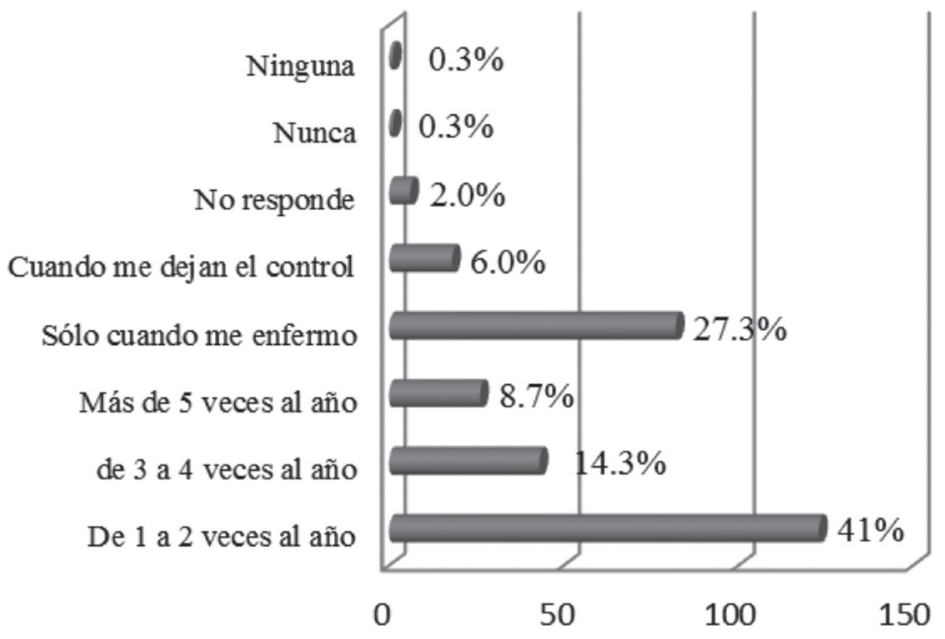




\section{Cobertura de salud}

En cuanto a la cobertura de salud, se consultó a los participantes sobre qué servicios de salud utilizaban con mayor frecuencia. Al respecto cabe recordar que en El Salvador, según la Encuesta de Hogares de Propósitos Múltiples (DIGESCTYC, 2016), el 63\% de la población consulta en establecimientos públicos y cerca de un $20 \%$ en el Instituto Salvadoreño del Seguro Social (ISSS) y un $17 \%$ en hospitales y clínicas privadas.

Para el caso de este estudio, se puede notar que el $80 \%$ de los miembros de la corporación policial, mencionó que lo hace a través del ISSS, mientras que un $13 \%$ hizo la mención que en unidades privadas, y solo un $6.7 \%$ en la clínica de bienestar policial.

\section{GRÁFICO 44}

\section{¿Qué servicios de salud utiliza con mayor frecuencia?}

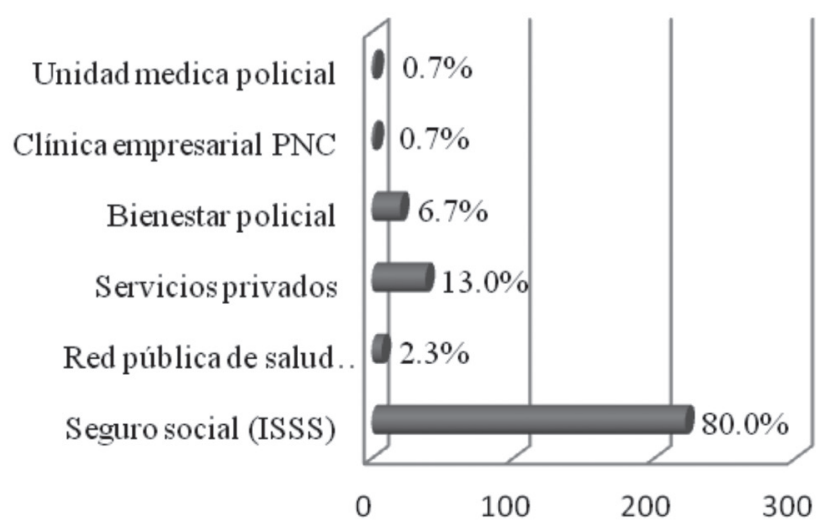

\section{Valoración de los servicios de salud}

\section{GRÁFICO 45}

¿Por qué hace uso con mayor frecuencia de estos servicios?

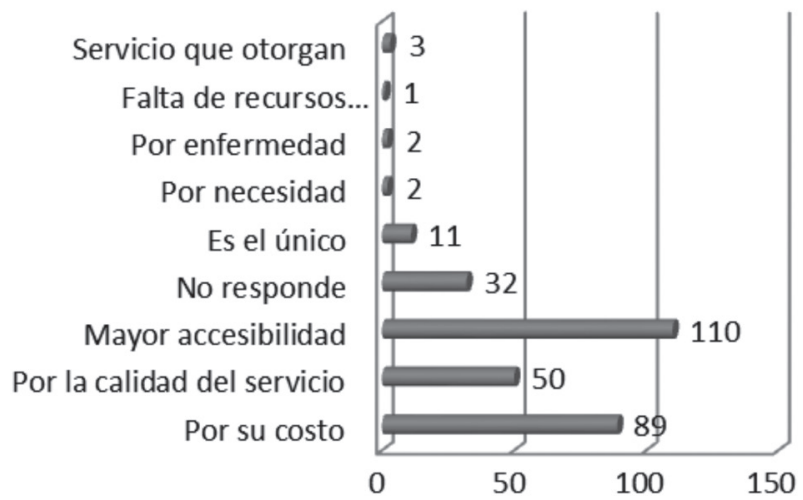


También es importante considerar porqué los usuarios se acercan a este tipo de cobertura, sobre todo para considerar el valor que le dan a la atención.

Al respecto, entre los consultados, el 36\% expresó que, por la mayor accesibilidad, el $29.7 \%$ por el costo y el $16.7 \%$ por la calidad del servicio.

Estas son las menciones mayoritarias por parte de los participantes en el estudio, confirmándose que la manera en que perciben los servicios de salud, tiene que ver en buena parte con aspectos propios de la ventaja de estos y no tanto -a pesar de que fue una mención- del factor económico, sino del acceso y de la calidad de los servicios.

\section{Situación de salud mental y estrés}

La salud mental es, según la OMS (2013a):

"Un estado de bienestar en el cual el individuo es consciente de sus propias capacidades, puede afrontar las tensiones normales de la vida, puede trabajar de forma productiva y fructífera y es capaz de hacer una contribución a su comunidad" (p.1).

A continuación, se analizarán los indicadores del test de estrés laboral del Instituto Mexicano del Seguro Social (IMSS, 2017), en cotejo de la labor de los miembros de la corporación policial.

\section{Imposibilidad de conciliar el sueño}

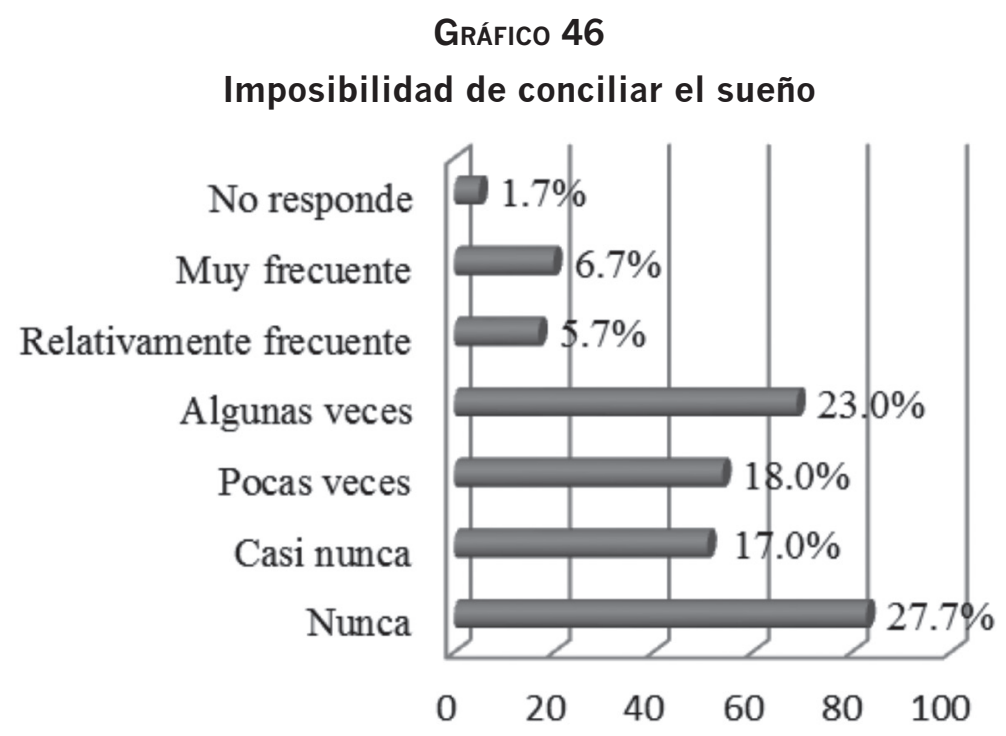


El sueño y el descanso, son factores importantes para la persona, sobre todo en función de sus beneficios para la salud. Sin embargo, cuando no se realizan adecuadamente, pueden propiciar afectaciones y denotar al. gún síntoma de estrés.

Al respecto, al consultarle a los participantes, el $27.7 \%$ mencionó que nunca lo padece, el $17.0 \%$ casi nunca, el $18.0 \%$ pocas veces, el $23 \%$ algunas veces, el $5.7 \%$ relativamente frecuente y un $6.7 \%$ manifiesta que lo padece de forma muy frecuente. Como se muestra, este indicador se encuentra presente en buena parte de la población entrevistada.

\section{Jaquecas y dolor de cabeza}

\section{GrÁFıco 47}

Jaquecas y dolor de cabeza

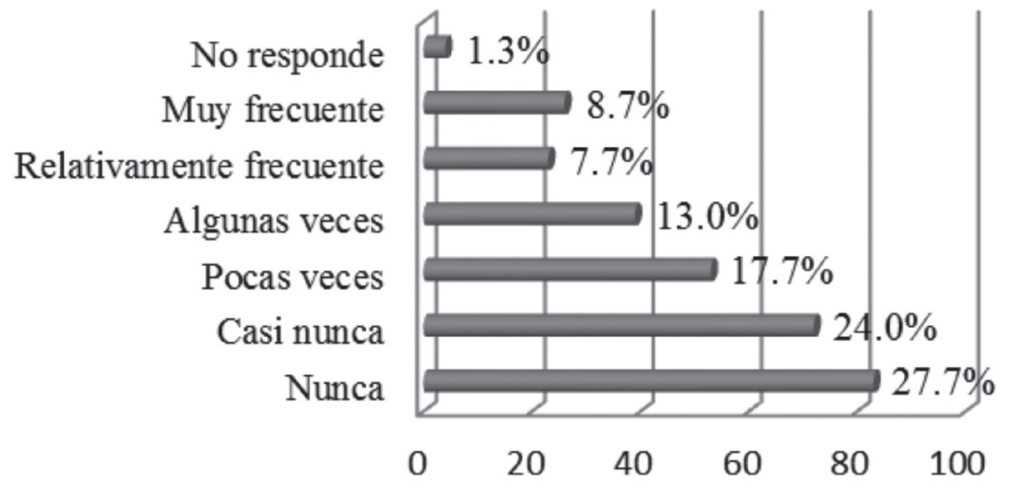

Se consultó sobre las jaquecas y el dolor de cabeza. Al respecto un $27.7 \%$ nunca lo padece, un $24.0 \%$ casi nunca, un $17.7 \%$ pocas veces, un $13 \%$ algunas veces, un $7.7 \%$ con relativamente alguna frecuencia, el $8.7 \%$ muy frecuentemente y únicamente el $1.3 \%$ no respondió.

Como se muestra, este indicador también se hace presente en un porcentaje significativo entre los participantes del estudio.

\section{Indigestión o molestias gastrointestinales}

La frecuencia de las enfermedades gastrointestinales, puede estar relacionada a problemas de estrés, ya que este desemboca en algunas afecciones como por ejemplo el síndrome del colon irritable (Vinaccia et al., 2005), el cual se hace recurrente cuando se tienen problemas laborales o personales. 


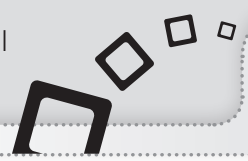

Al consultar a los participantes sobre la presencia de enfermedades gastrointestinales de forma periódica el $20.7 \%$ manifiesta que nunca ha tenido, el $28 \%$ menciona que casi nunca, el $19.3 \%$ pocas veces, el $17.7 \%$ algunas veces, el $7.7 \%$ los tiene con relativamente alguna frecuencia y un 3.0\% comenta tener dichas enfermedades de manera frecuentemente. Observando los resultados, puede evidenciarse la presencia de este indicador de estrés entre los participantes, de forma reiterativa en por lo menos 4 de cada 10 de ellos.

\section{GRÁfICO 48}

\section{Indigestiones o molestias gastrointestinales}

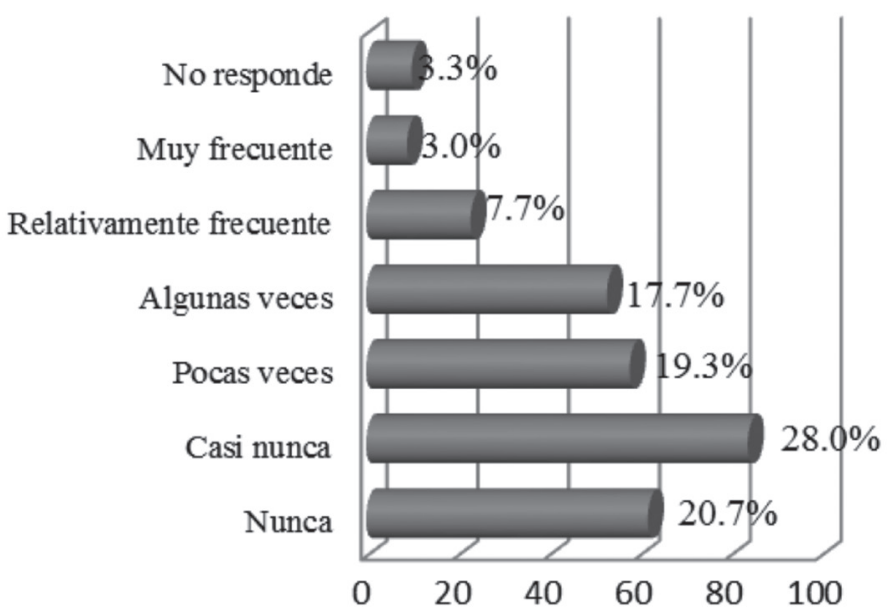

Agotamiento y cansancio

\section{Gráfico 49}

Sensasiones de cansancio o extremo agotamiento

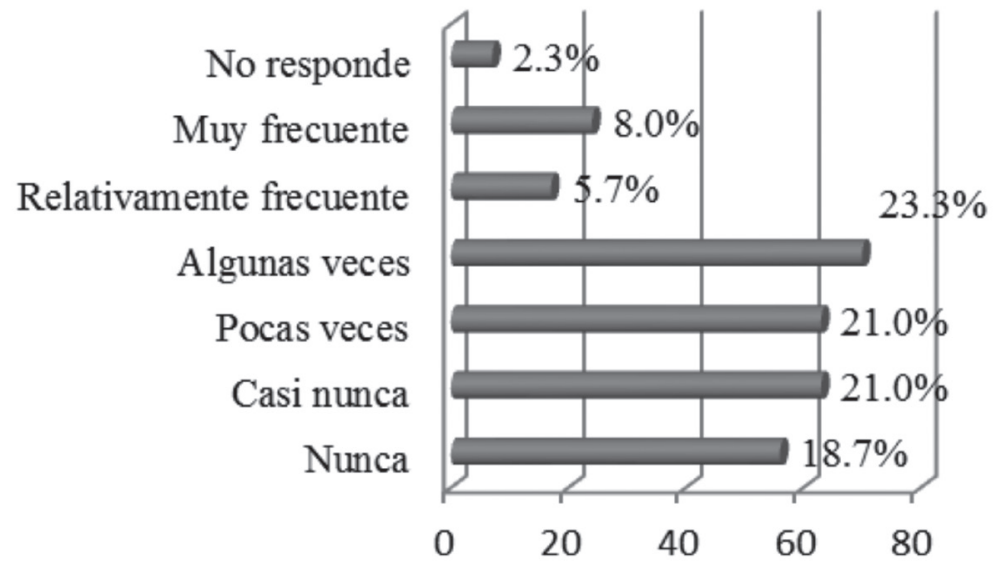


Un indicador del estrés es la sensación de cansancio extremo o agotamiento continuo (Bethelmy y Guarino, 2008), el cual se manifiesta en los trabajadores que están sometidos a cargas emocionales elevadas durante sus labores diarias.

Al consultar sobre estas situaciones al personal de la corporación policial, el $18.7 \%$ manifiesta nunca haberlo percibido, el $21 \%$ casi nunca, el $21 \%$ pocas veces, algunas veces el $23.3 \%$, relativamente frecuente el $5.7 \%$ y un $8 \%$ muy frecuentemente. Como puede notarse, en cerca del $70 \%$ de los participantes se ha presentado este síntoma de presencia de estrés, que es lo más recurrente y un indicador importante para comenzar a valorar la necesidad de apoyo.

\section{Disminución del deseo sexual}

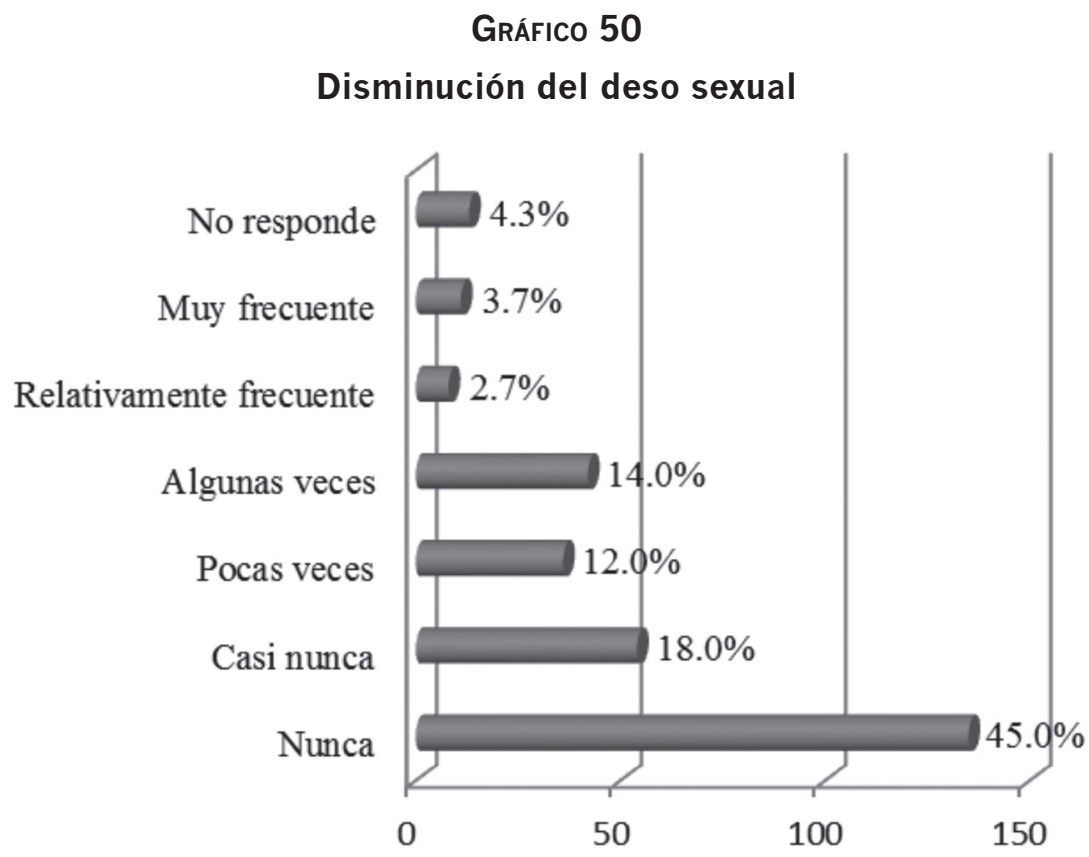

La sexualidad humana es compleja y forma parte de un componente funda-mental de la vida. El sexo y el erotismo, representan fuerzas motoras de la actividad de los seres humanos (Giddens, 1995).

La ausencia del deseo sexual, puede ser generado por varias razones tanto fisiológicas como psicológicas, particularmente vinculadas al estrés (Cas. telo, 2005). 
Al consultar a los participantes, el $45 \%$ mencionó que no había percibido este síntoma, un $18 \%$ casi nunca, el $12 \%$ pocas veces, el $14 \%$ algunas veces, el $2.8 \%$ relativamente frecuente y un $3.7 \%$ frecuentemente. Es de mencionar que este indicador suele ser evadido, sin embargo, en la intimidad de cada persona se encuentra la respuesta y, en el caso de este estudio, se manifiesta en por lo menos 3 de cada 10 personas.

\section{Respiración y asfixia}

\section{GráfICO 51}

\section{Respiración entrecortada o sensación de ahogo}

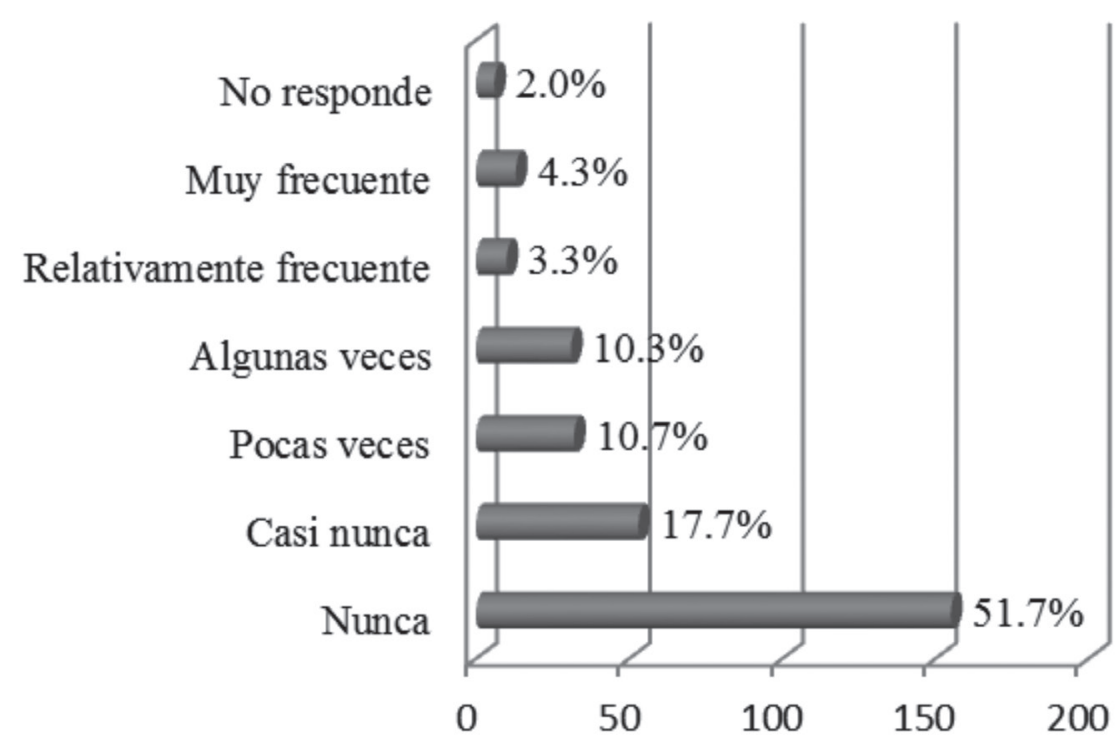

Otro indicador que puede expresar una situación de estrés compleja en el organismo es la respiración, ya que esta se ve afectada, al momento en el cual el organismo sufre en mayor medida del aparecimiento de este (Peiró, 2009).

En este sentido, se consultó a los participantes y se obtuvo que el $51 \%$ no ha percibido nunca este síntoma, mientras que un $17.7 \%$ casi nunca, el $10.7 \%$ pocas veces, el $10.3 \%$ algunas veces, para el $3.3 \%$ es relativamente frecuente y para el $4.3 \%$ muy frecuente. Como muestran estos datos, este síntoma está presente en por lo menos 2 de cada 10 participantes. 


\section{Disminución del apetito}

El apetito es una parte importante de la vida saludable, porque representa el interés del ser humano por la alimentación y, al mismo tiempo, permite la ingesta de las calorías necesarias para la subsistencia diaria (Elizondo, 2001).

Al considerar los resultados, se observa que el $41 \%$ no ha percibido falta de apetito, el $24 \%$ casi nunca, el $1.3 \%$ pocas veces, el $12.7 \%$ algunas veces, el $3 \%$ con relativa frecuencia y únicamente el $2.7 \%$ muy frecuentemente.

Cabe señalar, que la falta de apetito puede repercutir en otro tipo de trastornos psicosomáticos que pueden llevar incluso a la muerte (Elizondo, 2001). Por tanto, es de relevancia que se le preste la debida atención.

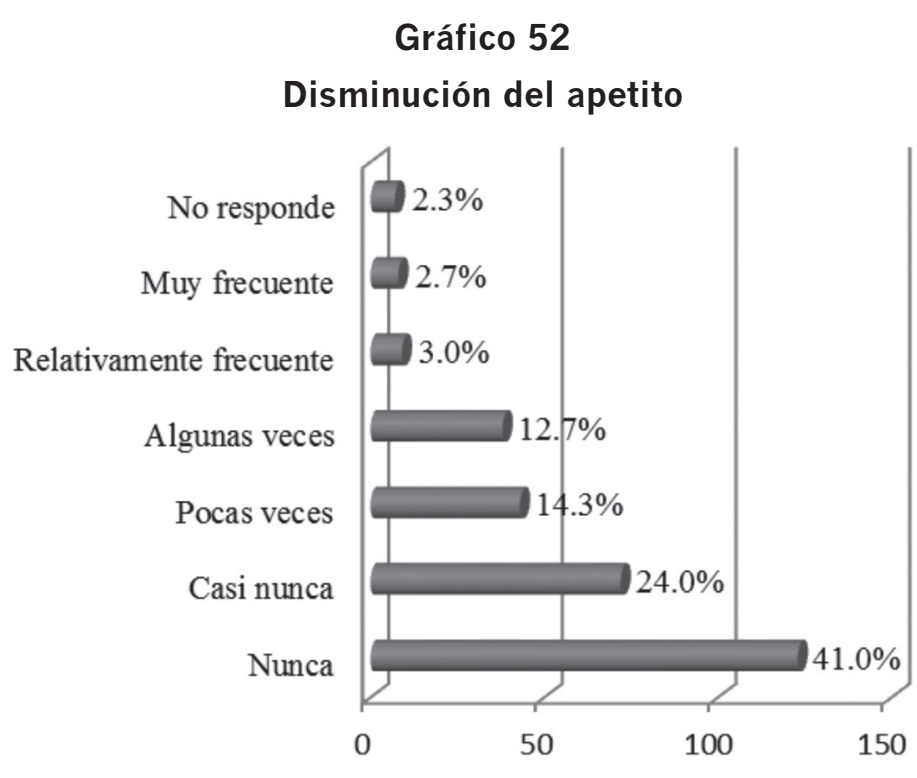

\section{Temblores musculares}

Uno de los efectos más notables en el estrés es lo relacionado con los temblores musculares como tics nerviosos o parpadeos, que surgen cuando el sistema nervioso central, tiende a resentir las consecuencias de la carga, producto de situaciones de presión y sobreesfuerzo (Peiró, 2009).

Al respecto, el 38\% de los participantes mencionó que nunca ha percibido esta situación, el $18.7 \%$ casi nunca, el $13.3 \%$ pocas veces, el $17 \%$ algunas veces, el $5.7 \%$ lo ha percibido con relativamente alguna frecuencia, el 


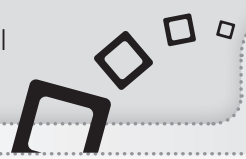

$5.7 \%$ muy frecuentemente y el restante $1.7 \%$ no responde. Como se puede observar, este síntoma del estrés está presente en buena parte de los participantes, y denota una situación que amerita ser analizada y tratada.

\section{GRÁFICo 53}

\section{Temblores musculares (por ejemplo, tics nerviosos o parpadeos)}

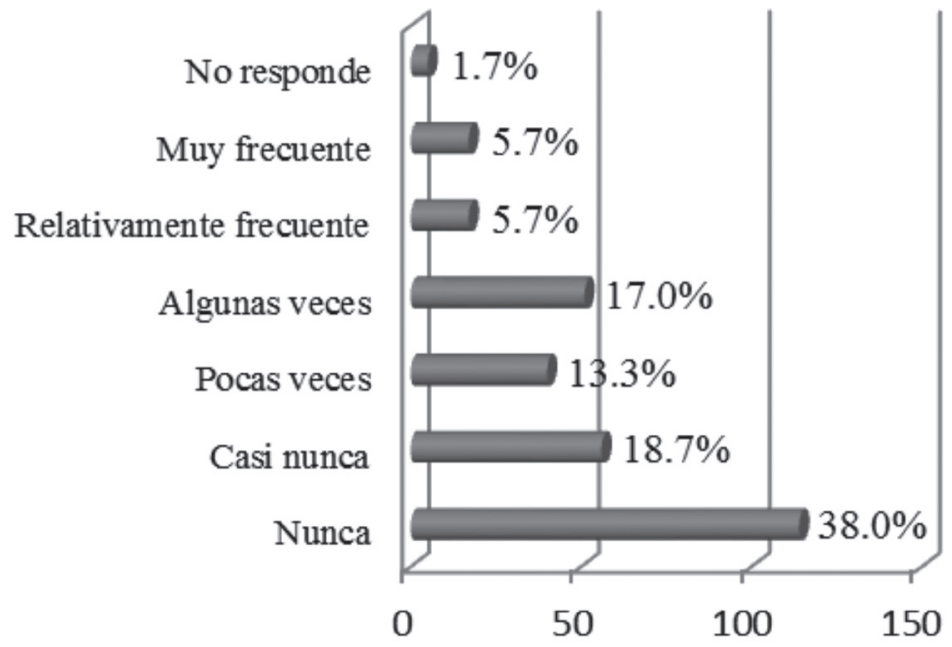

Pinchazo o sensaciones dolorosas en el cuerpo

Gráfico 54

Pinchazos o sensaciones dolorosas en distintas partes del cuerpo

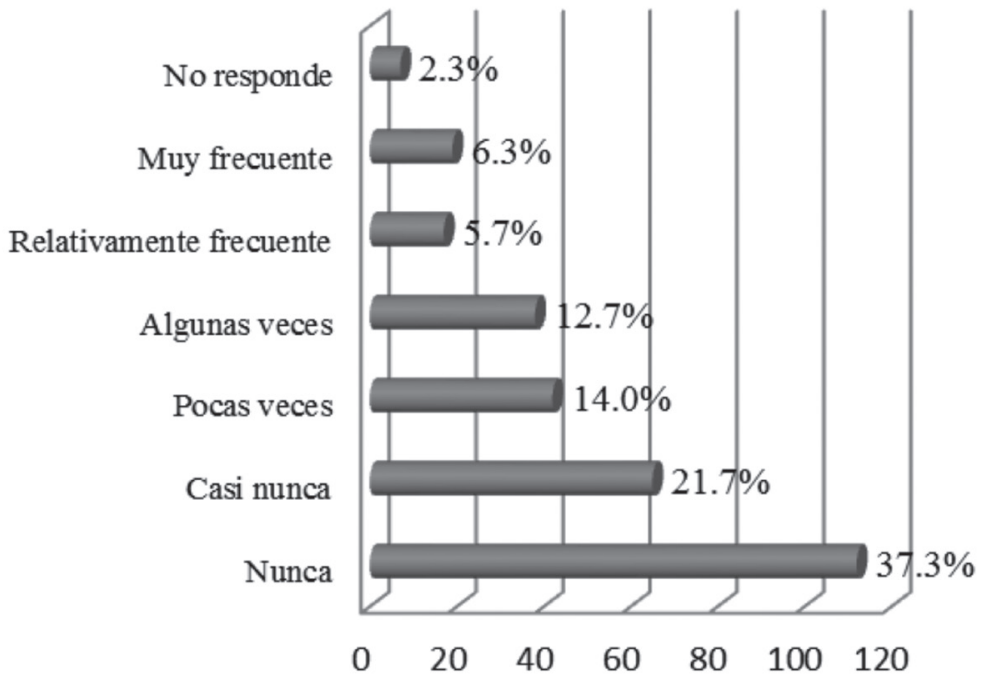


Otro importante síntoma de estrés son las sensaciones de pinchazos y sensaciones dolorosas, manifestadas en diversas partes del cuerpo, que pueden estar significando un desequilibrio en el sistema nervioso central, debido a la presión del trabajo o problemas alrededor de este (Bethelmy y Guarino, 2008).

Los resultados identificados en los participantes, denotan que el $37.3 \%$ nunca antes ha sentido eso, que un $21.7 \%$ casi nunca, un $14 \%$ pocas veces, el $12.7 \%$ algunas veces, el $5.7 \%$ con relativa frecuencia y el restante $6.3 \%$ muy frecuentemente. Es decir, que en por lo menos 2 de cada 10 personas, se ha manifestado de forma reiterativa este tipo de síntoma asociado al estrés laboral, algo que puede estar vinculado a las tareas y funciones que se desarrollan.

\section{Tentación fuerte de no levantarse por la mañana}

\section{GRÁFICO 55}

\section{Tentación fuerte de no levantarse por la mañana}

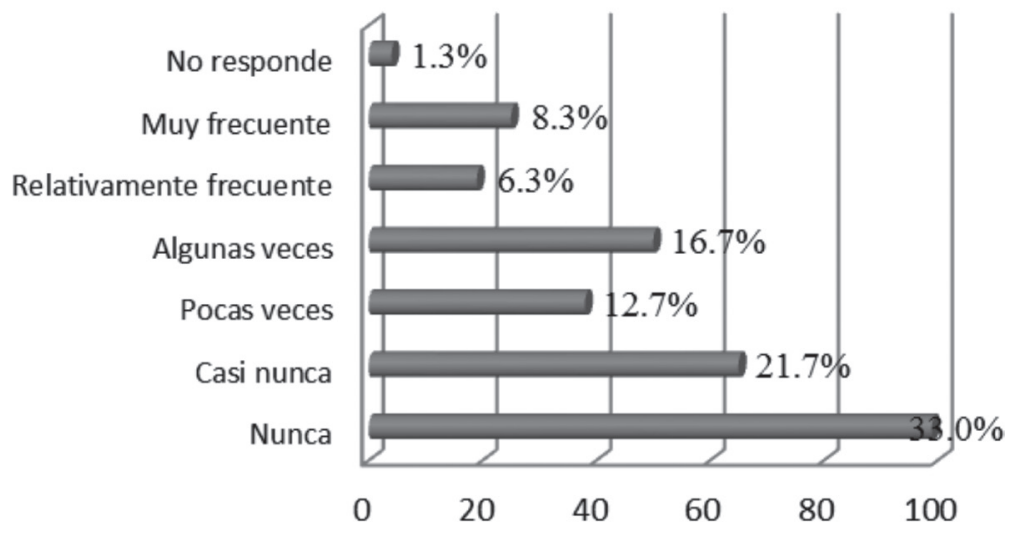

El cansancio constante y esa idea de no tener energías, puede llegar a ser un síntoma de estrés profundo que puede llegar inclusive a convertirse en un padecimiento conocido como el síndrome de Burnout por sus rasgos característicos (Cruz y Puentes, 2017).

Con respecto a lo anterior, los participantes, en un 33\% dijeron nunca haber sentido esos deseos, un $21.7 \%$ casi nunca, $12.7 \%$ pocas veces, el $16.7 \%$ algunas veces, el $6.3 \%$ relativamente frecuente y el restante $8.3 \%$ muy frecuentemente. Por lo que se puede plantear que cerca de 3 de cada 10 personas, de alguna manera han percibido un cansancio y un agotamiento excesivo, que pudiera explicarse en términos de un estrés laboral. 


\section{Percepción de depresión}

\section{GrÁfICo 56}

¿Se siente deprimido?

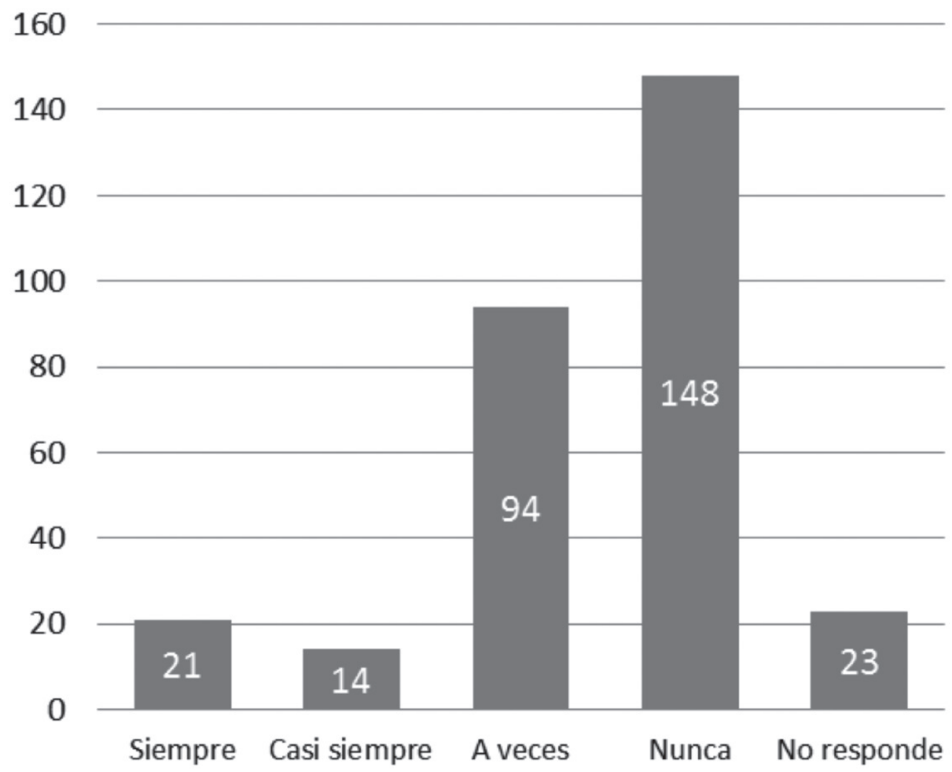

La depresión es compleja de definir, sin embargo, se entiende como un estado de melancolía que es patológico y normal, donde las personas experimentan episodios de frustración y desarraigo, además de una pérdida de su personalidad y puede tener consecuencias letales sino es tratada adecuadamente (Jervis, 2005).

Sobre este tema, los participantes en un $49.3 \%$ manifestaron que nunca han padecido depresión, sin embargo, un $31.3 \%$ dijo que a veces, un $4.7 \%$ casi siempre y un 7\% que siempre. Como se observa, casi 5 de cada 10 personas tienen algún nivel de percepción sobre la depresión, Ilamando la atención que 1 de cada 10 mantiene una depresión constante.

\section{Percepción de ansiedad}

La ansiedad se presenta como una reacción a ciertos estímulos que perciben las personas, como por ejemplo la sensación de peligro y puede generar síntomas neurovegetativos, conductuales y vivenciales (Mardomingo, 1994).

En ese sentido, la ansiedad como estado propio de afectación emocional, puede derivar en una serie de experiencias que ponen a la persona en una condición no adecuada para su salud mental. 
En ese plano, se obtuvo que un $47 \%$ nunca ha sentido ansiedad, un $33.3 \%$ a veces, el $5.3 \%$ casi siempre y un $6.7 \%$ siempre. El restante $7.7 \%$ no respondió a esta interrogante. Estos datos muestran que en por lo menos 4 de cada 10 personas encuestadas, la ansiedad se presenta como parte de un síntoma propio de estrés.

\section{GráfICo 57}

\section{¿Se siente con ansiedad?}

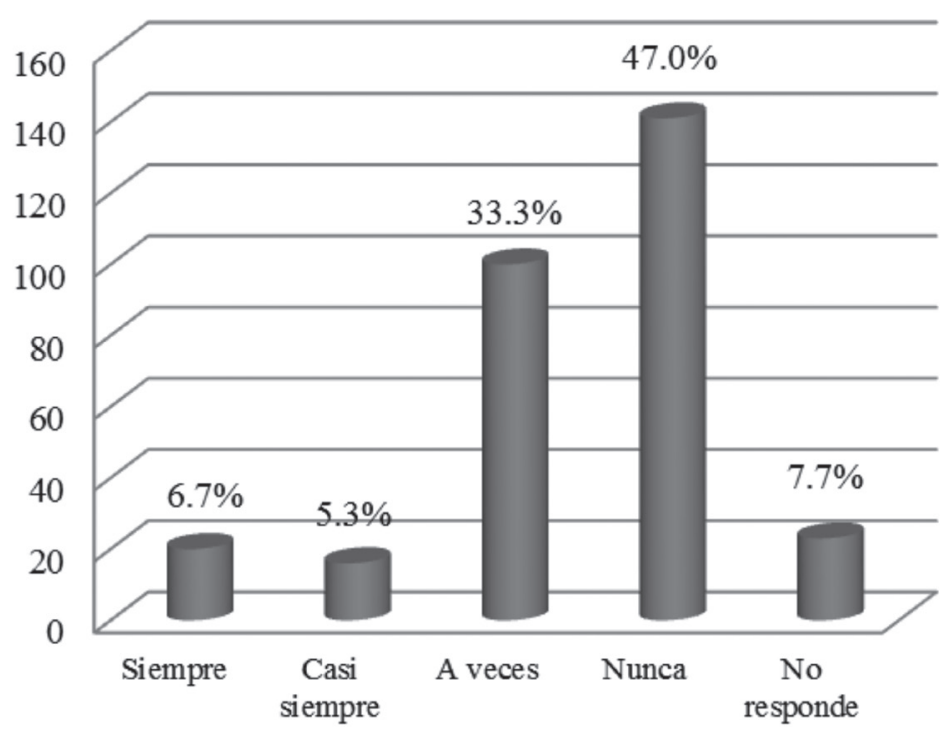

\section{Miedo y temores}

\section{GráfICO 58}

¿Ha sentido sensación de miedo?

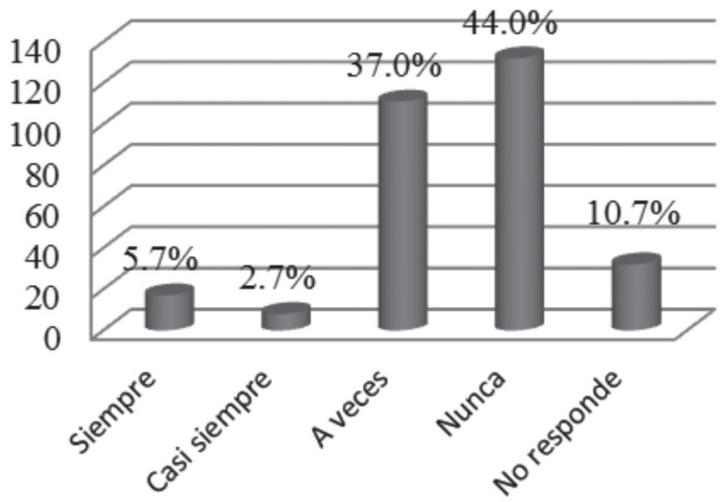


El miedo, como una condición psíquica, se encuentra asociado a una serie de factores diversos, los cuales devienen en contextos particulares (Mardomingo, 1994).

Contextos como el que viven los miembros de la corporación policial, los puede llevar a situaciones extremas donde la sensación de miedo puede hacerse presente. Sobre este particular, la investigación reflejó que el $44 \%$ nunca siente miedo, pero un $37 \%$ a veces, un $2.7 \%$ casi siempre y un $5.7 \%$ siempre.

\section{Sentimientos suicidas}

GráfICO 59

¿Siente deseos suicidas?

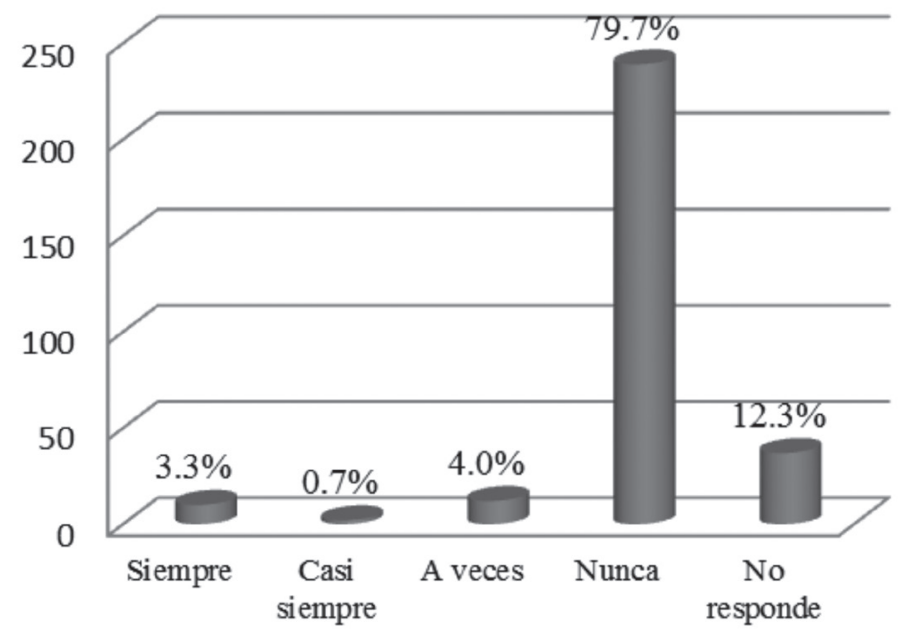

Los efectos de una salud mental no adecuada, pueden generar como consecuencia el suicidio, el cual según la OMS (2017), cobra la vida de más de 800000 mil personas al año, siendo la población en el rango de los 15 a los 29 años la más afectada, y por tanto representa la primera causa de defunción de este grupo etario.

El suicidio es la consecuencia de diversos episodios de depresión, a los cuales la persona llega ante la falta de una atención oportuna (Mardomingo, 1994).

Al consultarles a los entrevistados, se encontró que el 3.3\% siempre siente estos deseos, el $0.7 \%$ casi siempre y el $4.0 \%$ a veces. Esto muestra que existe una parte del personal que se encuentra en una situación crítica a la cual se le debe prestar atención oportuna. 


\section{Principales factores de estrés}

\section{Gráfico 60}

\section{¿Qué situaciones le generan mayor estrés?}

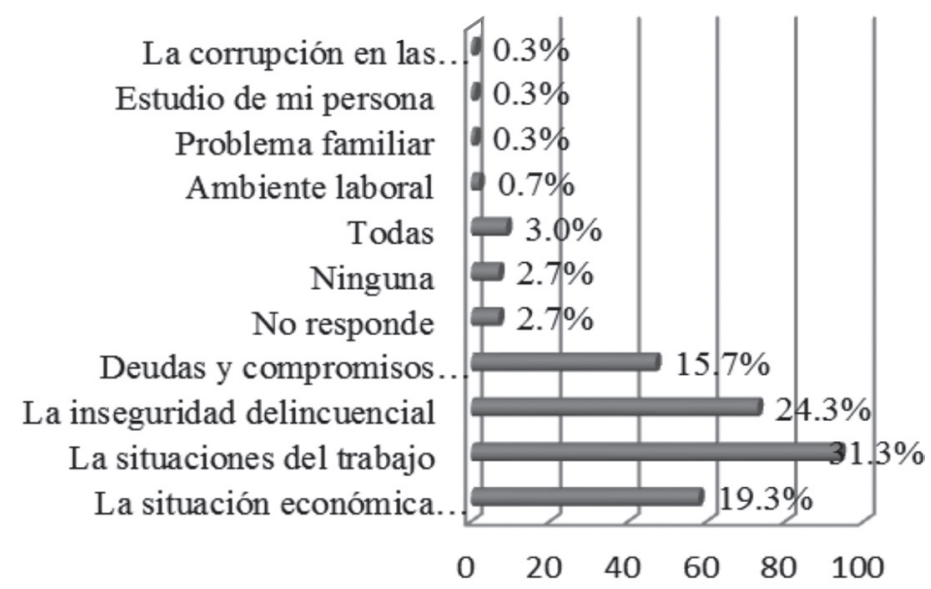

El tema del estrés es producido por diversos factores, los cuales, al conjun. tarse en muchos aspectos, pueden considerarse desencadenantes de diversos procesos de carga laboral y emocional (Bethelmy y Guarino, 2008).

Al consultar al respecto, para el $31.3 \%$ de los participantes, la situación del trabajo representa el principal factor de estrés, mientas la inseguridad y delincuencia el segundo con un $24.4 \%$ y la situación económica llega a un tercer lugar con un $19.3 \%$.

Al valorar el gráfico, se pone de manifiesto que las situaciones que se asocian al estrés, constituyen básicamente los problemas tanto de tipo personal, como la situación del contexto del país y, en gran medida, están vinculados a la labor policial.

\section{Valoración de la asistencia psicológica por parte de la corporación policial}

La atención psicológica comprende una serie de componentes que permiten establecer la búsqueda del bienestar psicosocial de la persona, algo que no solo debe ser visto de forma clínica sino integral (Oblitas y Becoña, 2000).

En ese marco, se consultó a los participantes en el estudio, sobre si actualmente habían recibido alguna asistencia psicológica por parte de la corporación policial en función a su trabajo, y los resultados reflejaron que al $78 \%$ no se le ha brindado dicha asistencia, mientras que al $21 \%$ sí. Lo que muestra que casi 8 de cada 10 personas no cuentan con un apoyo psicológico que les permita drenar emocionalmente las situaciones que viven como resultado del trabajo que realiza. 


\section{GRÁfICo 61}

¿Ha recibido alguna asistencia psicológica por parte de la corporación policial?

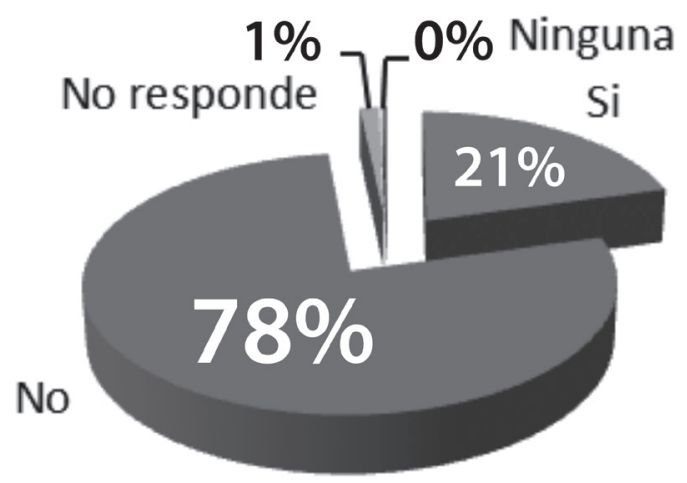

Importancia de la atención psicológica

GrÁFICO 62

¿Considera importante que se desarrollen programas de apoyo psicológico de parte de la corporación policial?

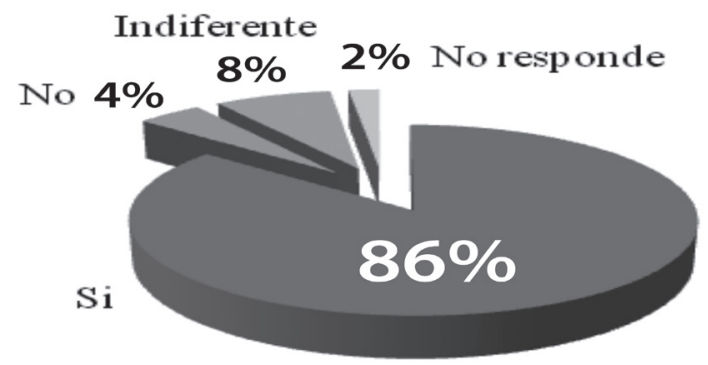

Siendo el componente psicológico, elemental para los efectos del contexto actual y la labor de los miembros de la corporación policial, se les consultó si valorarían el desarrollo de programas de apoyo.

Los resultados fueron contundentes, el $86 \%$ considera que, si son necesarios, al $8 \%$ le es indiferente y solamente el $4 \%$ valora que no son necesarios.

No obstante, cerca de 9 de cada 10 persona, considera que sería necesario que estos programas fueran permanentes y con suficiente atención en función de plantear mecanismos de afrontamiento ante situaciones, que a diario se vive como parte de la acción policial y del trabajo con sus propias dificultades, además de su vida personal que se conjuga en este sentido. 


\section{Discusión de resultados}

Con respecto a los resultados, se hizo una consolidación de la información obtenida y, en función a ella, se han realizado algunos aportes de discusión y se han comparado con otros estudios revisados.

\section{Índice de Masa Corporal (IMC)}

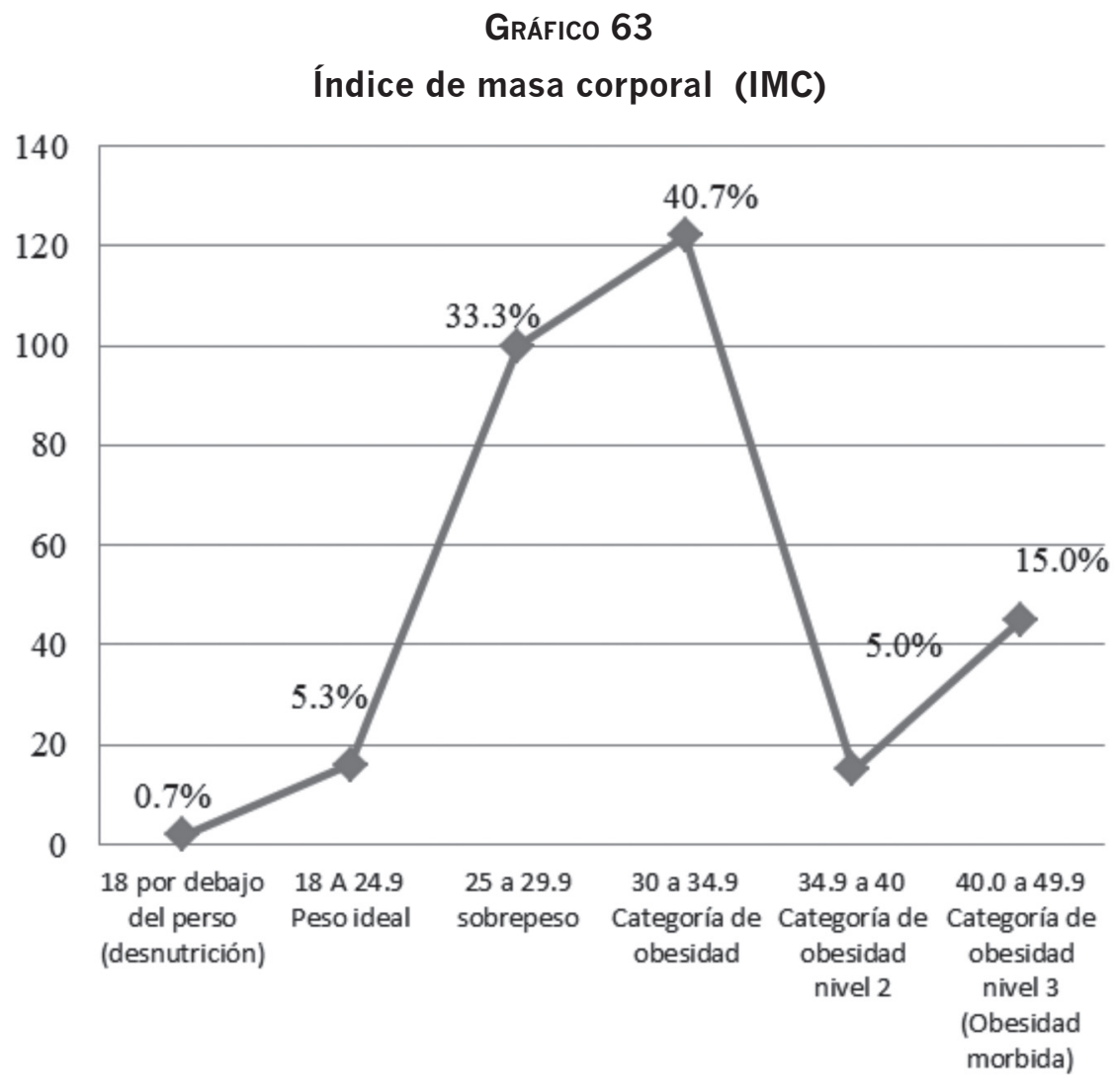

El Índice de Masa Corporal (IMC), es uno de los principales indicadores para establecer los riesgos en la salud y la presencia de obesidad o tras. tornos en el peso corporal, siendo establecido a partir de la relación entre estatura y peso, para establecer las escalas de relación con el tipo de peso y condición nutricional de las personas (Jiménez, 2007).

Al considerar la situación de la muestra tomada para el estudio de la po. blación de la corporación policial, se nota que solamente un $5.3 \%$ se encuentra en el rango de peso ideal, mientras cerca del 33.3\% aparece con sobrepeso, el $40.7 \%$ en categoría de obesidad, el $5 \%$ en segunda categoría de obesidad y un $15 \%$ en la categoría de obesidad mórbida. 
A nivel del país, según los resultados de la Encuesta Nacional de Enfermedades Crónicas No Transmisibles en Población Adulta de El Salvador 2014-2015 (MINSAL/INS, 2017), el 39.5\% de la población tiene un nivel de sobrepeso, mientras un $19.5 \%$ está en el nivel de obesidad.

De igual manera, el comportamiento hacia esta tendencia es también recurrente en poblaciones focalizadas como los adolescentes salvadoreños, donde un estudio reveló (Soriano, Kann, Kinche y Razeghi, 2013) que el 28.8\% tiene problema de sobrepeso y un $9.6 \%$ de obesidad, considerándose una edad en la cual la actividad física es una cuestión fundamental de su diario vivir.

En tal sentido, la situación presentada por este estudio, en comparación con otros, revela un rasgo conductual de país que está afectando significa. tivamente a la población, y esto se puede segmentar también por género, en miras de valorar algunos contrastes en este sentido.

\section{GRÁFICO 64}

\section{Índice de masa corporal por género}

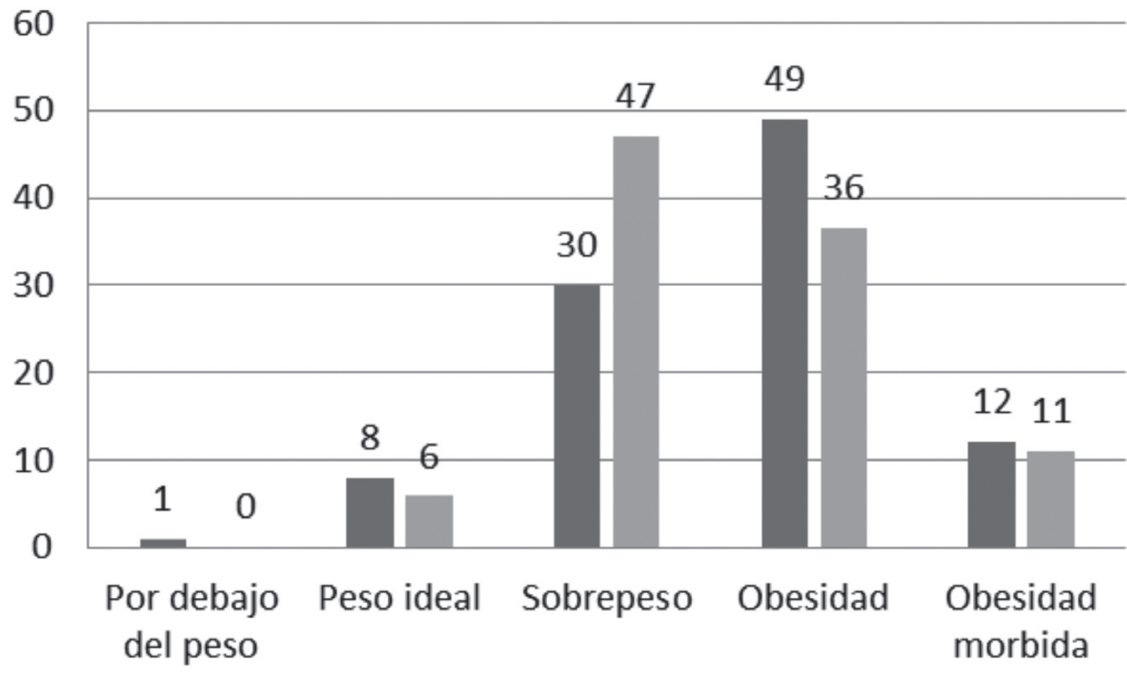

Masculino Eemenino

Como se puede observar en el gráfico, el género femenino tiende a presentar un menor Índice de Masa Corporal en cuanto a la obesidad, sin embargo, es superior por lo menos un $15 \%$ en sobrepeso. 
En el caso del género masculino, la obesidad se presenta en un mayor porcentaje en comparación a la mujer, ya que llega a casi 5 de cada 10 hombres, mientras la obesidad mórbida está casi equiparada en ambos géneros, lo que indica una grave situación en cuanto a la probabilidad de padecimientos crónicos degenerativos en el futuro como plantean una serie de estudios (Blanco, et al., 2017).

Por otra parte, otra variable que es importante analizar en cuanto al tema de la nutrición, es la relación entre el Índice de Masa Corporal y su función dentro de la corporación policial, ya que podría considerarse que ser personal administrativo u operativo marcaría una diferencia.

Al cruzar los datos se muestra, en el caso del peso ideal, que existe una considerable diferencia entre el personal operativo y el personal administrativo, ya que solamente un $1.8 \%$ del personal administrativo tiene su peso ideal.

Otra diferencia notable es la obesidad mórbida, donde el personal administrativo dobla al personal operativo, es decir que por cada persona operativa con obesidad mórbida, existen dos personas administrativas en la misma condición. Esta situación estaría siendo explicada en parte, por la diferencia de funciones, ya que a nivel administrativo se tiene en teoría, menos actividad física que conduciría a un estilo de vida más sedentario y proclive a desarrollar doblemente una obesidad de este tipo (Ortega, López, y Pérez, 2013).

\section{Caracterización del menú y hábitos alimentarios}

\section{GrÁfICO 65}

Tipo de dieta

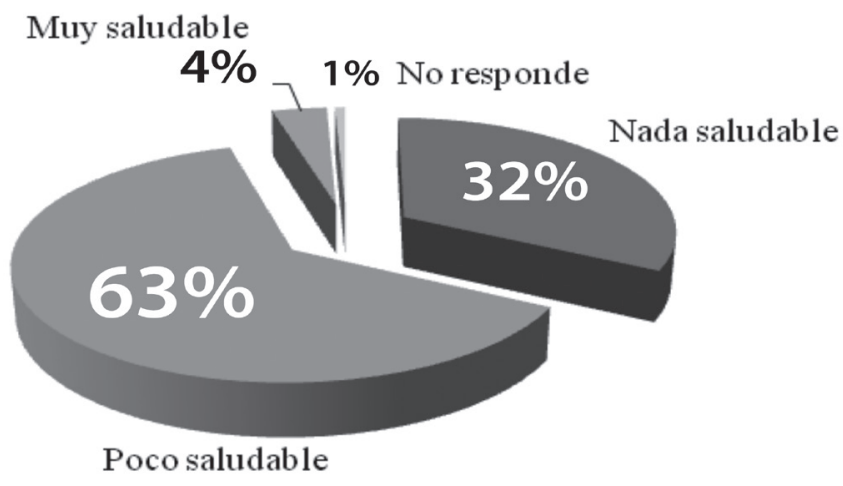

Lo anterior tiene una importante relación con los hábitos alimenticios que fueron identificados durante el estudio. 
Al consolidar los diversos indicadores relacionados a los hábitos de alimentación y al menú que ingieren los participantes, además de la valoración del consumo calórico, se logró determinar que el 63\% tiene hábitos poco saludables y el $32 \%$ nada saludables, además solamente un $4 \%$ tiene hábitos saludables.

Esto muestra que casi en un $90 \%$ existe un problema nutricional grave, que se agrava con la falta de actividad física y otros factores asociados a problemas metabólicos y de la edad como sugieren algunos estudios (Albala, Sánchez, Lera, Bárbara, y Cea, 2011).

En el caso del país, la situación nutricional también es una consideración de alerta, ya que los estudios encontrados (MINSAL/INS, 2017), hacen ver que el consumo de alimentos saludables para el caso de frutas y verduras es bajo, en cerca de un $93.8 \%$ de la población, situación que también ha sido identificada en esta investigación.

\section{Condición de autocuidado}

\section{Gráfico 66}

Situación de autocuidado

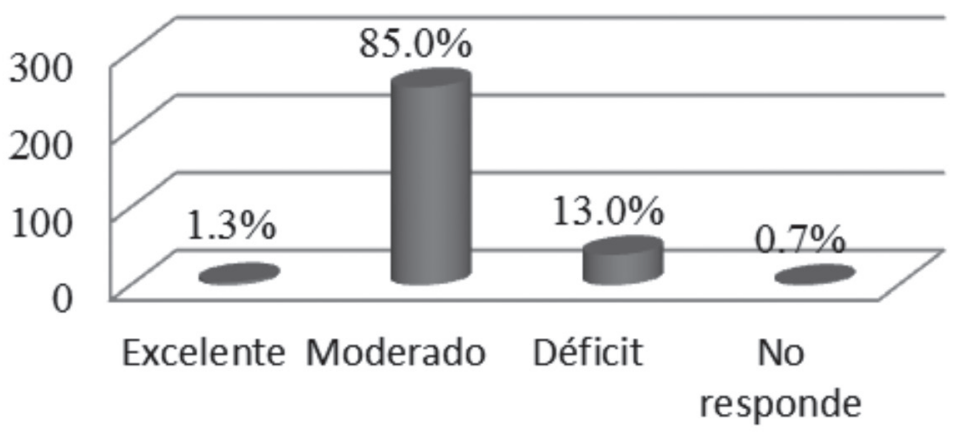

Al valorar lo anterior, se evidencia que el autocuidado, como una condición personal para darle seguimiento a la búsqueda de un estilo de vida saludable, en la población participante del estudio es moderada, en casi el $85 \%$, ya que existen factores que realizan de manera no frecuente, sin embargo el déficit de autocuidado es cercano a un 13\%, es decir, que cerca de 1 de cada 10 personas se encuentra en esta condición, donde requiere de una intervención (Vega y González, 2017). 


\section{Condición de prevención de la salud}

También fue necesario valorar lo referente al nivel de prevención de la sa. lud, ya no como autocuidado, sino en función a su acercamiento al perso. nal especializado y medidas en función de tener un estado de salud acorde a la calidad de vida.

A partir de ello, en este estudio es evidente que el nivel de prevención está en una situación baja, ya que no todos los miembros de la corporación policial que fueron encuestados expusieron prácticas de salud acordes a una expresión real del cuidado de esta.

La situación de prevención al consolidarse, es preocupante, ya que 6 de cada 10 personas no tienen hábitos preventivos eficientes que incidan en la posibilidad de una mejor calidad de vida, algo que pasaría por una acertada búsqueda de estilos de vida saludables (Muir y Fowler, 1990), sin embargo, al verificar la evidencia empírica, una buena parte de los participantes y a nivel de país, prácticas como el sedentarismo se presentan en cerca del $40 \%$ de la población (MINSAL/INS, 2017).

\section{GRÁFICO 67}

\section{Nivel de prevención de salud}

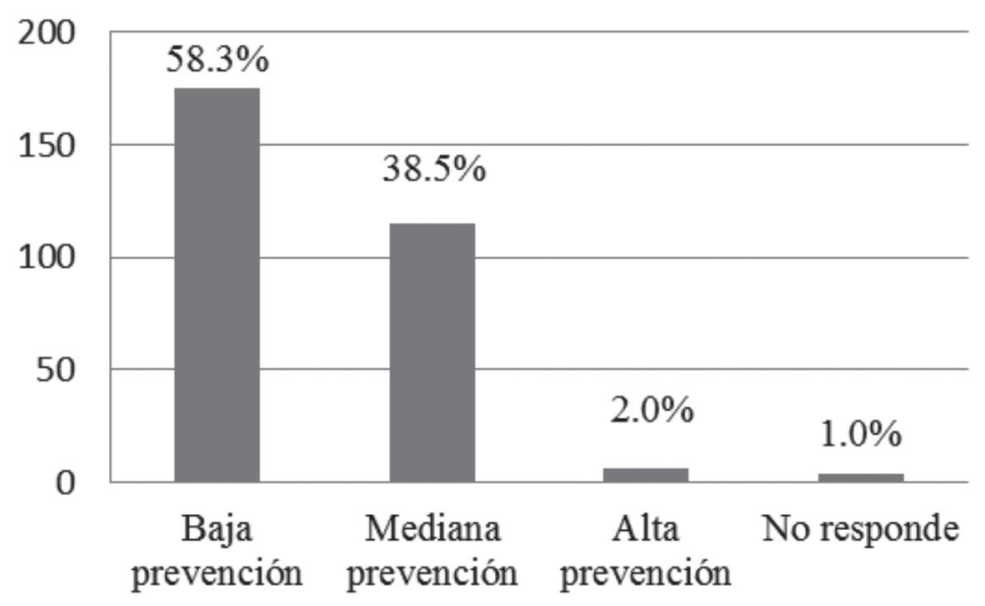




\section{Caracterización del estrés}

Otra consideración importante es el estrés, que también constituye un importante complemento de la salud.

Al tipificar el estrés, con base al test del Instituto Mexicano del Seguro Social (2017), solamente un 3.7\% no presentó síntomas, sin embargo, en por lo menos 2 de cada 10 personas, la situación amerita observación y de oportuna atención.

Hay que recordar que el trabajo del policía tiene sus propios bemoles que hacen que los agentes tengan elementos de estrés que, aunados con los propios del medio social y familiar, coadyuvan a una situación crítica en cuanto a su salud mental y al riesgo laboral (Barcelón et al., 2012).

\section{GráfICo 68}

\section{Tipificación del estrés}

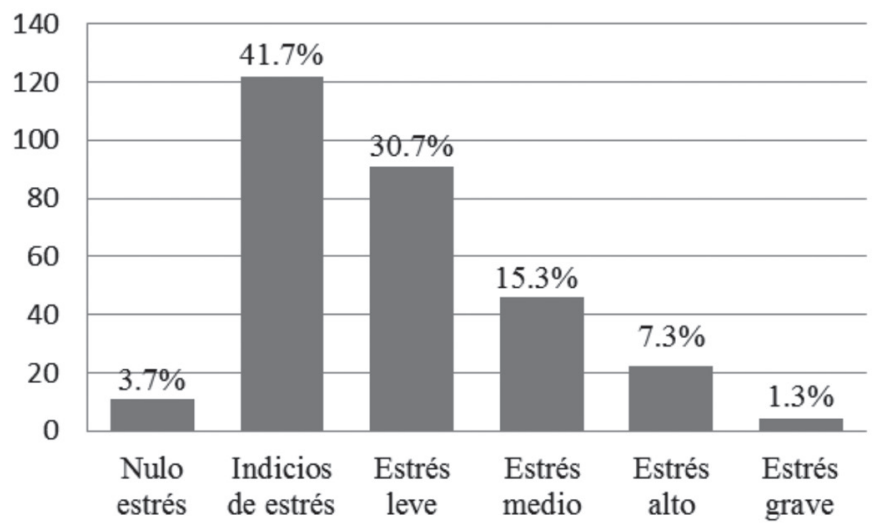

\section{Situación de salud}

\section{Gráfico 69}

\section{Situación de Salud}

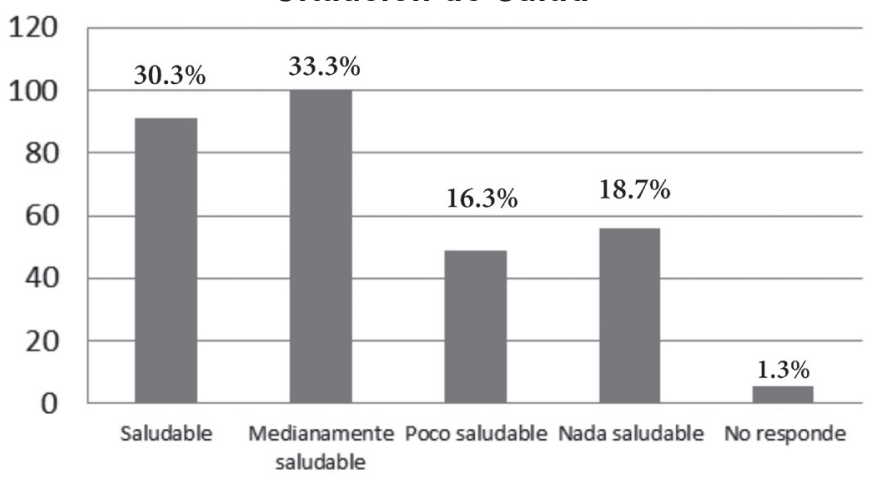


Para la OMS (2017e), la salud es "un estado de completo bienestar físico, mental y social, y no solamente la ausencia de afecciones o enfermeda. des"; implicando una serie de observaciones por autores diversos donde es necesario considerar la inequidad (Hernández y Bejarano, 2017).

Al considerar los indicadores vinculados a la situación de salud, se pudo definir que un $30.3 \%$ se encuentra en una condición saludable y un $33.3 \%$ tiene una salud aceptable, sin embargo, cerca de 4 de cada 10 personan tienen una situación de salud que no es la deseada.

Dentro del grupo de participantes, se mencionó además, el padecimiento de enfermedades crónicas, como la hipertensión, la diabetes, las dislipidemias, entre otros. A nivel de país, según los datos de la Encuesta Nacional de Enfermedades Crónicas no Transmisibles en población adulta de El Salvador (MINSAL/INS, 2017), hay situaciones que se comparan con este estudio y aún más preocupantes. Por ejemplo, un $27.2 \%$ se encuentra con prehipertensión y un $37 \%$ con hipertensión; un $26.9 \%$ presentan dislipidemia, el $25.2 \%$ tiene un cuadro de prediabetes y $12.5 \%$ tiene diabetes mellitus; finalmente, un $12.6 \%$ aparece con la enfermedad renal crónica.

En este estudio, los padecimientos de salud se encuentran determinados a partir de las situaciones antes mencionadas, las cuales tendrían que valorarse por el bajo nivel de autocuidado y de prevención de la salud que se ha observado.

De hecho, los estudios (Zubeldía, Quiles, Vinuesa y Rendón, 2016) consideran que la prevalencia de este tipo de padecimientos crónicos está asociados a la edad, al sobrepeso y al estilo de vida de las personas.

En este marco, la situación asociada a la salud del personal de la corporación policial debe atenderse oportunamente, y se debe valorar cómo la atención integral debe ir acompañada de factores como la salud mental, la convivencia sana y el estímulo para construir lazos familiares y sociales sólidos. 


\section{Conclusiones}

Algunas conclusiones que se deben considerar son las siguientes:

- La alimentación, como se mostró, se basa en un consumo calórico no acorde a lo establecido por los parámetros reconocidos a nivel mundial por organismos multilaterales, observándose a partir del inventario que se realizó del consumo de 24 horas, que las ingestas están condicionadas a un entorno que no brinda opciones nutritivas adecuadas y la práctica de hacer ingestas solo por un tema fisiológico, sin prestarle atención a lo que realmente se le está brindando al organismo para su nutrición.

- Con respecto al autocuidado, se logra evidenciar un déficit significativo particularmente en cuanto a un estilo de vida saludable, particularmente con respecto a prácticas que pudieran afectar en el futuro el cuidado particular de cada uno.

- Con respecto a la percepción de la salud preventiva, se debe destacar que también presentó un déficit importante, en el caso de las mujeres, el tema de la toma de la citología y la autoexploración de mama resulta un punto de preocupación significativa. En el caso de los hombres, de igual manera la mínima respuesta a la prevención de padecimientos asociados al aparato reproductor y demás.

- La situación de salud mental y el estrés, resulta también preocupante en la medida que hay una tendencia del grupo a estar en una situación de alto estrés y algunos, hasta con ideas suicidas, lo cual puede repercutir en su bienestar y en el de sus familias. El pensamiento suicida manifestado por algunos elementos, es preocupante como también el consumo de drogas, alcohol y cigarrillos.

- En cuanto a la valoración de salud, es preocupante que se estén presentando padecimientos crónicos degenerativos y enfermedades vinculadas a la situación del estrés, en cuanto a los aspectos propios del estudio, se puede afirmar que la condición de salud del grupo de encuestados es preocupante y sí es necesario superar el déficit de atención, a pesar de que, aunque se tiene cobertura y atención en establecimientos de salud, la prevención es aún mínima.

- Por último, considerar que, con la evidencia recolectada, es necesario que las autoridades de la corporación, particularmente en lo relacionado a la unidad de bienestar policial, aporten mediante la generación de programas de atención preventiva, dada la urgencia de capacitación en temas de nutrición, autocuidado y salud mental. 


\section{Recomendaciones}

- A partir de los resultados de la investigación, se han generado las siguientes recomendaciones, para ser implementadas desde la división de bienestar policial:

- Generar al interior de cada sede y establecimiento policial, un manual de alimentación y nutrición balanceada "ad hoc" a las condiciones del país y a la dieta disponible.

- Considerar la estimulación para la práctica de actividad física, generando espacios de recreación y, de ser posible, instalar gimnasios o equipos para la práctica de estos.

- Promover el énfasis en la salud mental y en la prevención de depre. siones y pensamientos suicidas, ya que se identificaron este tipo de casos, los cuales son de urgente atención.

- Desarrollar jornadas de educación para el autocuidado de la salud, para lo cual debe hacerse énfasis en prácticas que posibiliten la prevención de enfermedades crónicas degenerativas y enfermedades mortales como el cáncer, que en particular se debe prestar atención al personal femenino, ya que un buen porcentaje no se realiza la au. toexploración de mama ni el examen de citología de forma periódica.

- Propiciar alianzas con instituciones públicas y privadas, de los diversos sectores, a fin de propiciar alcances significativos en materia de la salud integral, ya que para dar una atención oportuna, los recursos internos no son suficientes.

- Por último, realizar las pruebas diagnósticas de exámenes de laboratorio y toma de presión arterial de forma más continua, para determinar con mayor precisión el aparecimiento de signos de enfermedades crónicas degenerativas en el personal. 


\section{Referencias}

Albala, C., Sánchez, H., Lera, L., Bárbara, A., y Cea, X. (2011). Efectos sobre la salud de las desigualdades socioeconómicas en el adulto mayor. Resultados basales del es. tudio, expectativas de vida saluda. ble y discapacidad. Revista médica de Chile, 139(10), pp. 1276-1285. doi:https://dx.doi.org/10.4067

Alonso de Ruiz, P., Lazcano, E. y Hernández, M. (2005). Cáncer Cervicouterino. Diagnóstico, prevención y control. (Segunda ed.). México. D. F., México: Médica Panamericana.

Ayus, J. C., Tejedor, A., y Caramelo, C. (2007). Agua, electrolitos y equilibrio ácido-base. Madrid, España: Médica Panamericana.

Barcelón, S., Carrero, C., González, S., Iglesia, V., Moreno, A., Navas, M., y Quirós, J. (2012). Manual de prevención de riesgos laborales en las Administración Pública. Madrid, España: Instituto Nacional de Administración Pública.

Bellido, D., y De Luis, D. A. (2006). Manual de nutrición y metabolismo. Madrid, España: Díaz de Santos.

Bethelmy, L., y Guarino, L. (2008). Estrés laboral, afrontamiento, sensibilidad emocional y síntomas físico y psicosociales en médicos venezolanos. Revista colombiana de psicología, 43-58. Obtenido de http://www. redalyc.org/articulo. oa?id=80411803003
Blanco, R., Pérez, P., López, J., Martínez, J., Delgado, J., Van Ommen, B., ... López, J. (2017). HDL cholesterol efflux normalised to apoA-I is associated with future develom. pment of type 2 diabetes: from CORDIOPREV trial. Nature, 7(1), pp. 1.10. doi:10.1038/s41598-017. 12678.9

Bonilla, G. (1999). Métodos prácticos de Inferencia Estadística (Octava ed.). San Salvador, El Salvador: UCA Editores.

Cárdenas, S. V. (2013). Estilos de vida e índice de masa corporal de los policias que laboran en la Comisiaría Alfonso Ugarte Lima. Recuperado de: http://200.62.146.130/bitstream/ cybertesis/1046/1/C\%c3\%a1rdenas_gs.pdf

Castelo, C. (2005). Sexualidad humana: una aproximación integral. Madrid, España: Médica Panamericana.

Cataño, J. G., De los Ríos, S., Díaz, J. E., Samacá, Y., y Wilde, T. (2006). Urología práctica. (J. M. Silva, Ed.) Bogotá, Colombia: Editorial Pontificia Universidad Javeriana.

Campos, C., Jaimovich, S., Moore, J., Pawlosski, L., Gaffner, K., \& González, M. (2008). Operaciones de Autocuidado asociadas a la nutrición en madres de escolares chilenos. Horizon Enferm, 19(2), Vol. 19, no 2 , p. 45-54 recuperado de: http://horizonteenfermeria.uc.cl/ images/pdf/19-2/operaciones_autocuidado.pdf 
Compagnucci, D. I. (2008). Estado nutricional de la Policía Marplatense. Recuperado de: http://redi.ufasta.edu. ar:8080/xmlui/bitstream/handle/123456789/612/2008_n_119. pdf?sequence $=1$

Cruz, D. M., y Puentes, A. (2017). Relación entre las diferentes dimensiones del sindrome de Borbout y las estrategias de afrontamiento empleadas por los guardas de una empresa privada de la ciudad de Tunja. Psicogente, 20(38), pp. 268-281. doi:https://dx.doi. org/10.17081/psico.20.38.2548

Dalet, F., y Del Río, G. (1997). Infecciones urinarias. Madrid, España: Médica Panamericana.

Díaz, M., y Rey, E. (2007). Trastornos motores del aparato digestivo (Segunda ed.). Madrid, España: Médica Panamericana.

DIGESCTYC. (2016). Encuesta de Hogares de Propósitos Múltiples (EHPM). Ciudad Delgado, San Salvador: Dirección General de Estadísticas y Censos (DIGECTYC). Recuperado de: http://www.digestyc.gob.sv/index.php/temas/des/ ehpm/publicaciones-ehpm.html

Durá, T. (2013). Análisis nutricional del desayuno y almuerzo en una población universitaria. doi:10.3305/ nh.2013.28.4.6597
Durán, S., Record, J., Encina, C., Salazar de Ariza, J., Cordón, K., Cerdeza, M., y Espinoza, S. (2015). Consumo de edulcorantes no nutritivos en bebidas carbonatadas en estudiantes universitarios en algunos países de América Latina. Nutrición Hospitalaria. Recuperado de: http://www.redalyc.org/articulo. oa?id=309233495056

Elizondo, L. (2001). Cuidemos nuestra salud. México, D. F., México: Editorial Limusa.

FAO. (Octubre de 2008). Actualizando las necesidades energéticas mínimas. Obtenido de Sitio oficial de la Organización de las Naciones Unidas para la Alimentación y la Agricultura: http://www.fao.org/fileadmin/ templates/ess/documents/food_security_statistics/metadata/FAO_MetodologiaPrivacionAlimentaria.pdf

Feldman, M., y Friedma, L. S. (2004). Enfermedades gastrointestinales y hepáticas. Madrid, España: Médica Panamericana.

García de Guadiana, G. H. (2002). Guía de hipertensión arterial (Segun. da ed.). Madrid, España: Norma . Capitel.

García, H. F. (2010). Caracterización del estado nutricional del adul. to mayor pensionado de la Asocia. ción Tolimense de Policías en Retiro "ATOLPORE" residentes en la ciudad de Inagué durante el período de septiembre -noviembre 2009. Revista Manos al Cuidado. Recuperado de: http://revistas.ut.edu.co/index.php/manosalcuidado/article/ view/1129 
Giddens, A. (1995). La transformación de la intimidad: sexualidad, amor y erotismo en las sociedades modernas. Madrid, España: Cátedra.

Gil, Á. (2010). Tratado de nutrición (Segunda ed., Vol. Tomo II: Composición y calidad nutritiva de los alimentos). México, D. F, México: Médica Panamericana.

Goldman, L., y Schafer, A. I. (2013). Tratado de medicina interna (24 ed.). Barcelona, España: Elsevier.

Gutiérrez, M. I., y Zapata, R. M. (2016). Prevención del cáncer masculino y femenino: autoexploración y exploración. En R. M. Zapata Bo. luda, y M. I. Gutiérrez Izquierdo, Salud sexual y reproductiva (pp. 211. 2117). Almería, España: Editorial Universidad de Almería.

Hernández, D. F., y Bejarano, J. E. (2017). Aporte de la universalización al logro de la equidad en salud. Revista de Salud Pública, 19(2), pp. 199.203.

Hernández, E., Severiche, D., Romero, D., López , M., Espitia, V., y Rodríguez, A. (2015). Promoción de alimentación saludable en hogares comunitarios infantiles del municipio de Sopó (Colombia) bajo la estrategia de Atención Primaria en Salud. Salud. Recuperado de: http://www.scielo.org.co/ scielo.php?script=sci_arttext\&pi. $\mathrm{d}=$ S0120-55522015000300008\& 1 . ng=en.http://dx.doi.org/10.14482/ sun.31.3.7632.
IMSS. (2017). Estrés laboral. Recuparado de: Instituto Méxicano del Seguro Social: http://www.imss. gob. $\mathrm{mx} / \mathrm{salud}$-en-linea/estres-laboral

Jervis, G. (2005). La depresión: entre la necesidad y el negocio. Madrid, España: Fundamentos.

Jiménez, A. (2007). Entrenando a poblaciones especiales. En A. Jiménez Gutiérrez, Entrenamiento personal (pp. 305-317). Barcelona, España: INDE.

Laespada, M. T. (2014). Consumo de alcohol en jóvenes y adolescentes. Una mirada ecológica. Bilbao, España: Universidad de Deusto.

Lostao, L. (2001). Detección precoz del cáncer de mama. Factores asociados a la participación en un programa de screening. Madrid, España: Díaz de Santos.

Mardomingo, M. J. (1994). Psiquiatría del niño y del adolescente. Madrid, España: Díaz de Santos.

Marín, Z. R. (1998). Elementos de nutrición humana. San José, Costa Rica: Editorial Universidad Estatal a Distancia (EUNED).

Meléndez, G. (2008). Factores asociados con sobrepeso y obesidad en el ambiente escolar. México, D. F, México: Panamericana. 
MINSAL/INS. (20 de marzo de 2017). Encuesta nacional de enfermedades crónicas no transmisibles. Recuperado de: Ministerio de Salud de El Salvador: http://www.salud. gob.sv/20-03-2017-minsal-presenta-encuesta-nacional-de-enfermedades-cronicas-no-transmisibles-en-adultos/

Muir, J. A., y Fowler, G. (1990). Fundamentos de medicina preventiva. Madrid, España: Díaz de Santos.

Oblitas, L., y Becoña, E. (2000). Psicología de la salud. México, D.F., México: Plaza y Valdés.

Ochoa, K., Rivas, M., Miguel-Soca, P. E., Batista, A., y Leyva, Y. (2015). Ensayo no aleatorizado: impacto de cambios en la dieta y ejercicios físicos en pacientes adultos con síndrome metabólico. Correo Científico Médico, 19(13), pp. 465-482. Recuperado de http://scielo.sld.cu/ scielo.php?script=sci_arttext\&pi$d=S 1560-43812015000300008 \&$ |ng=es\&tlng=es.

OMS. (Abril de 2012). Salud bucodental. Organización Mundial de la Salud. Recuperado de: http://www. who.int/mediacentre/factsheets/ fs318/es/

OMS. (Diciembre de 2013a). Salud mental: un estado de bienestar. Organización Mundial de la Salud. Recuperado de: http://www.who.int/ features/factfiles/mental_health/ es/
OMS. (2013b). Salud ocular universal: un plan de acción mundial para 2014-2019. Madrid, España: Organización Mundial de la Salud.

OMS. (Marzo de 2015). Papiloma virus humanos (PVH) y cáncer cervicouterino. Organización Mundial de la Salud-Recuperado de: http://www. who.int/mediacentre/factsheets/ fs380/es/

OMS. (2017a). Cáncer de mama: prevención y control. Organización Mundial de la Salud. Recuperado de: http://www.who.int/topics/cancer/ breastcancer/es/index1.html

OMS. (Mayo de 2017b). Cifras del tabaco. Organización Mundial de la Salud. Recuperado de: http://www. who.int/mediacentre/factsheets/ fs339/es/

OMS. (Julio de 2017c). Diabetes. Organización Mundial de la Salud. Recuperado de: http://www.who.int/ mediacentre/factsheets/fs312/es/

OMS. (2017d). La batalla mundial contra el cáncer no se ganará únicamente con tratamiento. Organización Mundial de la Salud. Recuperado de: http://www.who.int/mediacentre/ news/releases/2014/cancer-report-20140203/es/

OMS. (2017e). Preguntas más frecuentes. Organización Mundial de la Salud. Recuperado de: http://www. who.int/suggestions/faq/es/

OMS. (2017f). Suicidio. Organización Mundial de la Salud. Recuperado de: http://www.who.int/mediacentre/ factsheets/fs398/es/ 
Ortega, R. M., López, A. M., \& Pérez, N. (2013). Associated factors of obesity in Spanish representative samples. Nutrición hospitalaria, 28(5), pp. 56.62. doi:10.3305/ nh.2013.28.sup5.6918

Peiró, J. M. (2009). Estrés laboral y riesgos psicosociales. Investigaciones recientes para su análisis y prevención. Valencia, España: Universitat de Valéncia.

Ramírez, W., Vinaccia, S., y Suárez, G. R. (2004). El impacto de la actividad física y el deporte sobre la salud, la cognición, la socialización y el rendimiento académico: una revisión teórica. Revista de Estudios Sociales, 18, pp. 67-75.

Requejo, A., y Ortega, R. M. (2002). Nutrición en la adolescencia y juventud. Madrid, España: Complutense.

Richardson, M. (2004). Enciclopedia de la salud. Barcelona, España: Amat Editorial.

Romero, T. (2009). Hacia una definición de sedentarismo. Revista chilena de cardiología, 28(4), 409-413. Recuperado de doi: https://dx.doi.org/10.4067/S0718. 85602009000300014

Sailema, F. I. (2015). La alimentación nutritiva en la condición física de los policías de la Sub Zona Pastaza. Recuperado de: http:// repositorio.uta.edu.ec/bits . tream/123456789/14841/1/ TESIS\%20FINAL\%20SAILEMA\%20 ABRIL.pdf
Samet, J. M. (2002). Los riesgos del tabaquismo activo y pasivo. Salud Pública de México, 44(1), pp. 144-160. Recuperado de: doi:https://dx.doi.org/10.1590/S0036. 36342002000700020

San Martín, H. (1992). Tratado general de la salud en las sociedades humanas. México D. F., México : Ediciones científicas, la Prensa Médica Mexicana.

Soriano, M., Kann, L., Kinche, S., y Razeghi, G. (2013). Encuesta mundial de salud escolar. Resultados El Salvador 2013. San Salvador, El Salvador: Ministerio de Salud El Salvador, Organización Panamericana de la Salud y Organización Mundial de la Salud. Recuperado de: http:// w2. salud.gob.sv/archivos/comunicaciones/archivos_comunica. dos2015/pdf/Encuesta_mundial_ salud_escolar_el_salvador2014.pdf

Tebas, F. J., y Escobar, F. (2009). La Diabetes Mellitus en la práctica clínica. Madrid, España: Médica Panamericana.

Valenzuela, A., Yánez, C. G., y Golusa, C. (2010). ¿Mantequilla o margarina? Diez años después. Revista Chilena de Nutrición, 37(34), pp. $505-513$.

Vega, O., y González, D. (2017). Teoría del déficit del autocuidado: interpretación desde los elementos conceptuales. Revista Ciencia y Cuidado, 4(1), pp. 28-35. doi:http://dx. doi.org/10.22463/17949831.919 
Vinaccia, S., Fernández, H., Monsalve, M., y Quiceno, J. (2008). Diseño de un cuestionario psicométrico para evaluar creencias, actitudes y conocimientos asociados a la hiperplasia prostática benigna. Suma psicológica, 14(1), pp. 73-92. doi:http://dx.doi.org/10.14349/sumapsi2007.38

Vinaccia, S., Fernández, H., Amador, O., Tamayo, R. E., Vásquez, A., Contreras, F., . . . Sandin, B. (2005). Calidad de vida, ansidedad y depresión en pacientes con diagnóstico del sindrome del colon irritables. Terapia psicológica, 23(74), pp. 65. 74. Recuperado de: http://www.redalyc.org/articulo.oa?id=78523207

Zubeldía, L., Quiles, J., Vinuesa, J., y Rendón, J. (2016). Prevalencia de la hipertensión arterial y de sus factores asociados en población de 16 a 60 años en la Comunitat Va. lenciana. Revista Española de Salud Pública, 90(1), pp. 1-10. Recuperado de: http://www.scielosp.org/ scielo.php?script=sci_arttext\&pi . $\mathrm{d}=$ S1 135-57272016000100405\&l. ng=en\&tlng=es.

\section{Documentos institucionales}

Plan Estratégico 2015-2019 de la Policía Nacional Civil de El Salvador. 